\title{
BSHI guideline: HLA matching and donor selection for haematopoietic progenitor cell transplantation
}

\author{
Ann-Margaret Little ${ }^{1,2}$ (D) | Arash Akbarzad-Yousefi ${ }^{3}$ | Arthi Anand ${ }^{4}$ | \\ Natalia Diaz Burlinson ${ }^{5}$ | Paul P. J. Dunn ${ }^{6,7}$ | Irina Evseeva ${ }^{8}$ | Katy Latham ${ }^{9}$ | \\ Kay Poulton ${ }^{5}$ | Dawn Railton ${ }^{10}$ | Sharon Vivers ${ }^{8}$ | Paul A. Wright ${ }^{5}$ (i) \\ ${ }^{1}$ Histocompatibility and Immunogenetics Laboratory, Gartnavel General Hospital, Glasgow, UK \\ ${ }^{2}$ Institute of Infection, Immunity and Inflammation, College of Medical, Veterinary and Life Sciences, University of Glasgow, Glasgow, UK \\ ${ }^{3}$ Histocompatibility and Immunogenetics Laboratory, NHS Blood and Transplant, Newcastle-Upon-Tyne, UK \\ ${ }^{4}$ Histocompatibility and Immunogenetics Laboratory, North West London Pathology, Hammersmith Hospital, London, UK \\ ${ }^{5}$ Transplantation Laboratory, Manchester Royal Infirmary, Manchester, UK \\ ${ }^{6}$ Transplant Laboratory University Hospitals of Leicester, Leicester General Hospital, Leicester, UK \\ ${ }^{7}$ Department of Respiratory Sciences, University of Leicester, Leicester, UK \\ ${ }^{8}$ Anthony Nolan, London, UK \\ ${ }^{9}$ Cellular and Molecular Therapies, NHS Blood and Transplant, Bristol, UK \\ ${ }^{10}$ Tissue Typing Laboratory, Cambridge University Hospitals NHS Foundation Trust, Cambridge Biomedical Campus, Cambridge, UK
}

\section{Correspondence}

Ann-Margaret Little, Histocompatibility and Immunogenetics Laboratory, Gartnavel General Hospital, 21 Shelley Road, Glasgow G12 OZD, UK.

Email: ann-margaret.little@ggc.scot.nhs.uk

Funding information

The study was funded by the authors' own departmental resources.

\begin{abstract}
A review of the British Society for Histocompatibility and Immunogenetics (BSHI) Guideline 'HLA matching and donor selection for haematopoietic progenitor cell transplantation' published in 2016 was undertaken by a BSHI appointed writing committee. Literature searches were performed and the data extracted were presented as recommendations according to the GRADE nomenclature.
\end{abstract}

\section{KEYWORDS}

bone marrow, donor selection, haematopoietic, HLA, stem cell, transplantation

\section{1 | INTRODUCTION}

The infusion (transplantation) of haematopoietic progenitor stem cells (HPC) into a patient with haematological failure due to malignant or nonmalignant causes can result in successful engraftment of donor-derived HPC which undergo haemopoiesis to replace the malfunctioning cells of the patient's immune system. The effectiveness of these transplants in terms of patient overall survival (OS) and disease-free survival (DFS) has improved with each decade due to accurate histocompatibility matching between donor and patient; use of alternative donors; improved patient conditioning protocols; use of therapeutic agents; prevention and treatment of infections and post-transplant supportive care.

This guideline is an update to the previous published guideline (Little et al., 2016) and describes the selection of donors for allogeneic, that is the donor is not genetically identical to the patient, HPC transplantation (HPCT).

This is an open access article under the terms of the Creative Commons Attribution License, which permits use, distribution and reproduction in any medium, provided the original work is properly cited.

(c) 2021 The Authors. International Journal of Immunogenetics published by John Wiley \& Sons Ltd. 


\section{2 | METHOD}

This guideline was produced by the following actions:

1. A writing committee (authors of this manuscript) comprising Histocompatibility and Immunogenetics (H\&l) scientists providing an $\mathrm{H} \& \mathrm{I}$ clinical service for related and unrelated donor haematopoietic progenitor cell transplantation was established. AnnMargaret Little was appointed as the chair of the committee.

2. A search of peer-reviewed literature to 31 December 2019 was undertaken, with additional literature reviews conducted in response to reviewers' comments.

3. Recommendations were produced from evidence obtained from the literature search. Due to the specialist nature of histocompatibility testing in the context of haematopoietic progenitor cell allotransplantation, there are few large and/or multicentre studies and meta-analyses are not available. Some recommendations are based on both literature review and consensus of expert opinion.

4. The evidence collected was evaluated using a modification of the GRADE nomenclature (https://www.gradeworkinggroup.org/). For each recommendation, the strength of recommendation has been indicated as one of:

Level 1 (we recommend)

Level 2 (we suggest)

Not graded (where there is not enough evidence to allow formal grading)

Within each level, the quality of evidence has been graded as:

A (high)

B (low)

\section{1 | Disclaimer}

These recommendations represent consensus opinion from experts in the field of $\mathrm{H} \& \mathrm{l}$ within the United Kingdom. They represent a snapshot of the evidence available at the time of writing. This evidence may become superseded with time. It is recognized that recommendations have been made even when the evidence is weak. The British Society for Histocompatibility and Immunogenetics (BSHI) cannot attest to the accuracy, completeness or currency of the opinions and information contained herein and does not accept any responsibility or liability for any loss or damage caused to any practitioner or any third party as a result of any reliance being placed on this guideline or as a result of any inaccurate or misleading opinion contained in the guideline.

\section{3 | RECOMMENDATIONS AND SUGGESTIONS}

Recommendations and suggestions are summarized in Tables 1 and 2. These evidence-based recommendations expand and adapt previous guidance (Little et al., 2016).

\section{4 | HLA MATCHING IN HPC TRANSPLANTATION}

Amongst the many factors that contribute to successful transplantation, the most significant is the degree of human leucocyte antigen (HLA) compatibility between donor and patient.

Unlike most genes in the human genome, HLA genes are hyperpolymorphic, that is there are many variations within their gene sequences and each variant is called an allele. Most allele differences are nonsynonymous and the majority of amino acid variations impact on the structure of the peptide-binding domains thus directly influencing how self and non-self peptides are presented to T cells and how they are recognized by natural killer (NK) cells.

In a HPCT, alloreactive cells of the patient can initiate an immune response against non-self antigens expressed by the transplanted donor cells, causing rejection of the donor cells. This is defined as either lack of initial engraftment of donor cells (primary graft failure) or loss of donor cells after initial engraftment (secondary graft failure). Pre-transplant conditioning of the patient with chemotherapy and/or irradiation reduces this HVG response allowing the donor cells to engraft. Conversely, immune reactive cells from the donor can target non-self patient antigens, expressed by tissues of the recipient, causing a graft versus host $(\mathrm{GVH})$ immune response. This acute GVH disease (aGVHD) is graded from I to IV (mild to severe) and involves multiple organs of the patient including skin, gut and liver with grade IV aGVHD being life-threatening. Alloreactive immune responses are reduced by the use of immunosuppression and by using T cell-depleted HPC products. The GVH response can also be beneficial when directed to cells expressing malignancy-specific antigens, that is graft-versus-leukaemia (GVL) (Craddock \& Chakraverty, 2016).

The impact of matching HLA alleles of patients with donors, as is the case when the donor is an HLA-matched sibling, contributes significantly to optimal outcome by reducing the allo-reactions that contribute to HVG and GVHD responses. In addition to HLA variability, non-HLA genetic polymorphisms can impact on GVHD and these are more frequent in unrelated donor transplants where there is less genetic compatibility outwith the Major Histocompatibility Complex (MHC, Petersdorf, 2017).

\section{5 | HLA TYPING AND HLA ALLOANTIBODY IDENTIFICATION}

\subsection{HLA testing methodologies}

HLA typing and HLA alloantibody identification can be undertaken by various methods. It is not the scope of this guideline to advocate which methods should be utilized. All methods used must be validated and/or verified within the laboratory where used. Within the United Kingdom, HLA typing and HLA alloantibody identification for HPCT must be performed according to the standards for histocompatibility testing produced by the European Federation for 
TABLE 1 Recommendations

\section{Supporting text \\ location \\ Section}

Level 1 (we recommend)

Quality of Evidence: GRADE A (high)

5.1 All laboratories performing H\&I testing for allogeneic HPCT in the UK must be accredited by EFI and UKAS

5.2 HLA typing definitions as described by Nunes et al. (2011) and within this document should be used

6 Alternative progenitor cell donors (single mismatched unrelated donor/umbilical cord blood (UCB)/haploidentical) should be considered early in the donor search when a patient is unlikely to have an HLA matched unrelated donor

HLA typing of patients and all donors (matched and mismatched, related, unrelated and cord) proceeding to transplant should be carried out at high resolution for HLA-A, B, C (exons 2 and 3 minimum) and DRB1, DQB1 and DPB1 (exon 2 minimum) which identifies polymorphisms within the antigen recognition domain (ARD)

When selecting an unrelated donor a 10/10 high or UHR/allele resolution HLA-A, -B, -C, -DRB1 and -DQB1 matched donor should be preferentially selected over a mismatched donor

8.3.1 Where a 10/10 matched unrelated peripheral blood stem cell (PBSC) or bone marrow donor is not available a single mismatch at HLA-A, B, C, DRB1 or DQB1 is acceptable with mismatches at DQB1 preferred

8.3.2 When selecting mismatched donors, avoid amino acid mismatches within the ARD

9.2.1 Ensure shortlisted UCB units meet the minimum threshold required for a single UCB transplant $\left(\mathrm{UCBT}^{\mathrm{B}}\right)$, $\left(>3 \times 10^{7} / \mathrm{kg}\right.$ recipient weight). In non-malignant conditions, especially bone marrow failure syndromes, or in cases where $\mathrm{HLA}$ match is $<6 / 8$, consider increasing the total nucleated cell (TNC) threshold to $>5.0 \times 10^{7} / \mathrm{kg}$. When the patient's weight indicates that a double UCBT is required, maintain a minimum TNC of $>3.5 \times 10^{7} / \mathrm{kg}$. The minimum TNC required for each unit is $1.5 \times 10^{7} /$ $\mathrm{kg}$, though preference should be given to the best HLA matched UCB with TNC in excess of this minimum threshold, where possible

Select UCB units with HLA match $\geq 4 / 8$ in adults and $\geq 5 / 8$ in children (nonämalignant disease). For double UCBT the unit-unit HLA match does not need to be considered.

9.2.3 For single UCBT select UCB units with minimum CD34+ cell dose $\geq 1.5 \times 10^{5} / \mathrm{kg}$; for double UCBT select units with minimum CD34+ cell dose $\geq 1.0 \times 10^{5} / \mathrm{kg}$ each

9.2.5 Avoid selection of red blood cell (RBC) replete UCB units with Haematocrit of $>40 \%$

7, 8, $9 \quad$ All patients and selected donor/UCB unit(s) must have their HLA types confirmed on a sample independent to the first HLA type, prior to commencement of transplant work-up

11.1 Select donors that are cytomegalovirus (CMV) matched with the patients

$11.4 \quad$ Younger donors should be preferentially selected

13 Homozygosity and novel HLA alleles identified within DNA extracted from patients with a high frequency of circulating tumour cells should be confirmed by family studies or using DNA extracted from non-diseased cells

Individuals actively involved in the provision of a donor selection service should undertake continuing professional development (CPD) (Grade A) and the service should be directed by a Royal College of Pathologist Fellow and Consultant in $\mathrm{H} \& \mathrm{I}$

\section{Quality of Evidence: GRADE B (low)}

5.3

6

7

8.3.3

8.3.4

10

10

10

11.2

11.3

12
Testing for HLA antibodies should detect antibodies reactive with HLA-A, B, C, DRB1, DRB3, DRB4, DRB5, DQA1, DQB1, DPA1 and DPB1 gene products

The clinical urgency should be made available to the individual performing the related and unrelated donor search

HLA typing of regions outside the ARD to achieve Ultra High Resolution (UHR) or allelic level typing is recommended

When a choice of otherwise equally matched donors is available, non-permissive HLA-DPB1 mismatches should be avoided. Patient HLA-DP expression levels should also be considered

HLA-DRB3, DRB4, DRB5 typing should be performed and, when a choice of otherwise equally matched donors is available, mismatches for these should be minimised

Additional testing for HLA-DPA1 and DQA1 is required if indicated by patient's HLA antibody status

Recipient HLA alloantibody testing should be monitored such that selection of HLA mismatched donors, against whom the patient may have antibodies, is avoided

If donor specific antibodies (DSA) are detected, define the risk further by determining the complement binding ability and/or perform a crossmatch between the patient and donor as locally agreed with the transplant team

Major ABO incompatibilities should be avoided when there is a choice of donors

Male donors should be preferentially chosen where the patient has multiple donor options

Identify a back-up donor option 
TABLE 2 Suggestions

\begin{tabular}{|c|c|}
\hline $\begin{array}{l}\text { Supporti } \\
\text { location } \\
\text { Section }\end{array}$ & Level 2 (we suggest) \\
\hline \multicolumn{2}{|c|}{ Quality of Evidence: GRADE A (high) } \\
\hline 9.2 .5 & $\begin{array}{l}\text { When considering an older UCB unit, evaluate infectious disease markers (IDM), sterility and haemoglobinopathy test results } \\
\text { at early stages of UCB unit selection. This allows time for any missing mandatory tests to be undertaken by the cord blood } \\
\text { bank (CBB), or the transplant centre }\end{array}$ \\
\hline \multicolumn{2}{|c|}{ Quality of Evidence: GRADE B (low) } \\
\hline 8.3 .2 & $\begin{array}{l}\text { When selecting donors with mismatches outside the ARD consideration of the location of the mismatched amino acid } \\
\text { residues and avoidance of described nonpermissive mismatches may contribute to better outcome. For HLA-B mismatches, } \\
\text { exon } 1 \text { sequences may be assessed and for HLA-C mismatches, apparent expression levels may also be considered }\end{array}$ \\
\hline 8.3.2 & Use the PIRCHE algorithm in aiding selection of mismatched donors \\
\hline 8.3.5 & $\begin{array}{l}\text { For mismatched donor selection, host-versus-graft (HVG) mismatches are favoured over bidirectional and graft-versus-host } \\
\text { (GVH) mismatches, unless there is a high risk of graft rejection due to stem cell source (e.g. UCB) or patient's disorder }\end{array}$ \\
\hline 6 & $\begin{array}{l}\text { Where HLA-DQA1 and HLA-DPA1 typing has been performed and there is a choice of otherwise equally matched donors, } \\
\text { consider avoiding donors with mismatches at these loci }\end{array}$ \\
\hline 9.2 .2 & $\begin{array}{l}\text { Where a choice of UCB unit is available, where possible, priority should be given to unidirectional GVH mismatches over HVG } \\
\text { unidirectional mismatches }\end{array}$ \\
\hline 9.2 .5 & $\begin{array}{l}\text { In case of a choice of equally mismatched UCB units with similar potency, the transplant centre may prefer units matching a } \\
\text { patient on paternal antigens and/or where the patient HLA mismatches match the noninherited maternal antigen (NIMA) of } \\
\text { the UCB }\end{array}$ \\
\hline 10 & $\begin{array}{l}\text { Post-transplant HLA alloantibody testing should be performed in cases of failed engraftment if there are mismatches in the } \\
\text { HVG direction }\end{array}$ \\
\hline 11.5 .1 & If an HLA-B-mismatched donor is selected, consider MICA-129 dimorphism \\
\hline 11.5.4 & $\begin{array}{l}\text { Where a choice of fully HLA-matched donors exists, recipients who are homozygous for C2 group HLA-C alleles should } \\
\text { receive a KIR2DS1-positive donor }\end{array}$ \\
\hline 11.5.4 & $\begin{array}{l}\text { Where a choice of fully HLA-matched donors exists, recipients who are mismatched with their donor for CMV serostatus } \\
\text { should receive a KIR B haplotype-positive donor, ideally categorized 'better' or 'best' in accordance with the B content } \\
\text { scoring model (Cooley et al., 2010). If the B content scoring model is used, the IPD-KIR ligand calculator (https://www.ebi. } \\
\text { ac.uk/ipd/kir/donor_b_content.html) should be utilized to avoid ambiguity }\end{array}$ \\
\hline
\end{tabular}

Immunogenetics (EFI) (https://efi-web.org/) and must be undertaken by a laboratory accredited by the United Kingdom Accreditation Service (UKAS) (https://www.ukas.com/) and EFI.

\section{2 | Definitions of HLA typing resolution}

The definitions for low, high and allele resolution typing as compiled by a joint international working party: the Harmonisation of Histocompatibility Typing Terms Working Group, to define a consensual language for laboratories, physicians and registries to communicate histocompatibility typing information are used within this guideline (Nunes et al., 2011). In addition, we accept the following definitions for intermediate resolution, and ultra-high resolution (UHR) typing (Mayor et al., 2019). Official names are assigned to the HLA genes, antigens and alleles by the World Health Organisation (WHO) Nomenclature Committee for Factors of the HLA System (Marsh et al., 2010). The Immuno Polymorphism Database-ImMunoGeneTics (IPD-IMGT)/HLA Database is the official repository of the HLA allele sequences (Robinson et al., 2015).

\subsection{1 | Intermediate resolution}

The term intermediate resolution can be applied when high resolution cannot be achieved, and the provided HLA type includes a subset of alleles sharing the digits in the first field of their allele name, for example $A^{*} 02: 01$ or $A^{*} 02: 02$ or $A^{*} 02: 07$ or $A^{*} 02: 20$ but not other $A^{*} 02$ alleles due to differences in the second or other fields. There may be cases in which the subset of alleles includes one or more alleles within a group beginning with different digits but these alleles should be the exception, for example $A^{*} 01: 01$ or $A^{*} 01: 02$ or $A^{*} 01: 14$ or $A: 36: 04$. Reporting intermediate resolution results as high resolution is inaccurate and could lead to inappropriate selection of optimum donor by missing rare and novel alleles.

\subsection{2 | Genotyping outside of the antigen recognition domain}

As most HLA typing strategies now target regions beyond the exons encoding the ARD, the impact of genetic variation within other 
exons, introns, $5^{\prime}$ and $3^{\prime}$ untranslated regions can be investigated. Sequence variation within these regions can affect HLA expression, for example encode null alleles, and function, for example CD8 and CD4 binding (Clayberger et al., 1994) which will impact on the assessment of compatibility between a patient and potential donor. Improvements in HLA typing by next-generation sequencing (NGS) and third generation sequencing (TGS) enable near full-gene (allele) sequencing with greater phase determination facilitating the potential matching of HLA genes beyond previously considered criteria, including polymorphisms in noncoding regions and consideration of synonymous nucleotide mismatches (Petersdorf \& O'hUigin, 2019). The terminology 'UHR' was introduced by Mayor et al. (2019) to describe HLA typing resolution achieved using these techniques which give greater than high but not quite achieving complete allele level. Table 3 gives examples of acceptable reporting conventions.

\section{3 | HLA antibodies}

The role of HLA alloreactive antibodies in HPCT outcome is described in Section 10. Laboratories should be able to detect IgG (at a minimum) antibodies reactive with HLA-A, HLA-B, HLA-C, HLA-DRB1, HLA-DRB3, HLA-DRB4, HLA-DRB5, HLA-DQA1, HLADQB1, HLA-DPA1 and HLA-DPB1 gene products. The use of multiple different testing assays may be required to allow detection of antibodies reactive with all donor mismatches.

\section{6 | STAGE OF DISEASE AND TIME TO TRANSPLANT}

One of the earliest steps in donor selection is to consider the disease status of the patient. Depending on the disease type and treatment plan, patients will have different timescales to transplant. In acute leukaemia, where the patient's condition can rapidly deteriorate, there may only be a limited window of opportunity to transplant when the patient is in clinical remission, thus limiting the time available for an extended related or unrelated donor search (Cutler et al., 2004). A patient progressing to an advanced disease usually has a higher mortality risk from the disease than the added risk of a transplant from a single allele mismatch donor or alternative donor therapy such as UCB or haploidentical donor transplantation. The impact of the time required to identify an optimum matching donor has to be offset against the potential negative impact of the disease stage and progression and will determine the source of progenitor cells selected for treatment (Brissot et al., 2017; Weisdorf, 2008). The H\&I scientists should be given an indication of the clinical urgency and the $\mathrm{H} \& \mathrm{l}$ specialist must advise on the likelihood of finding a matched or other donor within the time frame defined by the transplant team.

\section{7 | HISTOCOMPATIBILITY MATCHING: RELATED DONOR SELECTION}

The initial search for an HLA-matched donor is usually within the patient's family although for certain genetic diseases a related donor may not be appropriate if they are a carrier of the same genetic mutation. Even if studies show good outcomes with both related and unrelated donors (Robin et al., 2013; Shouval et al., 2019), there is still an advantage in selecting a related donor. Related donors are usually quick to identify and cheaper to workup and are flexible in terms of timing the transplant; thus, transplants can be expedited to suit the patient's clinical condition.

\section{1 | HLA matching for related donor selection}

There is a $25 \%$ theoretical chance of a patient and a sibling being an HLA match. However due to parents sharing common haplotypes, the actual number of patients identifying an HLA-A, B, C, DRB1, DQB1-matched sibling donor is closer to $30 \%$. The selection of mismatched and haploidentical relatives increases the options of finding a donor within the patient's family. Single allele-mismatched related donors may be identified within families when an HLA-matched donor is not identified and outcome data support no difference in OS, DFS, transplant-related mortality (TRM), relapse and grade III-IV
TABLE 3 Suggested reporting comments for indicating level of HLA typing used to assess matching between patient and donor

\begin{tabular}{|c|c|}
\hline $\begin{array}{l}\text { Comment } \\
\text { on report }\end{array}$ & Interpretation \\
\hline $\begin{array}{l}10 / 10 \mathrm{HR} \\
\text { match }\end{array}$ & $\begin{array}{l}\text { The patient and donor have been typed to high resolution, i.e. the } \\
\text { polymorphisms within the ARD have been defined }\end{array}$ \\
\hline $\begin{array}{l}\text { 10/10 UHR } \\
\text { match }\end{array}$ & $\begin{array}{l}\text { The patient and donor have been typed to ultra high resolution, i.e. } \\
\text { polymorphisms within and outside the ARD have been defined }\end{array}$ \\
\hline $\begin{array}{l}10 / 10 \text { allele } \\
\text { match }\end{array}$ & $\begin{array}{l}\text { The patient and donor have been typed to allele resolution, i.e. the } \\
\text { polymorphisms within the full HLA gene sequence, that is exons and introns } \\
\text { and untranslated regions have been defined }\end{array}$ \\
\hline $\begin{array}{l}\text { 10/10 HR } \\
\text { match and } \\
9 / 10 \text { UHR } \\
\text { match (B } \\
\text { mismatch) }\end{array}$ & $\begin{array}{l}\text { The patient and donor have no mismatches at high resolution HLA typing for } \\
\text { HLA-A, HLA-B, HLA-C, HLA-DRB1 and HLA-DQB1. A mismatch outside the } \\
\text { ARD has been identified for HLA-B by UHR typing }\end{array}$ \\
\hline
\end{tabular}


aGVHD (Valcárcel et al., 2011). Haploidentical transplantation is discussed in Section 7.2.

The availability of parental HLA typing data are useful for assignment of haplotypes. These data can usually be derived for paediatric patients but are rarely available for adult patients. Although meeting current EFI standards, HLA-A, HLA-B and HLA-DRB1 typing of siblings (without parents), to identify potential matches, does not allow accurate determination of haplotypes and can lead to wrongly (a)

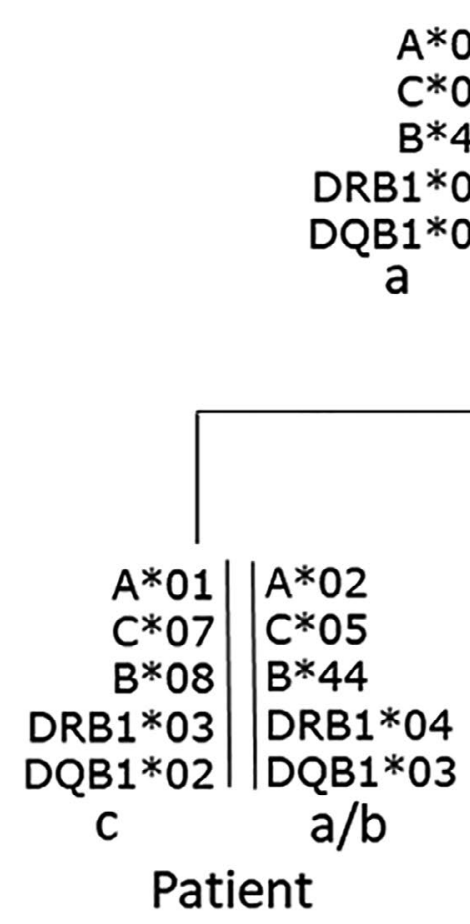

Father

$A * 02|| A * 02$

$C * 05$

$B * 44$

DRB $1 * 04$

$\mathrm{DQB} 1 * 03$

b
Mother

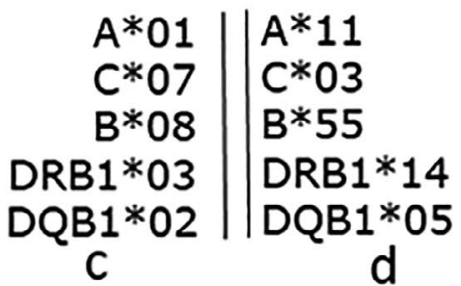

(b)

Father

\begin{tabular}{r||l}
$A * 01$ & $A * 02$ \\
$C * 07$ & $C * 05$ \\
$B * 08$ & \\
$B * 44$ \\
DRB $1 * 03$ & \\
DRB1*04 \\
DQB1*02 \\
DQB1*03 \\
C $\quad$ a/b \\
\multicolumn{2}{c}{ Sib 1}
\end{tabular}

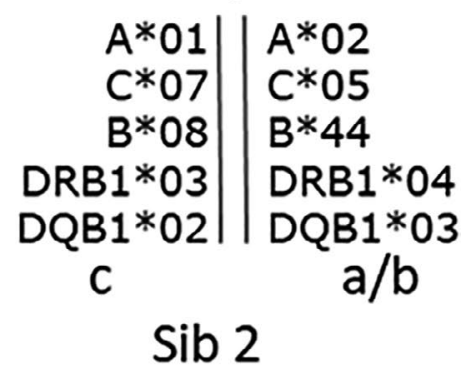

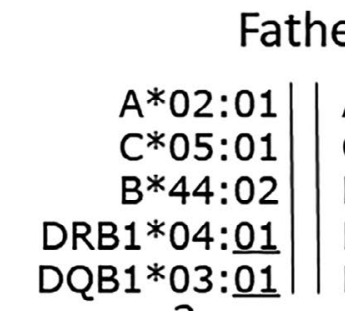

a
$A * 02: 01$
$C * 05: 01$
$B * 44: 02$
DRB1*04: $\underline{04}$
DQB1 $* 03: \underline{02}$
$b$

Mother

\begin{tabular}{l||l}
$A * 01: 01$ & $A * 11: 01$ \\
$C * 07: 01$ & $\mid C * 03: 03$ \\
$B * 08: 01$ & $B * 55: 01$
\end{tabular}

DRB1*03:01

DQB1*02:01

$\mathrm{C}$

d

DRB1*14:54

DQB1*05:03 
establishing presumptive matches. This is a particular concern when there is haplotype sharing between parents or apparent homozygosity (at low/intermediate resolution HLA typing) for a parent. This is illustrated in Figure 1. Also, novel alleles and recombination (especially between HLA-DQ and HLA-DP genes) may be undetected if HLA typing is restricted to only HLA-A, B, DRB1 loci. High, UHR or allelic HLA typing resolution is required as low/intermediate resolution typing could mask additional mismatches (Hansen, 2012; Kanda et al., 2012). HLA-DPB1 typing is also useful in identifying fully matched sibling donors when common haplotypes are present.

\section{2 | Haploidentical family donors}

The use of haploidentical donors has had a significant positive impact on the transplant opportunities for patients who do not have an HLAidentical sibling or volunteer unrelated donor option, as most patients will have a haploidentical relative within their family (Fuchs, 2012). Current protocols include the post-transplant administration of cyclophosphamide (PTCy) to actively destroy proliferating alloreactive lymphocytes, without impairing haematopoietic progenitor cells, thus reducing the risk of severe GVHD caused by HLA mismatches (Chang \& Huang, 2014; Reisner et al., 2011). As the clinical outcome of haploidentical transplants is proving to be comparable to matched related donors (Rashidi et al., 2019), an increase in the number of haploidentical transplants has been documented (Passweg et al., 2019). For the majority of paediatric patients, the donor will either be the patient's mother or father. For adult patients, this choice is often impracticable and siblings and children are usually considered, with second degreerelated donors also possible (Elmariah et al., 2018). Preferred donor characteristics, which vary depending on the transplant protocol ( $T$ cell deplete or T-cell replete), have been reviewed and published in the European Society for Blood and Marrow Transplant (EBMT) consensus recommendations (Ciurea et al., 2020). For T-cell deplete haploidentical transplants, the preference is a first degree relative over second degree and when parents are being considered the mother is preferred over the father due to the benefit of NIMA, discussed further in Sections 8.3.6 and 9.2.5.5. For T-cell replete transplants, siblings (NIMA mismatched) and children are preferred over a parent donor (Wang et al., 2014) and the father is the preferred parental donor. When multiple haploidentical donors are available, the donor may be selected based on non-HLA donor characteristics discussed in Section 11.

As for other related donor transplants, high, UHR or allelic resolution typing (HLA-A, B, C, DRB1, DQB1, DPB1) of the potential haplotype-matched donor is recommended to aid assignment of haplotypes. All haploidentical donors will be at least a 5/10 match to the patient. There are currently no data that suggest a different outcome for haploidentical donors who may have no sharing of DP type due to recombination, that is $5 / 12$ v 6/12 (Jaime-Pérez et al., 2020). Additional HLA matching on the mismatched haplotype may be observed; however, the EBMT consensus recommendation (Ciurea et al., 2020) concluded that there was no evidence to support a beneficial effect of selecting haploidentical donors based on the degree of additional HLA matching due to heterogeneity in data currently available. Patients receiving a haploidentical donor transplant require testing for HLA antibodies (discussed in Section 10).

Haploidentical transplantation involves HLA mismatching and may include mismatching for HLA proteins that interact with different NK cell inhibitory receptors (Killer-cell Immunoglobulinlike Receptors, KIR). The role of NK cell receptors is discussed in Section 11.5

\section{3 | Related UCB donor}

HLA typing of potential related UCB donors must be performed to the same resolution as described for other related donors to allow identification of haplotypes. HLA antibody testing of the patient (if the UCB is mismatched) is also required.

\section{4 | Final donor selection}

Both patient and the selected related donor must be HLA typed using a second independent sample to exclude any sampling or laboratory errors and must take place prior to the initiation of the patient's conditioning protocol.

\section{8 | HISTOCOMPATIBILITY MATCHING: VOLUNTEER UNRELATED DONOR SELECTION}

An unrelated donor search should be carried out for those patients without a suitable HLA-matched related donor. For 2018, the EBMT reported that there were almost equal numbers of allogeneic transplants using unrelated donors (50.5\%) and related donors (49.5\%) (Passweg et al., 2020). These figures and those from previous years (Passweg et al., 2019) demonstrate a decrease in the overall number of unrelated donor transplants due to an increase in related donor, particularly haploidentical transplants over the last 10 years.

\subsection{The search process}

Time to transplant is an important consideration when deciding to initiate an unrelated donor search (see Section 6). For those patients with high clinical urgency, unrelated donor searches may be initiated at the same time as undertaking a search for a related donor. Before an unrelated donor search is commenced, it is necessary to gain the appropriate authorization (Scotland) or consent (rest of United Kingdom) from the patient to permit the sharing of their personal and genetic data with national and international donor registries. 
Within the UK, the Anthony Nolan and National Health Service (NHS) Stem Cell Donor Register is an aligned unrelated donor register, operated by Anthony Nolan, which provides search reports including donors from Anthony Nolan; the British Bone Marrow Register (BBMR); the Welsh Bone Marrow Donor Register (WBMDR) and DKMS UK. Initial search requests are sent, by the transplant centre or associated H\&I laboratory, to Anthony Nolan who produce a search report consisting of potential UK donors, as well as a summary report generated from the World Marrow Donor Association (WMDA) international database of donor registries (WMDA Search \& Match). The number of potential matched UK donors is used to determine the need to initiate searches of international registries. Laboratories and transplant centres who routinely request unrelated donor searches should establish with the Anthony Nolan Search Team a set of criteria for when international donor searches are to be initiated. It is the responsibility of the transplant centre to agree specific criteria to be used to filter donor lists, for example male in preference to female, age and CMV status. It is also essential that the urgency of the patient case is communicated to the Anthony Nolan Search Team to allow them to take this into account when performing international searches.

The most useful results from the unrelated donor search are obtained when the patient has been HLA typed to high, UHR or allelic resolution to eliminate mismatching donors from the search summary.

\subsubsection{The search algorithm}

The minimum requirements for an unrelated donor search algorithm have been published by the WMDA in their 'Framework for the implementation of HLA matching programs in haematopoietic stem cell donor registries and cord blood banks' (Bochtler et al., 2011). The current search algorithm used in the UK by Anthony Nolan identifies donors that are potentially matched at $5 \mathrm{HLA}$ loci (HLAA, HLA-B, HLA-C, HLA-DRB1 and HLA-DQB1). Other registries such as the NMDP (National Marrow Donor Program, USA registry) and ZKRD (German registry) use algorithms that match to high resolution for HLA-A, HLA-B, HLA-C, HLA-DRB1 and give a probability value on the likelihood of a donor being a match for a patient based on HLA allele and haplotype frequencies in the donor populations.

It is essential that the person interpreting search reports understands the algorithm used by the various different registries to ensure optimum donor selection.

\section{2 | Factors impacting on the identification of an HLA-matched unrelated progenitor cell donor}

Caucasoid patients have a $40 \%-75 \%$ chance of identifying a highresolution matched donor at HLA-A, HLA-B, HLA-C, HLA-DRB1 and HLA-DQB1 (10/10 match) and finding this match is highly predictable
(Gragert et al., 2014; Hirv et al., 2009; Tiercy et al., 2000, 2007). The chance of a 10/10 match in other ethnic groups, with HLA haplotypes that are less well represented on the unrelated donor registries, is significantly lower (Gragert et al., 2014; Heemskerk et al., 2005; Schmidt et al., 2009). Hence, patients are less likely to find a matched donor from an ethnic group differing from their own and patients with parents coming from differing ethnic groups are at increased risk of not finding any match.

The use of 'minimally' mismatched adult volunteer donors and UCB units increases significantly the likelihood of finding a usable donor (Gragert et al., 2014). The frequencies of HLA-B and HLA-C and/or HLA-DRB1 and HLA-DQB1 associations in differing ethnic groups are available for comparison with the HLA type of the patient (Gragert et al., 2013; Kollman et al., 2007; Mack et al., 2013; Maiers et al., 2007; Sanchez-Mazas et al., 2017), and these tools can be used to help predict how likely it will be to find a match for a patient.

The following factors must be considered when searching for a high, UHR or allelic resolution matched unrelated donor.

- Uncommon HLA-B and HLA-C and/or HLA-DRB1 and HLA-DQB1 associations have a negative impact on likely donor identification.

- When search results reveal mainly low-resolution HLA-typed donors, the presence of a low frequency allele $(<5 \%)$ in the patient (e.g. B*44:05), when other low-resolution matched alleles have frequencies $>10 \%$ (e.g. $B^{*} 44: 02$ ), will negatively impact on the identification of a matched donor.

- The presence of alleles from the low-resolution typing group HLA-B*51 and HLA-B*18 and the presence of alleles $B^{*} 27: 05$, $B * 44: 02$ and $B * 44: 03$ in the patient have an increased risk of a HLA-C mismatch.

- The presence of alleles from the low-resolution typing group HLA-DRB1*04 and HLA-DRB1*07 in the patient have a raised risk of a HLA-DQB1 mismatch.

The optimal number of donors to select for verification HLA typing should be decided on a patient by patient basis taking into account all the factors that can influence the likelihood of finding a suitable donor, including donor factors (Lown et al., 2014) and the clinical urgency. Acceptable levels of matching and mismatching must be determined and agreed by local transplant policies.

\section{3 | HLA matching requirements for unrelated donor transplants}

Multiple studies have reported optimum transplant outcome is achieved when the patient and donor are matched for HLA-A, HLAB, HLA-C and HLA-DRB1 at high resolution (Flomenberg et al., 2004; Lee et al., 2007; Mayor et al., 2019; Morishima et al., 2002; Petersdorf et al., 2001, 2004, 2020; Woolfrey et al., 2011).

Assessment of matching for full length HLA class I genes $(A, B, C)$ and exons encoding the extracellular domains of HLA class II genes 
(DRB1, DQB1 and DPB1) in a cohort of 891 patients with haematological malignancies, transplanted with unrelated donors, identified better out comes for those patients who were fully matched across all regions targeted with their donors (Mayor et al., 2019). These data supports a previous finding that MHC haplotype matching is beneficial compared with phenotype only matching in related and unrelated donor HPCT (Petersdorf et al., 2013).

\subsubsection{Impact of mismatches at individual HLA loci on transplant outcome}

The role of HLA-DQ matching is less well supported, NMDP data from 3,857 transplants for malignant disease (Lee et al., 2007), showed that individual mismatches for HLA-DQB1 had no impact on survival. However, if the DQB1 mismatch was associated with an additional mismatch, for example $7 / 8$ or $6 / 8$ HLA-A, B, C, DRB1 mismatch, then an association with poorer survival, albeit not statistically significant was observed. Although HLA-DQB1 mismatching did not reach significance in relation to survival, in a German study (Fürst et al., 2013), HLA-DQ antigen mismatching achieved a higher hazards risk for survival compared with HLA-DQ antigen matches. A meta-analysis evaluating data from 36 studies published between 2002 and 2016 concluded that HLA-DQB1 mismatches were better tolerated than other HLA loci for acute GVHD, supporting previous conclusions (Tie et al., 2017).

There are no data to support matching for HLA-DQA1 (and DPA1 discussed in Section 8.3.3). However, as many commercial HLA typing methods include these loci, if transplants are performed that are mismatched for DQB1 and/or DPB1, then mismatches are also likely to be present for DQA1 and DPA1. Testing for these additional loci may inform future matching strategies.

Overall, in the absence of a 10/10 high-resolution matched donor, a donor with a selected single mismatch for HLA-A, HLA-B, HLA-C, HLA-DRB1 or HLA-DQB1 can be acceptable, with multiple mismatches conferring significantly worse outcomes with the effect observed greater when the patient had acute leukaemia and was transplanted early during first remission compared to patients with advanced disease (Crocchiolo, Ciceri, et al., 2009; Tiercy, 2016).

There is no consensus regarding which of the HLA-A, B, C, DRB1 loci are more detrimental to mismatch. HLA-A and HLA-DRB1 mismatching were reported as being less well tolerated compared with HLA-B and HLA-C mismatches in a NMDP study with all mismatches reducing OS at 1 year by $9 \%-10 \%$ (Lee et al., 2007). In contrast, the Japanese registry reported transplants with HLA-A and HLA-B mismatches had worse survival than HLA-C and HLA-DRB1 mismatches (Morishima et al., 2002), with single DRB1-mismatched unrelated donors being preferentially selected if a matched unrelated donor is not available (Atsuta et al., 2019). HLA-B mismatches were associated with a higher risk of aGVHD II-IV in an Italian study of 805 patients transplanted for haematological malignancies (Crocchiolo, Ciceri, et al., 2009) whereas HLA-C antigen mismatches were associated with lower leukaemia-free survival (LFS) and increased risk for mortality and grade III-IV GvHD in an NMDP/Centre for International Blood and Marrow Transplant Research (CIBMTR) study of 1933 patients transplanted with haematological malignancies (Woolfrey et al., 2011). More recent analysis of transplant data held by the 'International Histocompatibility Working Group in HPCT' has demonstrated individual locus-specific risks. In this analysis, HLA-A, HLA-B and HLA-C mismatches were more detrimental than HLA-DRB1 and HLA-DQB1 mismatches for all endpoints with the exception of relapse. Mismatching at each locus (compared with HLA-DQB1) was detrimental and the risk increased with increasing numbers of mismatches (Petersdorf et al., 2020).

The variability in the outcomes of these studies can be attributed to differences in study design; patient demographics; source of stem cells, including T-cell depletion; differences in HLA polymorphism within groups of patients of different ethnicities; use of serotherapy and GVHD prophylaxis and also the level of HLA typing resolution utilized.

A retrospective analysis of 2,646 T-cell replete transplants performed for haematological malignancies was conducted in Germany (Fürst et al., 2013), with all patients and donors HLA typed to high resolution. The impact of mismatches, defined at both high and antigen resolution, on OS; DFS; relapse, TRM and primary graft failure (GF) were analysed. Mismatches of alleles at either of HLA-A, HLA-B, HLA-C, HLA-DRB1 and HLA-DQB1 were associated with a decrease in OS (only significant for HLA-A, HLA-B, HLA-C and HLADRB1); a decrease in DFS (significant for HLA-C) and an increase in TRM (significant for HLA-A, HLA-B, HLA-C and HLA-DRB1). Thus, any type of mismatch can have a negative impact on outcome. Of all associations observed, the most significant were with HLA-C antigen mismatches, affecting OS and DFS, with HLA-B high resolution mismatching being the most significant affecting TRM. HLA-C high resolution mismatches gave consistently lower hazard risks for the outcomes studied suggesting that there may be permissive mismatching at the HLA-C allele level (Fürst et al., 2013). Permissive HLA-C mismatching has been described for HLA-C*03:03 and HLA-C*03:04, where transplant outcomes for patients receiving a $\left(C^{*} 03: 03 / C^{*} 03: 04\right)$-mismatched transplant were not significantly different from patients receiving an 8/8 matched transplant (Fernandez-Viña et al., 2014).

The impact of HLA-C antigen versus high-resolution (allele) mismatches has been further elucidated in a study of 1,975 HLA-C only mismatched (matched HLA-A, HLA-B and HLA-DRB1) transplants (Petersdorf et al., 2014). HLA-C protein expression varies for different HLA allotypes and in this study patients with HLA-mismatched HLA-C allotypes with higher expression were significantly associated with increased risks of aGVHD III-IV; nonrelapse mortality (NRM) and overall mortality but with no impact on relapse. When the higher expressing HLA-C mismatch allotype was present in the donor, an increase in NRM and mortality, but no effect on aGvHD or relapse was observed. In this study, the allele mismatches were predominantly $C^{*}$ 07:01/07:02 and $C^{*} 03: 03 / 03: 04$, which have low levels of protein expression and this may account for previously reported permissive HLA-C allele mismatches. 
Mismatching for lower expressing HLA-C alleles of the patient compared with higher expressing HLA-C alleles may lower the GVH immune response supporting selection of mismatches for lower expressed over mismatches for high expressed alleles and avoidance of HLA-C-mismatched donors for patients with two highly expressed HLA-C. This study also demonstrated a higher risk in double mismatch (8/10) transplants involving a class I and II mismatch compared with double class I or double class II. Other research has highlighted the impact of the HLA-C bearing haplotype on HLA-C expression which could differ in HLA-C-mismatched transplants (Bettens et al., 2014). Further to this, Bettens et al. (2016) investigated the cytotoxic T lymphocyte response to HLA-C mismatches and identified that specific mismatches were more immunogenic than others. As predicted from earlier work (Fernandez-Vina et al., 2014), HLA-C*03:03/03:04 mismatching did not initiate a significant alloresponse.

One of the problems making it difficult to define an accurate risk estimate for a single locus mismatch is the extensive polymorphism exhibited at HLA loci. Mismatches at any locus may involve 1 versus 10 versus 20 amino acid mismatches, for example a mismatch of $A^{*} 01: 01$ with $A^{*} 02: 01$ will be different to a mismatch of $A^{*} 01: 01$ with $A^{*}$ 03:01, which also will differ from a mismatch of $A^{*} 01: 01$ with $A^{*} 23: 01$. Not all mismatches at a given locus will have equal effects on GVL and GVH immune responses post-transplant. It has been calculated that a database of 11,000 to 1.3 million transplants would be required to provide sufficient statistical power to detect an association between particular HLA allele mismatches and survival (BaxterLowe et al., 2009). In reality, having a choice of a particular locus to mismatch is not always available.

\subsection{2 | Impact of individual amino acid substitutions on transplant outcome}

The impact on transplant outcomes (acute, chronic GVHD [cGVHD], TRM, relapse and OS) of amino acid substitutions at peptide-binding positions 9, 99, 116 and 156, and KIR-binding position at amino acid 77 was studied in a multivariate analysis of a heterogeneous cohort of patients transplanted for haematological malignancies (Pidala et al., 2013). Individual mismatches at residues 99 and 116 within HLA-C were associated with an increased TRM and severe aGVHD, respectively. A mismatch at residue 9 within HLA-B was associated with an increase in CGVHD. No mismatches studied had an effect on outcome when located within HLA-A.

In the study of Petersdorf et al. (2014), introduced in Section 8.3.1, patients receiving transplants with 'high expressing' HLA-C mismatches that were also residue 116 mismatched had an increased incidence of NRM compared with patients mismatched for higher expressing HLA-C alleles that were residue 116 matched. Similar findings were made for patients receiving high expressing HLA-C mismatches that were also mismatched for the KIR-interacting residues 77 and 80 (C1 and C2 epitopes discussed in Section 11.5.3). Thus, mismatching for HLA-C allotypes that are highly expressed and contain mismatches at residues 116 and/or 77 and 80 could be taken into account if a choice of different HLA-C-mismatched donors is available.

Analysis of 1,457 unrelated donor transplants with single mismatches for HLA-B (HLA-A, C, DRB1, DQB1 matched) by the International Histocompatibility Workshop working group for HPCT identified an increased risk for grade 3-4 aGVHD when the mismatched HLA-B allele leader peptide (encoded by exon 1, outside the ARD) was mismatched at position -21, compared with HLA-B allele mismatches with a match at this residue (Petersdorf et al., 2020). The mechanism for this association has yet to be proven and could involve the peptide impacting on HLA-E expression and recognition by NK and T cells or could also be a marker for another linked functional polymorphism. Thus, consideration of the exon 1 sequence of HLA-B-mismatched unrelated donors could improve the risk of aGVHD. The findings of this study remain to be confirmed.

The immunogenicity of mismatches beyond the ARD has also been investigated using cellular assays (Roelen et al., 2018). This study did not identify any class I mismatches that generated an alloreaction suggesting that these mismatches are permissive. This is in contrast to the UHR matching study where better outcomes were observed with greater matching beyond the ARD (Mayor et al., 2019). Weak responses in the presence of HLA-DRB1*14:01 individuals stimulated by DRB1*14:54 mismatches were identified. The difference between the proteins encoded by these two alleles is a single amino acid residue in the $\beta 2$ domain. This response was only present in one direction, suggesting that the directionality of the mismatch can also play a role in its immunogenicity.

In addition to the influence that amino acid substitutions can have on peptide and T-cell receptor (TCR) binding, evidence suggests that germline (inherited genome) variation in a patient's HLA can have an influence on post-transplant outcomes. Petersdorf et al. (2018) reported that specific amino acid substitutions in the DR $\beta$ peptide-binding groove could be used to determine HLA haplotypes that lead to increased risk of patient mortality. In a cohort of patients receiving a 9/10 HLA-matched transplant from an unrelated donor, a series of amino acid substitutions at residues $26 / 28 / 30$ of the HLA-DR $\beta$ molecule were identified that impacted on peptide binding, potentially resulting in an altered peptide repertoire. Two of the peptide motifs, FEY and FDH, were associated with increased mortality, whereas another motif, FDY, had a protective role. The risk of mortality associated with these motifs was independent of any specific HLA mismatch. These results suggest that understanding the variation in HLA molecules, regardless of the mismatches involved, has the potential to allow better risk stratification of individual patients.

Another approach to assess the impact of amino acid differences between patient- and donor-mismatched HLA alleles is to calculate the number of peptides that can be derived from the mismatched HLA molecule that could be presented by matched HLA class I or class II molecules with the aim to identify those mismatches that can initiate indirect T-cell allo-reactions. The predicted indirectly recognizable HLA epitopes (PRICHE) algorithm (Geneugelijk \& Spierings, 2017) determines values for both HLA 
class I and class II mismatches, and this has been applied in HPCT to assess permissiveness versus nonpermissiveness of individual transplant mismatches. In a study of patients transplanted with a 9/10 matched unrelated donor, patients with a high PIRCHE class II score had significantly lower OS, compared to those with a low PIRCHE class II score, which was attributed to an increased risk for severe aGVHD (Geneugelijk et al., 2019). A multicentre German study (Ayuk et al., 2019) of 9/10 matched unrelated donor transplants found that PIRCHE mismatches were associated with poorer OS and higher NRM in multivariate analysis. Thus when there is a choice of mismatched donor, consideration of PIRCHE scores may aid identification of permissive over nonpermissive donor mismatches.

\subsection{3 | Impact of HLA-DPB1 mismatching}

Recombination hotspots have been described between HLA-DQB1 and HLA-DPB1 genes (Cullen et al., 1997); therefore, matching patients and unrelated donors with common HLA-A, C, B, DRB1, DQB1 haplotypes does not necessarily infer matching for HLADPB1 and HLA-DPA1 alleles. It is reported that within families up to $5 \%$ of otherwise $10 / 10$ matched siblings will also be HLA-DPB1 mismatched, attributed to recombination (Büchler et al., 2002). HLA-DP-specific T cells have been detected and associated with both GVL (Herr et al., 2017; Rutten et al., 2008, 2013) and GVHD (Stevanovic et al., 2013) supporting the direct role of HLA-DP proteins in the immune responses occurring between patient and donor cells post-transplant.

Analysis of the impact of HLA-DPB1 matching and mismatching on transplant outcome has been studied in both single-centre and multicentre studies. In an analysis of a heterogeneous international cohort of transplant recipients, allelic HLA-DPB1 mismatches were shown to offer a GVL advantage via a reduction in relapse, but this was also associated with increased aGVHD and a suggestive increase in mortality (Shaw et al., 2007). In an NMDP study, there was no significant association of single or double HLA-DPB1 allele mismatches with survival compared with no HLA-DPB1 mismatches in an otherwise HLA-A, B, C, DRB1-matched group of recipients. An increased risk of TRM and decreased risk of relapse was suggestive in this study albeit not significant (Lee et al., 2007).

In a UK multicentre study, the impact of HLA-DPB1 allele matching was associated with better OS in patients transplanted with early leukaemia but not in patients transplanted with late stage disease (Shaw et al., 2010), supporting other studies where the effect of HLA matching is not as strong in patients transplanted at late stage.

A single-centre UK study of 130 patients transplanted for malignancies demonstrated a trend towards a negative impact of double HLA-DPB1 mismatching on OS in patients otherwise matched for 10/10 HLA loci (HLA-A, B, C, DRB1, DQB1). This finding was more evident in patients receiving myeloablative conditioning compared with those receiving reduced intensity conditioning (RIC, Burt et al., 2014).
HLA-DPB1 mismatches have been assigned as either permissive or nonpermissive based on observed immunogenicity to T-cell epitopes (TCE, Crocchiolo, Zino, et al., 2009; Zino et al., 2004). The effect of dividing HLA-DPB1 mismatches into these two groups has provided evidence of DPB1 mismatching impacting on survival in some but not all studies. In a study of 621 unrelated donor HPCTs, recipients with permissive DPB1 mismatches had a significantly higher 2-year survival than those with nonpermissive DPB1 mismatches (55\% vs. $39 \%$ ). This improved survival was due to a decrease in NRM (Sacchi, et al., 2009). Overall nonpermissive DPB1 mismatches (unlike earlier studies of DPB1 allele mismatches) were not associated with an increase in aGVHD and concomitant GVL. In contrast, a retrospective study of 153 consecutive adult patients receiving a primary allogeneic transplant for haematological malignancies did not detect any effect of HLA-DPB1 mismatching on overall mortality or risk of relapse in 10/10 matched transplants (Moyer et al., 2017). HLA-DPB1 mismatches (both permissive and nonpermissive) were associated with increased risk of cGvHD. The risk of aGvHD and severe aGvHD was higher only in those with nonpermissive DPB1mismatched transplants when compared with HLA-DPB1-matched and permissive mismatch pairs combined.

The assignment of permissive and nonpermissive DPB1 mismatches was included in a large multicentre study $(8,539$ transplants) conducted by the International Histocompatibility Workshop Working Group in HPCT (Fleischhauer et al., 2012). Of the patients receiving a 10/10 matched transplant (HLA-A, B, C, DRB1, DQB1), HLA-DPB1 nonpermissive mismatches were associated with a significant increased risk of overall mortality; NRM and in this study an association was observed with severe GVHD but not relapse compared with permissive mismatches. Although differences in outcome were observed between the DPB1-matched and DPB1 permissive-mismatched patients, this did not affect overall mortality.

A CIBMTR study of a patient cohort considered more contemporaneous based on patient disease, transplant conditioning protocol and HPC source (peripheral blood stem cell, [PBSC] vs. bone marrow), has addressed the impact of DPB1 matching versus permissible and nonpermissive mismatches (Pidala et al., 2014). An increase in aGVHD grades II to IV and III to IV and a decreased risk of relapse was observed in patients receiving DPB1-mismatched donors. Dividing the DPB1-mismatched donors into permissive and nonpermissive mismatches identified the nonpermissive mismatches as having an increase in TRM and an increase in overall mortality compared with both the permissive mismatched and the matched patients. The DPB1 mismatching outcome was only significant within patients receiving an $8 / 8$ and a 10/10 matched donor.

Variations in the noncoding region of the HLA-DPB1 gene have been shown to influence antigen expression and patient outcomes in HLA-DPB1-mismatched transplants. A single nucleotide polymorphism (SNP) in the $3^{\prime}$ untranslated region (UTR) of the HLADPB1 gene ( $r$ 9277534 A/G) influences the expression of the HLA-DP protein. The presence of the high expressing ' $G$ ' allele in 
the patient is associated with a higher risk of aGvHD (Petersdorf et al., 2015). This SNP is in linkage disequilibrium with the HLADPB1 exon 3 sequence which can be used as a marker for two highly diverged allele clades with low or high expression levels (Klasberg et al., 2019; Schöne et al., 2018). A study by Morishima et al. (2018) demonstrated the expression level of a patient's mismatched HLADPB1 allele can influence the effect TCE permissibility status has on acute GvHD. In this study, patients with low expressing HLADPB1 allele mismatches had an increased risk of aGvHD when transplanted with a TCE nonpermissive mismatched donor compared with patients transplanted with a TCE permissive donor. For patients with high expressing allele mismatches, the risk of aGvHD was not significantly different between TCE permissive and TCE nonpermissive pairs. The risk of aGvHD was higher in patients with high expressing HLA-DPB1 alleles, and this was independent of donor's HLA-DP expression level (Morishima et al., 2018).

HLA-DPA1 is significantly less polymorphic than HLA-DPB1, and certain alleles encoded by the two loci are in linkage disequilibrium. Analysis of the role of HLA-DPA1 mismatches had no effect on transplant outcome observed for the DPB1 permissive and nonpermissive mismatches in an NMDP study of 1,281 10/10 matched unrelated donor transplants (Fleischhauer et al., 2014).

Although there are variations in the clinical outcomes for HLADPB1 allele and nonpermissive mismatched transplants, overall, matching for HLA-DPB1 and avoidance of nonpermissive mismatches is associated with better OS. Therefore, matching/mismatching at the HLA-DPB1 locus should be considered on an individual basis, taking into account matching at other loci and following the transplant physician's evaluation of the patient's transplant related risks. An online tool (see Section 15) is available for assignment of permissive and nonpermissive DPB1 mismatches based on the TCE analyses performed (Crivello et al., 2015; Shaw et al., 2013).

\subsubsection{Matching for HLA-DRB3, HLA-DRB4 and HLA-DRB5}

There is evidence for a potent immune response induced by mismatches at HLA-DRB3 (van Balen et al., 2017) and a small but significant effect of DRB4 mismatches on TRM and survival (Detrait et al., 2015).

Analysis of the NMDP dataset of 3,853 unrelated donor transplants has demonstrated that whilst not significant in isolation, mismatching for HLA-DRB3, HLA-DRB4, HLA-DRB5, HLA-DQB1 and HLA-DPB1 (defined as 'lesser expressed HLA loci', LEL) increased the risk associated with the presence of a mismatch at HLA-A, HLA-B, HLA-C or HLA-DRB1 (Fernández-Viña, et al., 2013). Transplants matched for 7/8 HLA-A, B, C, DRB1 with three or more LEL mismatches in the GvH direction had a higher risk of mortality and TRM than $7 / 8$ transplants with 0 or 1 LEl mismatches. Thus, HLA typing donors and patients for HLA-DRB3, HLA-DRB4, HLA-DRB5, HLA-DQB1 and HLA-DPB1 is warranted to minimize the number of mismatches at the LEL.

A retrospective multicentre French study of 1,975 patients with haematological malignancies who received 10/10 matched unrelated donor transplant showed significant increased risk of grade II-IV aGvHD in pairs with HLA-DRB3, DRB4, DRB5 mismatches when compared with those with no mismatch at these loci. There was no difference in CGvHD, NRM, relapse and OS between these two groups (Ducreux et al., 2018).

\subsection{5 | Direction of HLA mismatch}

Donor and patient HLA mismatches may be bidirectional, that is GVH and HVG or unidirectional. The effect of direction of HLA mismatch has been investigated within a cohort of 2,687 unrelated donor transplants in patients with malignant disease (Hurley et al., 2013). In multivariate analyses, patients receiving a 7/8 (HLAA, B, C, DRB1) matching graft with unidirectional GVH mismatch and patients receiving a $7 / 8$ bidirectional mismatch had significantly worse TRM; OS and DFS compared with patients receiving a $8 / 8$ matched transplant. This worse transplant outcome (compared with $8 / 8$ transplants) was not shared with patients receiving a 7/8 matching graft with unidirectional HVG mismatch.

This difference in outcome observed for the 7/8 HVG mismatches is likely caused by the observed reduction in probability of acute GVHD observed in this group. No differences were observed between the three $7 / 8$ mismatched groups and the $8 / 8$ matched transplants with other clinical outcomes including engraftment, relapse and chronic GVHD. These findings support selection of a $7 / 8$ HVG mismatch over a $7 / 8$ bidirectional or $7 / 8 \mathrm{GVH}$ mismatch unrelated donor for patients with malignant disease. This finding has not been reproduced in patients with nonmalignant disorders, nor in patients receiving UCB transplants, who may be at higher risk of graft rejection. For patients at risk of graft rejection, avoidance of HVG mismatches is desirable.

This study did not confirm previous data reported by the Seattle group in 2001 where transplants mismatched in the HVG direction were associated with lower neutrophil engraftment and secondary graft failure. However, the demographics of the transplant group in the latter study differ in that the transplants were bone marrow and HLA matching was not completely at high resolution (Petersdorf et al., 2001). HVG and GVH directional mismatches are illustrated in Table 4.

TAB LE 4 Example of HVG and GVH directional mismatches

\begin{tabular}{lll} 
HLA & Patient & $\begin{array}{l}\text { Potential } \\
\text { Donor }\end{array}$ \\
\hline A & ${ }^{*} 02: 01$ & ${ }^{*} 02: 01,{ }^{*} 03: 01$ \\
\hline B & ${ }^{*} 07: 02,{ }^{*} 08: 01$ & ${ }^{*} 07: 02,{ }^{*} 08: 01$ \\
\hline C & ${ }^{*} 05: 01,{ }^{*} 07: 02$ & ${ }^{*} 05: 01,{ }^{*} 07: 02$ \\
\hline DRB1 & ${ }^{*} 04: 01,{ }^{*} 15: 01$ & ${ }^{*} 04: 01,{ }^{*} 15: 01$ \\
\hline DQB1 & ${ }^{*} 03: 01,{ }^{*} 06: 02$ & ${ }^{*} 03: 01,{ }^{*} 06: 02$ \\
\hline DPB1 & ${ }^{*} 03: 01,{ }^{*} 04: 01$ & ${ }^{*} 04: 01$ \\
\hline
\end{tabular}

Note: The patient and donor differ with an HLA-A mismatch in the HVG direction and an HLA-DPB1 mismatch in the GVH direction. 


\subsection{6 | NIMA/NIPA}

Exposure of the patient to NIMA via transplacental trafficking of maternal and foetal cells during pregnancy may result in tolerance to these antigens when present on cells transplanted to the patient, thus reducing HVG immune responses. Additionally GVL reactions may be enhanced resulting in lower relapse rates. In a study of 118 patients receiving haploidentical transplants, an increase in 5-year event-free survival due to reduced relapse and reduced TRM was observed when the donor was the mother, compared with the donor being the father (Stern et al., 2008). This reduced relapse rate in recipients of maternal HPC is independent of NK cell allo-reactions. In contrast, multivariate analyses of 1,210 haploidentical transplants in China have shown that transplants where the mother is the donor have increased NRM, aGVHD and decreased survival compared with transplants where the father is the donor. In this study, a sibling donor with NIMA mismatches was deemed the optimum donor (Wang et al., 2014).

The EBMT consensus recommendations (Ciurea et al., 2020) concluded that NIMA-mismatched siblings may be preferred over NIPA-mismatched ones in T-cell replete haploidentical donor transplants with ATG but that it remains unclear whether this immunologic tolerance is associated with better outcomes in either T-cell replete haploidentical donor transplants with PTCy or T-cell deplete haploidentical donor transplants. NIMA and NIPA in UCB transplants is discussed in Section 9.2.5.5.

\subsection{7 | Other MHC matching}

MHC haplotype matching has also been reported as beneficial in related and unrelated donor HPCT, by reducing the incidence of aGVHD (Petersdorf et al., 2013). HLA class I and II genes are separated by the MHC class III region, also described as the gamma block, which contains genes encoding immune regulatory proteins including the complement components $\mathrm{Bf}, \mathrm{C} 2$ and $\mathrm{C} 4$. Comparison of SNPs within the complement C4A and C4B genes did not identify any association between SNP mismatching and transplant outcome (Clancy et al., 2019; Getz et al., 2020). Similarly, no significant associations between gamma block mismatching and unrelated donor HPCT outcomes were observed in a large retrospective cohort from the CIBMTR (Askar et al., 2019), nor in multivariate analysis of a single-centre cohort (Maskalan et al., 2020).

\section{9 | SELECTION OF UNRELATED UMBILICAL CORD BLOOD UNITS}

\subsection{Use of UCB}

UCB is an alternative source of HPCs that can be used to treat patients with both malignant and nonmalignant disorders (Ballen, 2017; Ballen et al., 2013). An early study undertaken by the CIBMTR-Eurocord showed similar survival outcomes comparing paediatric patients receiving HLA-identical UCBT with patients receiving HLA-identical sibling donor transplants. This study highlighted delayed granulocyte and platelet engraftment in UCBT recipients but also demonstrated a reduction in both acute and chronic GVHD (Rocha et al., 2000). Similarly, a comparison of unrelated HLA-mismatched UCBT to matched unrelated adult donors transplants in paediatric patients demonstrated recipients of the UCBT experienced delayed engraftment but less acute and chronic GVHD with a similar relapse rate, OS and LFS (Rocha et al., 2001). Similar OS and significantly improved cGvHD and relapse-free survival were reported for adult patients with different malignant conditions after UCBT compared with matched sibling PBSC in a single-centre study in Colorado (Sharma et al., 2020).

The use of UCB was initially restricted to children due to the low cell doses obtained and poorer results obtained with adult recipients (Laughlin et al., 2001). However, the selection of UCBs with higher cell doses and the success with infusion of two UCBs to adult recipients (dUCBT) giving comparable results to matched related and matched unrelated donor transplants (Brunstein et al., 2010) together with improved conditioning protocols has led to UCB being a source of HPCs for both children and adults (Barker et al., 2003; Scaradavou et al., 2013).

More recently, UCBT has been shown to provide improved outcome for patients (paediatric and adult) transplanted in the presence of minimal residual disease. Significantly higher OS and lower risk of relapse was observed in UCBT recipients compared with recipients of HLA-mismatched unrelated donor transplants (Milano et al., 2016). Similarly, outcomes for older patients (>50 years) receiving RIC transplants were comparable when the donor source was either matched sibling, unrelated donor or UCB, although there was an observed increase in TRM and reduced LFS in the recipients of UCBT (de Latour et al., 2013; Weisdorf et al., 2014). A joint CIBMTR/EBMT/EUROCORD study looking at transplant outcome for patients transplanted with FMS-like tyrosine kinase 3+ (FLT3+) acute myeloid leukaemia (AML) concluded UCB donor options as acceptable in the absence of an HLA-matched sibling, as the relapse risks were similar, although UCB was associated with higher NRM, but also lower chronic GVHD (Ustun et al., 2017).

The reduced incidence and severity of acute and chronic GVHD observed following UCBT, and comparable outcome data have allowed the use of mismatched UCB donors which would exceed the mismatches accepted in related or unrelated adult donor transplants. This has enabled transplantation of patients who do not have an appropriately matched or mismatched adult donor and has significantly enhanced the transplant options for patients from Black, Asian and Minority ethnicities where unrelated donor options are reduced. Although a decrease in UCBT has been observed in the last few years, concomitant with an increase in the use of haploidentical donors (Passweg et al., 2020), UCB donations remain an important source of stem cells for many patients. This has been highlighted during the worldwide SARS-CoV-2 pandemic in 2020 whereby the clinical and logistical utility of having a domestic donor HPC source available without the need for international flights or donor medicals has been advantageous. Over the past 5 years, UCB provisions for UK patients 
remained at approximately $10 \%$ of all stem cell products shipped to UK transplant centres. Since the start of the SARS-CoV-2 pandemic in March 2020, a significant increase in UCB unit search and reservations have been made, reflecting the use of UCB as a legitimate backup option by UK transplant centres. As the overall number of UK patients receiving HPCT decreased by approximately $10 \%$ between April and October 2020 compared with the previous year, the number of UCB shipments increased by $48 \%$ (Anthony Nolan, unpublished data).

\subsection{The UCB unit search process}

A search for an UCB unit can be undertaken simultaneously with an adult unrelated donor search. This is essential if the patient has a rare HLA type or if a transplant is required to be expedited. Within the UK, a joint Anthony Nolan and BBMR UCB search report is produced when requested. International UCB units are available from the WMDA 'Search \& Match' service, and a search report of these will be provided along with the UK UCB search results. Additional information on UCB units stored within CBB in the USA can be obtained via searching the NMDP. As most UCBT are undertaken with a degree of HLA mismatching between the patient and the transplanted UCB unit, all patients should be screened for HLA alloantibodies prior to undertaking UCB selection. The role of HLA alloantibodies is discussed in detail in Section 10.

It is suggested that a shortlist of up to 10 UCB units should be produced for each patient. These cords are selected based on the information extracted from the search reports. Minimally, the search results will provide the TNC count and HLA type, with many UCB units also having data on $\mathrm{CD} 34^{+}$cell counts. In the majority of cases, the search report will also contain information about the accreditation status of the relevant CBB.

\subsection{1 | TNC}

The TNC of the UCB unit is recognized as having a significant impact on the outcome of UCBT. An association between HLA mismatch and TNC with TRM was first published by Barker et al. (2010). Several years later, a large study found that NRM was increased in recipients who received a UCBT with $<3 \times 10^{7} / \mathrm{kg}$ TNC, such that the group recommended prioritizing a minimum pre-freeze TNC of $3 \times 10^{7} / \mathrm{kg}$ followed by HLA allele match (Eapen et al., 2014). Recent NMDP/ CIBMTR guidelines confirm the minimum TNC dose of $3 \times 10^{7} / \mathrm{kg}$ (Dehn et al., 2019). It has also been found that increasing the infused TNC dose abrogates, to some extent, the presence of HLA mismatches. The UK cord selection guidelines recommend increasing the TNC from a minimum of $3.0 \times 10^{7} / \mathrm{kg}$ for $8 / 8 \mathrm{HLA}$ allele-matched UCB to $5.0 \times 10^{7} / \mathrm{kg}$ for $5-7 / 8 \mathrm{HLA}$ match (Hough et al., 2016). NMDP/ CIBMTR guidelines did not mention increasing cell dose beyond $3 \times 10^{7} / \mathrm{kg}$ to compensate for HLA mismatch (Dehn et al., 2019), but the American Society for Transplantation and Cellular Therapy (ASTCT) guidelines for UCB unit selection (Politikos et al., 2020) recommend increasing the TNC threshold to $4.0-5.0 \times 10^{7} / \mathrm{kg}$ for nonmalignant diseases. Achieving this minimum cell dose in paediatric patients is rarely an issue, but becomes more problematic for older children and adults, where the recipient weight excludes the possibility of a single UCBT due to insufficient cell dose with the majority of available UCB units. In these cases, dUCBT is a successful transplant option. More data are needed to clarify the balance between TNC dose and HLA mismatch and how increased TNC can compensate HLA mismatch for malignant and nonmalignant conditions, and to resolve some contradictions with the published UK cord selection guidelines.

\subsubsection{HLA matching}

Since a joint Eurocord and CIBMTR study, on a predominantly paediatric cohort of 1,568 single UCBT for haematological malignancies, demonstrated that HLA allele mismatches were associated with a threefold increase in risk of NRM (Eapen et al., 2014), further studies have evaluated the impact of HLA allele mismatches in other clinical conditions. These studies support a significant impact of HLA mismatching on clinical outcome in paediatric patients with nonmalignant disorders where mortality was higher in transplants mismatched for two or more alleles compared with HLA-matched and single mismatched transplants (Eapen et al., 2017). Similarly fewer HLA allele mismatches predicted more favourable outcomes in transplants for inherited metabolic disorders (Mallhi et al., 2017).

The impact of allele level mismatching on outcome in dUCBT was described in a single-centre cohort of 133 patients transplanted for haematological malignancies where 2-year TRM was significantly increased in patients with $\leq 4 / 8$ allele match (60\%), compared with 5-6/8 match (39\%) and 7-8/8 match (0\%) (Oran et al., 2015). This study supports matching at least 5/8 HLA-A, B, C, DRB1 alleles to reduce TRM. In contrast, a separate single-centre study, also with patients receiving a dUCBT for haematological malignancy, found that patients receiving a 2-5/10 HLA match UCBT had lower relapse risk and treatment failure compared with better matched transplants (Brunstein et al., 2016). The NMDP/CIBMTR guidelines recommend using UCB units with $\geq 4 / 8$ high resolution match for patients with haematological malignancies, and $\geq 5 / 8$ match for children with non-malignant disease. Selecting UCB units with a better HLA match is recommended in cases where the TNC and $\mathrm{CD} 34^{+}$doses allow, otherwise, dose optimisation is considered more important (Dehn et al., 2019). For non-malignant diseases a higher HLA match has been associated with improved UCBT outcomes (Politikos et al., 2020).

An outcome of dUCBT is that only one of the two transplanted units will maintain long term engraftment. A retrospective study under the auspices of EBMT could not predict unit dominance but did observe that compared with better matched 'winning' cords ( $\geq 5 / 6)$, the poorer matched 'winning' cords ( $\leq 4 / 6)$ had lower LFS; lower OS; increased NRM and increased aGVHD, thus recommending selection of units with lower number of HLA mismatches (Tozatto-Maio et al., 2018).

Larger, multicentre studies are required to resolve the apparent disparate data regarding the impact of HLA matching in double cord 
transplantation. In the meantime, $\mathrm{H} \& \mathrm{I}$ laboratories are recommended to continue to identify the best HLA-matched UCB unit possible for their patients, without compromising TNC and $\mathrm{CD} 34^{+}$cell doses.

To date, the impact of allele matching in single and dUCBT has considered HLA-A, HLA-B, HLA-C and HLA-DRB1 loci. There are no data regarding HLA-DQB1, although if DRB1 matching is undertaken, this will promote HLA-DQB1 matching via linkage disequilibrium. There is also no definitive evidence to support the selection of HLA-DPB1-matched or HLA-DPB1-mismatched UCB units. In a study of 1,157 single UCBT for haematological malignancies, the Japanese Cord Blood Transplantation Histocompatibility Research Group found HLA-DPB1 allele mismatches associated with a significant reduction in leukaemia relapse, whereas other HLA loci mismatches were not (Yabe et al., 2018). In addition, the HLA-DPB1 mismatch did not affect the risk of acute GVHD, engraftment or mortality, leading the authors to suggest that HLA-DPB1 mismatch increased the GVL effect without induction of severe acute GVHD or deterioration of survival rate. Further data are required before indicating the selection of an HLA-DPB1-mismatched UCB as the preferable option. The role of allele matching for HLA-DQB1 and HLA-DPB1 will only be conclusively ascertained following large-scale retrospective analysis.

Evidence indicates that inter-unit HLA matching is not required (Brunstein et al., 2017), although this study only considered HLA-A, $B$ low-resolution and DRB1 high-resolution typing, excluding the potential impact of allele mismatching as well as mismatching for HLAC, HLA-DQ and HLA-DP. In order to accurately dissect the impact of HLA matching, it is important to know the true level of matching, and therefore, it is recommended that high (or greater) resolution HLA typing is performed for HLA-A, HLA-B, HLA-C, HLA-DRB1, HLADQB1 and HLA-DPB1 for all recipients and UCB units utilized in a single or double UCBT to allow retrospective analyses of outcome data. This is also necessary for accurate consideration of the impact of recipient HLA alloantibodies.

\section{Direction of HLA mismatch}

The effect of direction of HLA mismatch was investigated in a cohort of 1,202 single UCBTs. Unidirectional mismatches were identified and classified as either GVH or HVG (rejection) mismatches. Engraftment was faster in patients with $\mathrm{GVH}$ unidirectional mismatches compared to patients with single bidirectional mismatches $\mathrm{HR}=1.6, p=.003$ ). Other benefits to unidirectional mismatches included lower TRM, lower overall mortality and treatment failures. The HVG unidirectional mismatches exhibited slower engraftment, higher graft failure and higher relapse rates (Stevens et al., 2011).

However, these findings were not confirmed in a Eurocord study of 1,565 single UCBT for malignant disease. In this cohort, one or two HLA mismatches in the GVH or HVG direction were not associated with NRM and survival (Cunha et al., 2014).

A Japanese study of 2,977 single UCBT for malignant disease did not find any significant association with overall mortality for transplants performed with unidirectional mismatches in either GVH or HVG direction (Kanda et al., 2013). GVH mismatches were associated with a lower incidence of NRM for paediatric recipients only.
The HLA data included in these three studies were not high resolution and HLA-C, HLA-DQ and HLA-DP matching was not considered; therefore, additional mismatches not accounted for in the analysis are likely. The role of HLA alloantibodies was not addressed. The impact of NIMA matching (discussed in Section 9.2.5.5) was included in the study of Stevens et al. (2011), but not in the others. These studies are also complicated as multiple mismatches are present and not all mismatches (in the same direction) will impact the same biological effect. Further work is required to elucidate the impact of unidirectional mismatches.

\section{Verification typing}

All UCB units must receive verification HLA typing (VT) prior to infusion. VT is performed on a segment (if available) by the CBB as part of the release process. VT on a segment of the shipped UCB unit should be performed by the transplant centre upon receipt of the unit prior to reinfusion to confirm UCB identity. If a segment is not available, the empty UCB bag should be sent to the H\&l laboratory for a VT to be performed on DNA extracted from residual donor cells in the bag.

\subsubsection{CD34 $^{+}$cell count}

The pre-cryopreserved $\mathrm{CD} 34^{+}$cell dose is a marker for haematopoietic progenitor potential post-infusion and is a critical factor to consider for optimal UCB unit selection. Considering TNC dose with no knowledge of the $\mathrm{CD} 34^{+}$cell dose can be misleading. It is possible that some units selected on adequate TNC dose can contain dangerously low $\mathrm{CD} 34^{+}$cell doses, especially if they are not red blood cell (RBC) depleted (Barker et al., 2017). The CD34 ${ }^{+}$cell dose is usually provided together with HLA and TNC data, in the UCB search report, and can be used to aid then ranking of UCB units. The speed of neutrophil, platelet and RBC engraftment has been shown to be significantly correlated with pre-cryopreserved $\mathrm{CD} 34^{+}$cell dose (Konuma et al., 2017). The risk of developing extensive chronic GVHD was associated with the highest $\mathrm{CD} 34^{+}$cell doses, but this did not negatively impact on OS. The pre-cryopreserved $\mathrm{CD} 34^{+}$cell dose can reliably predict the post-thaw $\mathrm{CD} 34^{+}$cell yield in most units and was shown to be an independent predictor of neutrophil engraftment in a study of single UCB transplants (Sanz et al., 2010). This study indicated a pre-cryopreserved $\mathrm{CD} 34^{+}$cell dose of $1.5 \times 10^{5}$ / $\mathrm{kg}$ of patient weight as a recommended threshold for faster neutrophil engraftment. The same threshold is recommended by NMDP/ CIBMTR (Dehn et al., 2019). The ASTCT guidelines for UCB unit selection (Politikos et al., 2020) recommend to select, even higher CD $34^{+}$cell dose when possible, that is $>2.0 \times 10^{5} / \mathrm{kg}$ for a single UCBT. Eurocord gives a range and recommends 1.0-1.7 $\times 10^{5}$ / $\mathrm{kg}$ of pre-cryopreserved $\mathrm{CD} 34^{+}$cells in single UCBT (Querol \& Rocha, 2019). The same findings were demonstrated for dUCBT where pre-cryopreservation and post-thaw viable $\mathrm{CD} 34^{+}$cell doses were independent statistically significant characteristics associated with engraftment, with an arbitrary pre-cryopreservation CD $34^{+}$ 
cell dose of $\geq 0.7 \times 10^{5} / \mathrm{kg}$ for each unit identified as optimal, and $0.5 \times 10^{5} / \mathrm{kg}$ as minimum (Purtill et al., 2014). In Eurocord recommendations, the combined $\mathrm{CD} 34^{+}$cell dose in dUCBT is recommended to be in excess of $1.8 \times 10^{5} / \mathrm{kg}$ (Querol \& Rocha, 2019) with the recent NMDP/CIBMTR guideline suggesting $1 \times 10^{5} / \mathrm{kg}$ minimum for each cord (Dehn et al., 2019) and $>1.5 \times 10^{5} / \mathrm{kg}$ for each cord where possible (Politikos et al., 2020).

The UK recommendations for single UCB unit selection suggest different $\mathrm{CD}_{3} 4^{+}$cell dose thresholds depending on patient condition: $\geq 1 \times 10^{5} / \mathrm{kg}$ for malignant, and $\geq 1.7 \times 10^{5} / \mathrm{kg}$ for nonmalignant disorders. For dUCBT, the combined CD $34^{+}$cell dose should be $\geq 1.8 \times 10^{5} / \mathrm{kg}$ (Hough et al., 2016).

Analysis of the NMDP CBU inventory on the precryopreservation $\mathrm{CD} 34^{+} / \mathrm{TNC}$ ratio as an indicator of the expected $\mathrm{CD}_{3} 4^{+}$content showed that high TNC dose does not necessarily correlate with high $\mathrm{CD}_{3} 4^{+}$dose. The study recommends using both TNC and CD34 $4^{+}$cell doses as criteria in UCB unit selection. The ASTCT guidelines for UCB unit selection (Politikos et al., 2020) mention expected median CD34 ${ }^{+} / T N C$ ratio of $0.34 \%$ (range 0.23-0.48). It is recommended to question and verify cases where reported $\mathrm{CD} 34^{+}$cell dose is disproportionally high (Barker et al., 2019).

\subsection{4 | UCB bank accreditation status}

Quality and safety of the UCB unit have paramount importance in UCBT outcome, and thus, selecting units from the reliable accredited CBBs is recommended. The NetCord-Foundation for the Accreditation of Cellular Therapy (FACT) accreditation is a gold standard giving reassurance that the providing CBB follows agreed quality standards (http://www.factwebsite.org). Separately from FACT, the CBB can be accredited by the AABB, which is also a reputable body with a slightly different set of standards. It is recommended to avoid nonaccredited CBBs where possible (Hough et al., 2016; Politikos et al., 2020) or use extra caution in assessing UCB quality and safety information when it is not avoidable. Units from non-NetCord-FACT-accredited CBBs were more likely to have poorer recovery and together with units with cryovolumes outwith $24.5-26 \mathrm{ml}$ had an increased likelihood of having poor post-thaw viability (Purtill et al., 2014). If the accreditation status of the CBB is not marked on the Search Report, this information will be available on the UCB unit report requested from the bank.

\subsection{5 | Secondary criteria in UCB unit selection}

For each of the UCB units shortlisted, a request should be made to the CBB, via the Anthony Nolan in the UK, for a detailed unit report. This will give additional information on factors including quality parameters further describing potency and safety of the UCB unit that can be used to aid selection:
Potency of an UCB unit

The ability of the cells in an UCB unit to regenerate the haematopoietic system in a recipient should be assessed holistically looking at a range of parameters. In addition to TNC and $\mathrm{CD} 34^{+}$cell dose, these include TNC recovery, viability and capability to form colonies in vitro.

TNC recovery describes the percentage of cells recovered after thawing a segment attached to a unit. According to the NetCordFACT Standards, v7 (2020), TNC recovery should be no less than $60 \%$ of the pre-cryopreservation TNC. The Food and Drug Administration in the United States of America (FDA) requires $\geq 70 \%$ $\mathrm{TNC}$ recovery and $\geq 50 \% \mathrm{CD} 34^{+}$cell recovery. Post-thaw information from attached segments is not always available at UCB unit selection stage. In the majority of cases, especially if the CBB is NetCord-FACT accredited, post-thaw cell counts are part of the quality control (QC) releasing tests.

Cell viability is another important parameter in UCB unit potency evaluation as it indicates the percentage of live cells that are able to divide. There are different methods of viability assessment, the most common being 7-aminoactinomycin D (7-AAD) staining. Viability of the UCB cells is fundamental for successful engraftment. It was clearly shown in the dUCBT setting that increasing CD $34^{+}$ viable cell dose correlated with increased engraftment (Scaradavou et al., 2010). NetCord-FACT standards (2020) require TNC viability to be $\geq 85 \%$ post-processing (pre-cryopreservation) and post-thaw CD $34^{+}$viability $\geq 70 \%$. Some CBBs provide Annexin V viability, which can detect apoptotic cells in the UCB unit. When available, it is recommended to consider the results of both 7-AAD and Annexin $V$ methods.

Colony forming unit (CFU) defines the number of viable cells capable of proliferating in vitro to form colonies in agar. In a multivariate analysis of 435 UCB transplants performed at Duke University Medical Center (USA), CFU was shown to be the best predictor of engraftment. A threshold of $19.1 \times 10^{4}$ total CFU/kg in a fresh sample and $3.3 \times 10^{4}$ total CFU/kg in a thawed sample were considered good prognostic factors for UCBT outcome (Page et al., 2011). Although a numerical CFU characteristic gives an opportunity to calculate the UCB unit potency for a particular patient weight, not all CBBs will provide these data, as NetCord-FACT Standards require just the evidence of CFU growth on a post-thaw segment or representative sample as 'growth or positive result for potency'. Some CBBs provide post-processing and even post-thaw CFU data in UCB unit reports. Alternatively, it is provided as a part of $\mathrm{QC}$ releasing tests.

Clonogenic Efficiency (CLONE) is a combined parameter for CBU potency assessment to 'holistically' describe the ability of stem cells, usually measured as the percentage of $\mathrm{CD} 34^{+}$cells, to grow into colonies indicating their projected effectiveness in repopulating a recipient's haematopoietic system. It is measured by the ratio between post-thaw CFU and pre-cryopreservation $\mathrm{CD} 34^{+}$cells. It is suggested that this value should be higher than $10 \%$, and any decrease, below this threshold, indicates impairment of the functional ability of CD34 ${ }^{+}$ cells and therefore the unit should be considered at risk of engraftment failure (Querol et al., 2010). A later study showed that CLONE 
$\geq 20 \%$ predicted faster neutrophil and platelet engraftment and contributed to a decrease in the nonrelapse mortality (Castillo et al., 2015). It is recommended to assess CBU potency holistically looking at precryopreservation TNC recovery ( $\geq 60 \%$ ); post-thaw $\mathrm{CD} 34^{+}$viability ( $\geq 70 \%$ ); post-thaw CFU (reported growth, ideally $3.3 \times 10^{4}$ total CFU/ $\mathrm{kg}$ ) and CLONE, if available (minimum $10 \%$, ideally $\geq 20 \%$ ).

\section{ABO matching (see also Section 11.2)}

There are no conclusive studies showing a beneficial impact of $A B O$ matching on UCB transplant outcome, but in general, a match is preferred due to fewer risks of adverse events at time of infusion of UCB cells. In 2015, the Eurocord group presented the results of multivariate analysis demonstrating $\mathrm{ABO}$ major and minor incompatibility resulting in a significant increase of TRM in patients receiving dUCBT (Rocha et al., 2015). Based on Eurocord data, EBMT recommend where possible to avoid $A B O$ incompatible units in dUCBT (Querol \& Rocha, 2019).

\section{UCB unit age}

Although some published studies demonstrated a lower correlation between pre-cryopreserved and post-thaw $\mathrm{CD}_{3} 4^{+}$cell doses in units banked before 2005 (Purtill et al., 2014), the general consensus is that UCB age is not a factor of inferior potency. Analysis of 530 single UCBTs, received by patients in the USA, with acute leukaemia, did not identify differences in haematopoietic recovery or OS based on the years of banking experience, year of collection of UCB unit or the length of time the UCB unit was stored at the CBB (Ballen et al., 2015). Nevertheless, older units have a higher likelihood of lacking important test results as the list of mandatory IDMs has changed over the years reflecting new scientific findings. Recent units (those collected in last 10-15 years) are more likely to have undergone more optimized procedures than those collected in earlier years (Politikos et al., 2020).

\section{UCB processing method}

Variations in UCB manufacturing are common. Nowadays, the majority of CBBs use automated processing methods, but manually processed UCB units are still available in the worldwide inventory. Compared with automated processed units, manually processed UCB units were reported to be associated with significantly lower day 28 neutrophil recovery after single UCBT (Ballen et al., 2015). A concern of UCB processing is the method of RBC depletion. Manually processed UCB units are more often RBC replete and contain $28-70 \mathrm{ml}$ of $\mathrm{RBC}$ versus $1-15 \mathrm{ml}$ in RBC reduced products. It is expected that $5 \%-20 \%$ of RBCs would undergo lysis during the freeze-thaw cycle; thus, the infusion of RBC lysate may bring circulating free haemoglobin to toxic levels. The infusion dose of UCB $\mathrm{RBCs} \leq 0.4 \mathrm{ml} / \mathrm{kg}$ is considered safe (Akel et al., 2014).

\section{NIMA/IPA matching}

A phenomenon of sensitization and lasting tolerance following foetal exposure to NIMAs has been described in relation to its impact on UCBT outcome. An additional match on NIMAs in HLA-mismatched
UCBTs was reported to be associated with higher neutrophil recovery, lower NRM and higher OS in several studies performed by the New York Blood Centre (van Rood et al., 2009) and EurocordCIBMTR (Rocha et al., 2012). Considering NIMAs as permissive mismatches significantly increases the potential number of 'virtual' $5 / 6$ and 6/6 UCB matches for recipients (van der Zanden et al., 2014) including patients with rare HLA alleles and haplotypes, thus increasing chances of finding a suitable graft for Black, Asian and Minority Ethnic patients (Powley et al., 2016). This principle has been applied by the Hellenic Cord Blood Bank (Panagouli et al., 2018).

Evidence, albeit indirect, of maternal cell microchimerism present in UCB units that may mediate a GVL effect in UCBT suggests a match on Inherited Paternal Antigens (IPAs) may also be beneficial (van Rood et al., 2012), but has not been proven by other studies (Politikos et al., 2020).

Advice on UCB unit selection is described in Section 14.

\section{0 | HLA ALLOANTIBODIES}

The presence of HLA alloantibodies in recipients directed against HLA mismatches of their donors has been linked with primary GF characterized by the absence of initial donor neutrophil engraftment. As such patients receiving an HLA-mismatched transplant from any donor source must be assessed for the presence of circulating HLA alloantibodies that may react with HLA mismatches of the donor (DSA). This is particularly a problem in haploidentical transplantation when there are multiple HLA class I and class II mismatches, and many patients will have been sensitized by blood products. Additionally, female patients are at increased risk to be sensitized due to pregnancy and this poses a problem if children are considered as haploidentical donors. Overall approximately one third of patients requiring a mismatched donor will possess HLA alloantibodies reactive with one or more HLA specificity (unpublished data, Anthony Nolan). Several studies have indicated that DSA in the recipient are a risk factor for delayed and nonengraftment in mismatched unrelated donor, haploidentical donor, and single and dUCB transplants (reviewed in Morin-Zorman et al., 2016). The data are conflicting with regard to UCBT with some groups reporting sustained engraftment in the presence of HLA antibodies (Brunstein et al., 2011; Dahi et al., 2014). Also, a study of patients receiving transplants for nonmalignant disorders did not find an association between presence of DSA and GF and OS (Woolfrey et al., 2019). The UK cord guidelines recommend that all recipients being considered for HLA-mismatched transplants (including HLA-DP mismatches) are screened for HLA-specific antibodies and cognate antigens should be avoided, especially where antibodies are identified at 'high' level (Hough et al., 2016). This approach is supported by the recent NMDP/CIBMTR guidelines (Dehn et al., 2019).

Assessment of donor-specific HLA antibodies for haploidentical transplants has been addressed by the EBMT (Ciurea et al., 2018), who recommend that all candidate patients for 
haploidentical (or HLA-mismatched) donor transplants should be tested for the presence of DSA. These guidelines recommend the consideration of HLA-DRB3, HLA-DRB4, HLA-DRB5, HLA-DQA1, HLA-DPA1 and HLA-DPB1 which may be outside of usual donor selection protocols but should be considered in the context of an alloantibody testing strategy. The guidelines specify that for assays that define positivity based on Mean (or median depending on commercial assays utilized) Fluorescence Intensity (MFI), patients possessing DSA with $\mathrm{MFI}>1,000$ require additional testing to determine whether the DSA are complement binding and/or recommend cell-based (e.g. flow cytometry) cross-match assays to further assess the risk to the transplant. DSA that are complement binding and/or cause a positive cross-match are likely to have MFI $>5,000$ and these are predicted to pose a higher risk to the transplant recipient. The MFI values quoted may not be relevant to all antibody detection assays, and all laboratories should evaluate the sensitivity and specificity of the assays utilized and determine appropriate cut-off values.

If no other donor is available, it is recommended that the patient undergoes a desensitization protocol to reduce circulating DSA. Not all studies show a detrimental impact to transplant outcome in the presence of DSA. Currently, there are no data to stratify any differential impact of HLA class I versus class II DSA or the cumulative impact of multiple antibody specificities. The clinical impact of historic versus current DSA is unknown; however, a patient who has had historic DSA but is currently negative could be considered to have undergone natural desensitization. A differential clinical impact due to cause of sensitization, that is pregnancy or transfusion or other source, is also unknown.

At present, there is no formal testing of donors for the presence of antibodies reactive with HLA mismatches of the recipient; recipient-specific antibodies (RSA). One single-centre study has described an increased incidence of either aGVHD or CGVHD in patients transplanted with donors who were sensitized to HLA class II, predominantly mismatched HLA-DPB1 alleles (Delbos et al., 2016). It has been reported that donor-derived HLA antibodies can be detected post-transplant in patients transplanted with donors that are positive for HLA antibodies which suggests they could impact on engraftment in HLA-mismatched transplants (Taniguchi et al., 2012).

If a mismatched donor is being considered for transplant, the patient should be tested for HLA antibodies before donor verification typing samples are requested, or workup tests are performed on an UCB unit. HLA antibody testing should be repeated prior to the final donor being selected for workup, and multiple testing is recommended to monitor the dynamic antibody response. This is particularly relevant for patients undergoing desensitization or antibody reduction treatment or in the presence of continued administration of blood products and where a significant delay to transplant has occurred. For patients being considered for clinical trials, where the presence of DSA is an exclusion criteria, the H\&I Laboratory should be made aware of the trial protocol determining the exclusion threshold MFI and relevant testing timelines.

\section{1 | NON-HLA FACTORS TO BE CONSIDERED FOR RELATED AND UNRELATED DONOR SELECTION}

\section{1 | Cytomegalovirus}

Cytomegalovirus (CMV) infection can cause significant complications post-transplantation. CMV disease affects different organs including lung (pneumonia); liver (hepatitis); gut (gastroenteritis); eye (retinitis) and the brain (encephalitis). Even with improvements in anti-viral prophylactic therapies, CMV seropositivity remains associated with an adverse prognosis and is still a major cause of morbidity and mortality in allogeneic HPCT (reviewed in Ljungman, 2014). CMV positivity can be transmitted from a positive donor to a negative patient and patients who are CMV-positive pre-transplant are susceptible to CMV reactivation post-transplant.

A large study undertaken by EBMT of 16,628 allo-transplanted acute leukaemia patients reported that donor or recipient CMV seropositivity (versus donor and recipient CMV seronegativity) was associated with a significant decrease in LFS and OS with an increase in NRM and a small increase in relapse incidence. The negative impact on DFS and OS held up in multivariate analyses. There was no effect of CMV status on acute and chronic GVHD. CMV-seropositive patients receiving transplants from CMV-seropositive donors had a significantly better OS compared with CMV-seropositive recipients of a CMV-seronegative graft, with no difference in LFS observed (Schmidt-Hieber et al., 2013).

The negative impact of CMV-seronegative patients receiving CMV-seropositive products from unrelated donors was confirmed in a second EBMT study of transplants performed in 20,193 CMVseronegative patients. However, a similar effect was not observed in related donor transplants (Ljungman et al., 2014). In this study, CMV-positive patients receiving myeloablative transplants from CMV-positive donors had improved OS and a decreased NRM, compared with CMV-negative donors, but no benefit was seen for patients receiving RIC transplants.

Two smaller studies of patients transplanted for B-cell lymphoma (Mariotti et al., 2014) and myeloma (El-Cheikh et al., 2013) did not identify any impact of CMV serostatus on outcome.

The impact of multiple donor factors including CMV on survival was investigated in a multicentre study of 1,271 UK patients transplanted with an unrelated donor for malignant disease (Shaw et al., 2014). Patients who were CMV seropositive at the time of transplant had a reduced median survival (1.7 years) compared with CMV-seronegative patients ( 2.5 years). The donor and patient CMVmatching status had a significant effect with median survivals of 2.8, 2.2, 1.5 and 1.1 years in the categories of neg/neg, pos/pos, neg/ pos and pos/neg.

Analysis of 29,349 CMV-seropositive transplant recipients identified within the EBMT registry found no effect of donor CMV status on outcome for transplants performed with a matched or mismatched family donor (Ljungman et al., 2014). An effect was observed for $\mathrm{CMV}$-seropositive patients receiving transplants from 
unrelated donors with lower relapse mortality observed albeit at borderline significance when a CMV-seropositive donor was used. For patients receiving myeloablative conditioning better OS, lower NRM and improved relapse-free survival outcomes were observed when the donors were CMV seropositive. Similar effects were not observed for patients transplanted with RIC. The retention of host CMV-specific T-cell function in patients receiving RIC is an explanation for the lack of an association observed (Ljungman et al., 2014).

More recently, a UK study of 1,271 patients receiving unrelated donor $\mathrm{T}$ cell-depleted grafts demonstrated CMV mismatching was significantly associated with inferior survival. Combining HLA matching and CMV matching suggested that CMV matching could counteract the effect of HLA mismatching, whereas patients receiving both HLA- and CMV-mismatched transplants have worse overall survival (Shaw et al., 2017).

The British Committee for Standards in Haematology, the British Society of Blood and Marrow Transplantation and the UK Virology Network guideline for Management of cytomegalovirus infection in haematopoietic stem cell transplantation recommend CMV matching between patient and donor (Emery et al., 2013). In 2019, the National Institute for Health and Care Excellence (NICE) approved Letermovir, a novel viral terminase inhibitor, for the prophylaxis of CMV reactivation and disease, in adult CMV-seropositive recipients of an allogeneic HPCT for the first 100 days post-transplant (https://www.nice.org.uk/guidance/TA591). In clinical trials, this drug has been shown to be effective in reducing both CMV infection and the need for pre-emptive therapy. In cases where a suitable CMV-matched donor cannot be identified, Letermovir offers a prohylactic treatment to reduce the risk of CMV reactivation for seropositive patients receiving a seronegative donation. As knowledge of the impact of letermovir in HPCT increases and more randomized clinical trials are conducted, its best use in CMV management will be further realized (Anderson et al., 2020; El Helou \& Razonable, 2019).

In contrast, there are conflicting reports for haploidentical donor transplantation resulting in no recommendations for donor selection based on donor and recipient CMV serostatus for T-cell replete haploidentical transplantation within the recent EBMT review (Ciurea et al., 2020).

\section{2 | ABO blood group incompatibility}

$A B O$ incompatibility ( $\mathrm{BBO}$ ) between patient and donor is a common feature of HPCT. The ABOi can be major, minor or bidirectional (Table 5). Major ABOi transplants, in particular for blood group $O$ patients, can cause delayed red cell engraftment and infrequently pure red cell aplasia (PRCA). Reduced-toxicity regimes such as low intensity conditioning and graft versus host prophylactics are associated with extended host isohemagglutinin production and PRCA (Bolan et al., 2001).

Major and minor $A B O$ incompatibilities do not have a significant effect on overall survival and incidence of GVHD (reviewed in Booth
TABLE 5 Types of donor-recipient ABO incompatibilities

\begin{tabular}{lll} 
& & \multicolumn{2}{l}{ ABO blood type } \\
\cline { 2 - 3 } Mismatch type & Recipient & Donor \\
\hline Major & $\mathrm{O}$ & $\mathrm{A}, \mathrm{B}, \mathrm{AB}$ \\
\hline Major & $\mathrm{A}$ & $\mathrm{AB}$ \\
\hline Major & $\mathrm{B}$ & $\mathrm{AB}$ \\
\hline Minor & $\mathrm{A}$ & $\mathrm{O}$ \\
\hline Minor & $\mathrm{B}$ & $\mathrm{O}$ \\
\hline Minor & $\mathrm{AB}$ & $\mathrm{O}, \mathrm{A}, \mathrm{B}$ \\
\hline Bidirectional & $\mathrm{A}$ & $\mathrm{B}$ \\
\hline Bidirectional & $\mathrm{B}$ & $\mathrm{A}$ \\
\hline
\end{tabular}

et al., 2013) and do not constitute a major contraindication to donor selection. However, there are several single-centre studies that indicate ABOi having an impact on clinical outcome.

Recipients of major and minor ABOi RIC transplants are dependent on red blood cell transfusions for longer compared with $A B O$ compatible RIC transplants (Watz et al., 2014). Patients receiving major ABOi RIC transplants who then developed persistent recipient type $A B O$ (PRABO) antibodies had a poorer overall survival TRM compared with patients receiving major $A B O$ incompatible RIC transplants without PRABO (Watz et al., 2014).

An investigation into red cell aplasia, for transplants performed between 2007 and 2008, identified 27\% of patients received major ABOi transplants and $7.5 \%$ of these major $A B O i$ transplanted patients developed PRCA (Aung et al., 2013). Chimerism studies for Tcell and myeloid cell lineage and time to engraftment for neutrophil and platelets did not differ significantly for the major ABOi patients that did, and did not develop PRCA. All patients with PRCA required red cell transfusion support for several months and suffered from significant iron overload. These complications can be reduced where major $\mathrm{ABO}$ mismatches are avoided in donor selection.

Therefore in selection of HPC donors, avoidance of major $A B O i$ is preferred, but in the absence of a minor $A B O i$ or $A B O$ compatible donor, major $\mathrm{ABO}$ incompatibilities can be selected. When a blood group $O$ patient is being considered for $A B O i$ transplant, it is useful to determine the patient's anti-A and anti-B titres as this may help the selection when there is a choice of $A B O i$ donors.

The EBMT guideline for haploidentical donor transplantation recommends that donor $\mathrm{ABO}$ compatibility should be considered and also recommends, when possible, to use peripheral blood donations when there is a major ABO mismatch (Ciurea et al., 2020).

\section{3 | Donor sex}

Using a male donor has been reported in some studies as having a positive effect on long-term survival regardless of the sex of the recipient (Gustafsson-Jernberg et al., 2004; Pond et al., 2006) but not in others (Lee et al., 2007). Regardless, donor sex selection priority is usually given to male donors due to their usually larger 
size associated with higher HPC counts obtained and also the increase in GVHD reported with female multiparous donors (Kollman et al., 2001). A German study of 2,646 transplants performed in patients with haematological malignancies found that transplants performed with international donors had a worse outcome compared to transplants with national donors and male patients transplanted with female international donors showed an even higher hazard ratio in analysis of OS than other sex-matched groups (Fürst et al., 2013).

In contrast, a multicentre analysis of the effect of donor characteristics on the outcome of 709 RIC transplants (Passweg et al., 2011) demonstrated no association between donor age, parity and sex matching with transplant outcome, with only HLA matching being predictive for survival.

An investigation into the impact of cord blood donor sex compatibility has demonstrated no impact on survival in adults with haematological malignancies receiving a myeloablative single unit cord blood transplant. However, a higher incidence of chronic GVHD was observed in male recipients of female cord blood donors and a lower incidence of platelet engraftment in female recipients with male cord blood donors (Yuji et al., 2014). These findings require confirmation in further studies.

In unmanipulated haploidentical transplantation, Chang et al. (2016) concluded that a male donor is preferred with usage of anti-thymocyte globulin (ATG) or PTCy, due to the potential for superior survival of the patient. The more recent EBMT consensus recommendations for donor selection in haploidentical haematopoietic cell transplantation (Ciurea et al., 2020) suggest that a male donor should be the preferred choice when selecting a haploidentical donor for a male recipient, with PTCy. However, the EBMT recommendation also highlights conflicting evidence regarding benefits versus detriments of using mothers as donors for their children, regardless of the recipient's sex. These apparently conflicting results suggest that perhaps the donor's relationship (mother), rather than the donor's gender (female) has a stronger influence on transplant outcomes.

\section{4 | Donor age}

Donor age has been a consideration in unrelated donor selection, with younger donors being preferentially selected based on factors including their predicted better medical fitness to donate; being better HLA typed due to being recruited more recently and also on early data that indicated better post-transplant outcome (Kollman et al., 2001).

Shaw et al. (2018) have followed up on an earlier CIBMTR study (Kollman et al., 2016) which showed that transplants performed with HLA mismatches and older donors had worse survival. Multiple variables in two cohorts from nonoverlapping transplant periods were analysed. Increasing donor age was the only variable identified in both cohorts, in the presence of an HLA-matched 8/8 transplant, as having a negative impact on survival.

In their reviews of the effect of donor age on haploidentical donor transplants, both Ciurea et al. (2020) and Chang et al. (2016) concluded that younger donors were preferable in both T-cell depleted (TCD) and unmanipulated haploidentical donor transplants.

\subsection{NK cell receptors in graft selection}

NK cells participate in the defence against infection, malignancy and allo-antigens. These reactions are mediated by receptors on the NK cells including KIR and NK cell lectin-like receptors that interact with HLA and MICA ligands, plus others, on the target cells and as a consequence may impact upon graft outcome. Although evidence of KIR influencing HPCT outcome has been accumulating for over two decades, considering the interactions of NK cell receptors in the transplant setting has been research focussed, rather than as essential for routine testing. Changes to clinical practice during this time span, particularly the use of T-cell depletion, alongside variation in transplant protocols and methods of genotyping has complicated the potential for direct correlation between studies which report conflicting observations. The question which remains to be answered is whether there is now sufficient evidence available to justify the additional economic impact of assessing KIR in the transplant setting to balance improved quality of life and reduced healthcare costs managing clinical complications post-transplant. The evidence for considering the impact of some or all known NK cell receptors upon transplant outcome is assessed, with the main focus upon additional steps that can reasonably be taken during the selection process which would significantly improve outcome.

\subsection{1 | NK cell lectin-like receptors}

NKG2D is an activating C-type lectin-like receptor expressed by NK cells, CD8 ${ }^{+} \mathrm{T}$ cells and $\gamma \delta^{+}$T cells where it functions to promote cytotoxicity including the elimination of malignant cells expressing its ligand (Guerra et al., 2008). One of its ligands, the MHC encoded MHC class I like molecule, MICA, possesses a dimorphism at amino acid 129 within the $\alpha 2$ domain. MICA molecules expressing methionine at this location bind to NKG2D with high avidity promoting strong NK and T-cell activation, whereas MICA molecules expressing valine bind to NKG2D with lower avidity resulting in weaker NK/T-cell activation (Steinle et al., 2001). Data relating to MICA-129 mismatching in recipient and donor are conflicting. Mismatching for the MICA-129 dimorphism has been suggested to be associated with reduced overall survival, nonrelapse mortality and disease-free survival, and increased severe GvHD, compared with MICA-129matched transplant pairs, but findings are not consistent across studies (Askar et al., 2017; Carapito et al., 2016; Wulf et al., 2016; Martin et al., 2020; Patel et al., 2020). In addition, the MICA-129 V/V genotype in the donor (but not MICA-129 mismatching) has been indicated to increase the risk of CMV infection and disease posttransplant (Patel et al., 2020).

The likelihood of mismatching at MICA-129 increases if the donor is mismatched at HLA-B, which lies in close proximity to 
the MICA genes. Linkage disequilibrium confounds analysis of the MICA-129-matching effect independently from HLA mismatch, and this is also likely to negate any benefit of additional laboratory testing, at least in HLA-identical sibling transplants. In unrelated donation, the risk of mismatching at MICA-129 decreases as the level of the HLA matching increases and, as a priority, HLA mismatching should be avoided if possible, especially at HLA-B. In cases where HLA mismatching is unavoidable, there may be a potential for additional matching for the MICA-129 dimorphism, but the benefit to the patient of the additional matching is difficult to assess independently of the HLA matching effect. At present, there is no available commercial assay to test for this dimorphism, which places any testing performed in the research setting until streamlined assays and external proficiency testing schemes are available. It is an area to monitor, as this could be an interesting additional selection criterion if donors of equivalent HLA match cannot be separated using alternative algorithms, and if the facilities exist locally to run this as a test.

\subsection{2 | Killer-cell immunoglobulin-like receptors (KIR)}

The KIR gene cluster on chromosome 19q13.4 encodes KIR glycoproteins expressed on the surface of NK cells and some subsets of $\mathrm{T}$ cells. Most KIR initiate either activating or inhibitory signalling pathways within the NK cell in response to engaging with their corresponding ligand(s). The KIR genes are inherited as haplotypes, broadly classified as 'A' or 'B'. Both haplotypes possess four framework genes: KIR3DL3, 3DP1, 2DL4 and 3DL2. KIR A haplotypes are highly conserved containing an additional five KIR genes of which only one is an activating gene, KIR2DS4. In contrast, KIR B haplotypes are highly variable (González-Galarza et al., 2015), containing up to $16 \mathrm{KIR}$ genes including two to six activating KIR genes, giving them the moniker of being 'activating haplotypes', and are considered to effect greater alloreactivity than KIR A haplotypes (Hsu et al., 2002; Uhrberg et al., 1997).

The population of the United Kingdom $(n=584)$ and Ireland $(n=319)$ has been characterized with regard to KIR gene haplotypes with KIR A/A genotypes being the most frequently observed (approximately $27 \%-37 \%$ ) and lowest for KIR B/B genotypes (approximately $11 \%$ ) with the remainder of the population being KIR A/B (Guinan et al., 2010; Hiby et al., 2010). Consequently, the majority of individuals possess both inhibitory and activating receptors in differing combinations according to their KIR haplotype status. Due to the inability of presence/absence genotyping to assign KIR genes to a defined haplotype, $B / B$ and $A / B$ diplotypes are often described as $\mathrm{B} / \mathrm{x}$ diplotypes.

A hotspot for recombination lies in the middle of the KIR gene complex, between KIR3DP1 and 2DL4, dividing the KIR gene cluster into two regions: the centromeric region (closest to the chromosomal centromere) and telomeric region (closest to the chromosomal telomere). As a result, a wide assortment of KIR haplotypes can be drawn from a common pool of centromeric and telomeric regions. This phenomenon can produce a haplotype containing a combination of both $\mathrm{A}$ and $\mathrm{B}$ haplotype content (Jiang et al., 2012; Vierra-Green et al., 2012). As such, KIR haplotypes can also be described according to their centromeric and telomeric gene content, denoted as cenX/telX or $c X-t X$, where $X$ describes the $A$ or $B$ content, for example cenA/telB or CA-tB for a haplotype with $A$ content in the centromeric region and $B$ content in the telomeric region.

KIR genes are highly polymorphic, with some suggestions that allelic polymorphism may influence HPCT outcomes (Alicata et al., 2016; Bari et al., 2013; Boudreau et al., 2017). High-resolution sequencing has identified recombinant KIR genes that may be missed by some genotyping techniques and defined novel haplotypes that would not have been predicted by common imputation techniques (Artavanis-Tsakonas et al., 2003; Roe et al., 2017). The clinical value of these findings remains unknown.

In contrast to the lectin-like NK cell receptors, testing for KIR genes is more advanced, with commercial reagents available to identify the presence or absence of these genes, and external quality assessment schemes are established to ensure parity of testing. Commercial genetic sequencing assays, including NGS, are also available, facilitating the definition of allele polymorphisms of KIR genes.

\subsection{3 | KIR ligands}

Whilst ligands for some KIR (particularly activating KIR) remain unknown, others have been identified as specific motifs on HLA class I proteins. Amino acid residue 80 of HLA-C, and residues 77 and 80 of the HLA-Bw4 epitope represent key ligands for inhibitory KIR. Approximately half HLA-C alleles encode proteins with asparagine at amino acid 80 ( 1 epitope), and the other half encode lysine (C2 epitope). Recognition of these epitopes is partially restricted, with most KIR2DL2 and 2DL3 glycoproteins binding the $\mathrm{C} 1$ epitope, most KIR2DL1 glycoproteins binding the C2 epitope, and KIR3DL1 binding the HLA-Bw4 epitope. HLA-A3 and HLA-A11 also share an 'A3/11' epitope, which is recognized by KIR3DL2.

\subsection{4 | KIR: ligand interactions}

A number of groups have attempted to apply an algorithm to quantify the complex interaction of activating and/or inhibitory KIR in the context of the presence or absence of known ligands. This effect was first documented in haploidentical transplantation by Ruggeri et al. (1999, 2002). Further evidence followed, to support the preferential selection of a donor with an increased number of $B / x$ diplotypes (activating haplotypes) in patients with $A M L$, or other myeloid malignancies, when unrelated donors are the stem cell source (Cooley et al., 2009, 2010, 2014). These studies were 
performed in a cohort of patients receiving T-cell replete, myeloablative conditioning with bone marrow being the predominate source of stem cells.

The KIR B content scoring model classifies all potential donors as 'neutral' (lowest priority ranking), 'better' or 'best' (highest priority ranking) according to the donor's A or B haplotype content of both the centromeric and telomeric regions, with priority given to donors who possess two KIR B haplotypes in the centromeric region ('Best') (Cooley et al., 2009, 2010). In the international donor registry pool, approximately $70 \%$ of donors are categorized as neutral, $20 \%$ as better and $10 \%$ as best (Weisdorf et al., 2019). By selecting donors with activating KIR haplotypes (high B content), there is mounting evidence that recipients experience reduced relapse and improved survival, possibly due to selective elimination of minimal residual disease (MRD) in the recipient (Bao et al., 2016; Cooley et al., 2009, 2010, 2014). This effect has also been observed in paediatric haploidentical donor transplantation (Oevermann et al., 2014). To aid interpretation of KIR gene content data, the European Bioinformatics Institute hosts the online IPD-KIR Ligand Calculator to assess the KIR B haplotype content score of potential donors according to assignments detailed in Cooley et al. (2010) (https://www.ebi.ac.uk/ipd/kir/donor_b_content.html).

Alternatively, KIR receptors can be assessed in the context of their biological activity, by considering the presence or absence of a $\mathrm{KIR}$ gene and its cognate ligand. The level of resolution required for HLA matching of HPCT donors and recipients means that the recipient's C1/C2 epitope status is known at the time of donor selection, and if the KIR gene content of the donor is also known, the combined data could potentially be used to inform donor choice. Patients whose HLA type causes them to be homozygous for $\mathrm{C} 1$ or $\mathrm{C} 2$ group alleles (C1/C1 or $\mathrm{C} 2 / \mathrm{C} 2$ ) are potentially 'missing' ligands for either their own KIR, or KIR present in a potential donor. 'Missing' ligands may also occur in individuals who lack HLA-A or HLA-B antigens with the Bw4 public epitope, or lack HLA-A3 or HLA-A11.

Lacking a ligand may manifest as improved OS, decreased relapse or reduced aGVHD, if the additional presence of a KIR B haplotype donor can drive a GVL effect as suggested in HLAmatched sibling transplants (Cardozo et al., 2016) unrelated UCBT (Martínez-Losada et al., 2017) and in unrelated donor transplants (Wu et al., 2010).

In a study of ATG conditioned HLA-matched sibling and unrelated donor transplants, patients missing HLA ligands $(\geq 1)$ for unrelated donor inhibitory KIR were associated with a reduction in relapse and an improvement in relapse-free survival (Faridi et al., 2016). In the same study, recipients possessing at least one HLA-C C1 ligand and a KIR genotype-matched donor had significantly improved 'cGVHD and relapse-free' survival compared with recipients who were C2/ $C 2$. The authors suggest that KIR genotyping potential donors to identify a KIR genotype ( $A / A, B / x)$ match would have a beneficial impact on 'cGVHD and relapse-free' survival.

Thus, reports show mixed reproducibility of the positive effect of donor KIR B haplotypes, which may reflect the total number of KIR ligands present and despite reports describing beneficial outcomes for patients with missing KIR ligands, other data support a disadvantage to patients homozygous for HLA C1 or C2 groups. Recent experimental data supporting the presence, in both patient and donor, of ligands (C1, C2 and Bw4) for all donor inhibitory KIR, associated with lower relapse rates following haploidentical transplantation. This was attributed to better functional NK cell reconstitution post transplantation (Zhao et al., 2019).

Worldwide, the evidence base is building to show that recipients who are homozygous for HLA C1 or C2 group alleles are disadvantaged in the HPCT setting compared with those who are heterozygous (Cook et al., 2004; Cooley et al., 2014; Neuchel et al., 2017; Shimoni et al., 2017; Sobecks et al., 2015). Moreover, the evidence highlighting worse outcomes for HLA C2/C2 group recipients (approximately $20 \%$ of the population) is reproducible for all donor categories (related, unrelated, haploidentical, UCB). Without directed donor selection, these individuals will experience the poorest outcome post-transplant (Clausen et al., 2010).

There is supporting evidence that single KIR receptors may exert a higher profile than others. For example, Neuchel et al. (2017) and Sobecks et al. (2015) have both highlighted the key role for KIR2DS2 in the donor; a gene present on most KIR B, but not KIR A haplotypes. Similarly, matching for KIR3DS1, 2DS1, 2DS4 or whole KIR haplotypes have also been reported to have an impact upon survival (Burek-Kamenaric et al., 2017; Faridi et al., 2016; Mancusi et al., 2015; Sahin et al., 2018; Sobecks et al., 2015; Venstrom et al., 2012).

Donor KIR characteristics not only impact on the GVL effect of transplants but can also contribute to immunological responses to infectious agents. Reduced incidence of CMV reactivation has been observed in transplants using donors who possess $\geq 5$ activating KIR genes (Sobecks et al., 2011), or B/x diplotype characteristics in the telomeric region (TelB/ $x$ ) of the KIR gene cluster (Heatley et al., 2018; Sobecks et al., 2011). Furthermore, transplantation using donors possessing KIR2DS2, a centromeric activating KIR gene, was found to be protective against CMV reactivation (Behrendt et al., 2013). Preferential cytotoxic activity against infected malignant cells may manifest clinically as promoting a GVL effect (Oevermann et al., 2014; Ruggeri et al., 2016; Zhao et al., 2007).

Given the strength of the supporting evidence for this effect, and the increased clinical complications incurred following an active post-transplant infection with CMV, it is economically viable to perform additional KIR genotyping to identify donors with high activating KIR gene content to support the clinical management of recipients at risk of CMV reactivation.

Supporting evidence for the involvement of individual KIR in clinical outcome is only just emerging, but suggests that the interaction is complex, and further evidence is required to support a consensus before recommendations for directed donor selection can be implemented. Current research into the relationship between KIR allelic polymorphism and phenotypical variation of the gene product may further our understanding of KIR/HLA interactions for the benefit of clinical algorithms. 
At present, it is within the capabilities of laboratories supporting transplant centres to perform KIR presence/absence genotyping for prospective recipients and donors, and to assign KIR A and $B$ diplotype status based on KIR gene content. This process should now become incorporated into routine selection procedures for recipients at highest risk, such as $\mathrm{C} 2 / \mathrm{C} 2$ individuals, especially if their donor is mismatched for CMV. There are suggestions that these individuals would benefit from a donor who is KIR2DS1 positive, if available (Sobecks et al., 2015). Unfortunately, many existing KIR assessment algorithms for donor selection (such as the $B$ content scoring model) have been found to be ineffectual in C2/C2 individuals (Cooley et al., 2014; Faridi et al., 2016). For those C2/C2 homozygous patients where a choice of fully HLAmatched donors exist, the process of additional KIR gene profiling should be applied to facilitate optimal outcome with fewest posttransplant complications. When considering transplant options, HLA typing must remain the primary priority in donor selection, as HLA-C mismatching results in detrimental transplant outcomes (Hoff et al., 2017).

A second group of recipients in whom there is a recognized risk are those with CMV serostatus-mismatched donors. Evidence is accumulating to suggest that if these transplants are unavoidable, prior knowledge of the KIR background of both donors and recipients may be able to direct CMV prophylaxis, highlight the requirement for closer post-transplant monitoring, and early therapeutic intervention for recipients with KIR B haplotype-negative donors.

\section{6 | CCR5- $\Delta 32$}

The successful transplantation of an HIV-infected patient, with AML, using an unrelated donor who was homozygous for a 32 basepair deletion in the CCR5 gene (CCR5 Delta 32/Delta32, $(\Delta 32 / \Delta 32)$ ), resulted in the patient being free of antiretroviral medication and without any evidence of virus (Hútter et al., 2009). Homozygosity for the CCR5 32 mutation prevents entry of HIV into target cells via the encoded CCR5 receptor. This success was repeated with an HIV-positive patient with Hodgkin's Lymphoma (Gupta et al., 2019). Individuals homozygous for CCR5 32 are present in only approximately $1 \%$ of caucasian populations, and therefore, the chance of finding an HLA-matched CCR $5 \Delta 32 / \Delta 32$ donor is very low; however, some bone marrow donor registries have CCR $5 \Delta 32$ genotypes available and this information can be requested when conducting an unrelated donor search.

\section{2 | BACKUP OPTIONS}

For all transplants, it is advised to identify a backup option in case there are last minute issues with the preferred donor option. The backup donor could be related or unrelated, but preferably one where the workup could be turned around quickly. Consideration of location of the preferred and backup donor is a necessity should situations affecting global transportation be affected during a crisis, for example pandemic 2020.

\section{3 | TUMOUR-SPECIFIC MUTATIONS}

The improvement and wide-scale application of high resolution HLA typing methods has led to a significant increase in the number of mutations identified when HLA typing patients using DNA extracted from peripheral blood. These mutations can be attributed to a novel HLA allele expressed in all tissues or could be specific to the patient's tumour (Mrazek et al., 2014). If discovered, effort must be made via HLA typing of relatives and HLA typing of DNA extracted from patient tissue not affected by disease (e.g. skin plug) to determine whether the allele is novel or tumour specific. Only novel alleles will be assigned an official HLA allele name (Marsh et al., 2010; Robinson et al., 2015).

The expression of HLA proteins can be reduced within tumours due to deletion or mutations within genes encoding HLA proteins. Loss of heterozygosity at HLA loci can also occur. Care must be taken when patients are HLA typed from DNA extracted from peripheral blood with a high frequency of tumour cells in circulation. Homozygosity at HLA loci must be confirmed via family studies or repeat HLA testing when the patient is in remission or by testing DNA extracted from nondiseased cells such as buccal swab or skin plug.

\section{4 | GRAFT IDENTIFICATION ADVISORY SERVICE (GIAS)}

The provision of a professional GIAS to a transplant centre requires trained staff able to undertake both straight-forward and complex donor selection. GIAS may be delivered from an H\&I laboratory supporting the transplant centre; from a donor registry or from within the transplant team. Key to the successful selection of optimum donors from related and unrelated sources is expert knowledge of the HLA system including: polymorphism, linkage disequilibrium, impact of recombination, ethnic variation and HLA serology. The GIAS team should participate in regular meetings with the transplant team, such as multi-disciplinary team meetings or service review meetings, to ensure the needs of individual patients are being delivered according to local, national and international transplant protocols. A GIAS service must be directed by a consultant grade Royal College of Pathologists Fellow trained in $\mathrm{H} \& \mathrm{I}$ with adequate cover provided during absences. This may be achieved via national network arrangements with other laboratories and organizations.

$\mathrm{H} \&$ I scientists who have completed the British Society for Histocompatibility and Immunogenetics (BSHI) Diploma or the NHS Scientist Training Programme (STP) and are Health and Care Professions Council (HCPC) registered will have achieved an adequate level of education to enable active participation within a 
GIAS structure. In addition, there are 'non-H\&I laboratory' training pathways such as the WMDA Search Coordinator Certification Programme that, upon completion, demonstrate the appropriate level of understanding to participate in GIAS provision.

All GIAS team members must participate in CPD to ensure maintenance of current knowledge and to be aware of future developments.

Within the UK, specific assistance in UCB unit shortlisting is available from the Anthony Nolan and NHSBT Cord Support Programme by emailing: cordsupport@anthonynolan.org.

Further advice on final cord selection is available from the Cord Blood Unit Selection Advisory Panel (CBUSAP), established under the auspices of the British Society of Blood and Marrow Transplantation (BSBMT) and BSHI in 2015. The role of this panel is to provide an independent advisory service for transplant physicians, $\mathrm{H \& l}$ scientists and referring haematologists in the final selection of UCB units out of a shortlist submitted by the Transplant
Centre. Guidance for using this service is available at the BSHI websites: https://bshi.org.uk/members/bshi-information/cordblood-unit-selection-advisory-panel/ and enquiries can be made at: ggc.cbusap@nhs.scot.

The CBUSAP discuss each case by email and the Chair will collate responses and formulate a consensus recommendation for the requesting centre that has responsibility for the final decision. Since 2015 , typical cases have been adults or older children often requiring two cords. The patients often have limited unrelated donor options, have unusual HLA types and almost half have a range of HLA alloantibodies which must be considered as well.

\section{5 | USEFUL WEBSITES}

Guidance and tools to assist in donor selection and allele frequencies are available at the websites listed in Table 6.

TABLE 6 Useful websites

\begin{tabular}{|c|c|}
\hline Website & Description \\
\hline $\begin{array}{l}\text { http://hla.alleles.org/nomen } \\
\text { clature/index.html }\end{array}$ & $\begin{array}{l}\text { HLA nomenclature. Source of information on names, validity, expression, sequences of HLA alleles, information } \\
\text { on genes, antigens, proteins }\end{array}$ \\
\hline $\begin{array}{l}\text { http://igdawg.org/cwd.html } \\
\text { https://www.ihiw18.org/ } \\
\text { component-immunogene } \\
\text { tics/download-common- } \\
\text { and-well-documented-allel } \\
\text { es-3-0/ }\end{array}$ & $\begin{array}{l}\text { Common, and well-documented alleles catalogue version 2.0. Can be downloaded in several file formats and has } \\
\text { a lookup tool. } \\
\text { Common, intermediate and well-documented HLA alleles in world populations (Hurley et al., 2020) version } 3.0 \text {. } \\
\text { An update to the previous version } 2.0\end{array}$ \\
\hline $\begin{array}{l}\text { http://www.ebi.ac.uk/ipd/ } \\
\text { imgt/hla/ }\end{array}$ & $\begin{array}{l}\text { IPD-IMGT/HLA Database permits access to HLA DNA and protein sequences and includes the official sequences } \\
\text { for the WHO Nomenclature Committee for Factors of the HLA System. The IPD-IMGT/HLA Database is part of } \\
\text { the Immuno Polymorphism Database (IPD). Provides links to HLA Aligning tool, HLA Dictionary search tool (see } \\
\text { below), HLA-DPB1 T-Cell Epitope Algorithm (see below) }\end{array}$ \\
\hline $\begin{array}{l}\text { https://www.ebi.ac.uk/ipd/ } \\
\text { imgt/hla/dpb_v2.html }\end{array}$ & DPB1 T-Cell Epitope Algorithm (version 2, August 2016) \\
\hline $\begin{array}{l}\text { https://www.pirche.com/ } \\
\text { pirche/\#/features/bioin } \\
\text { formatics/The-PIRCHE- } \\
\text { Algorithm-in-HSCT }\end{array}$ & $\begin{array}{l}\text { PIRCHE algorithm for assessment of indirect presentation of HLA class I and class II derived peptides in } \\
\text { mismatched transplants (free for research use) }\end{array}$ \\
\hline $\begin{array}{l}\text { https://www.ebi.ac.uk/ipd/ } \\
\text { imgt/hla/dictionary.html }\end{array}$ & The HLA Dictionary search tool (Holdsworth et al., 2009) \\
\hline $\begin{array}{l}\text { https://bioinformatics.bethe } \\
\text { matchclinical.org/ }\end{array}$ & $\begin{array}{l}\text { NMDP bioinformatics resources. Include information on allele/haplotype frequencies in different ethnic groups } \\
\text { in USA. Several tools, including Haplostats and multiple allele codes (MAC). Service tool for deciphering MAC } \\
\text { codes (previously known as DNA Type Lookup Tool) }\end{array}$ \\
\hline $\begin{array}{l}\text { https://www.haplostats.org/ } \\
\text { haplostats?execution=e1s1 }\end{array}$ & Haplostats for aiding haplotype prediction. Base on NMDP HLA haplotype frequencies \\
\hline $\begin{array}{l}\text { http://www.allelefrequenci } \\
\text { es.net }\end{array}$ & $\begin{array}{l}\text { This website from the Allele Frequency Net Database provides allele frequency information on classic and } \\
\text { nonclassical HLA genes and other polymorphisms in the human genome for different countries }\end{array}$ \\
\hline $\begin{array}{l}\text { http://www.pypop.org/ } \\
\text { popdata/ }\end{array}$ & $\begin{array}{l}\text { Worldwide allele distribution maps for HLA-A, HLA-B, HLA-C, HLA-DRB1, HLA-DQA1, HLA-DQB1, HLA-DPA1 } \\
\text { and HLA-DPB1 (Solberg et al., 2008) }\end{array}$ \\
\hline https://hla-net.eu/ & Information on EFI common and well-documented alleles, and population analysis tools \\
\hline https://www.wmda.info/ & $\begin{array}{l}\text { World Marrow Donor Association website with information for patients, donors and health professionals. } \\
\text { Includes Search\&Match (former BMDW, requires authorization to access) and NetCord information }\end{array}$ \\
\hline
\end{tabular}




\section{CONFLICT OF INTEREST}

The authors declare that they have no conflict of interests.

\section{AUTHOR CONTRIBUTIONS}

All authors have read and approved the final manuscript. A-ML designed the review. All authors performed the literature search, and all authors wrote the paper. A-ML completed the final organization of the paper.

\section{ETHICAL APPROVAL}

This study did not involve human subjects or animals, and therefore, no ethical approval was required.

\section{DATA AVAILABILITY STATEMENT}

Data sharing is not applicable to this article as no new data were created or analyzed in this study.

\section{ORCID}

Ann-Margaret Little iD https://orcid.org/0000-0003-0141-980X Kay Poulton iD https://orcid.org/0000-0002-5608-8107 Paul A. Wright iD https://orcid.org/0000-0002-0516-3218

\section{REFERENCES}

Akel, S., Regan, D., Wall, D., Petz, L., \& McCullough, J. (2014). Current thawing and infusion practice of cryopreserved cord blood: The impact on graft quality, recipient safety, and transplantation outcomes. Transfusion, 54(11), 2997-3009. https://doi.org/10.1111/ $\operatorname{trf} .12719$

Alicata, C., Pende, D., Meazza, R., Canevali, P., Loiacono, F., Bertaina, A., Locatelli, F., Nemat-Gorgani, N., Guethlein, L. A., Parham, P., Moretta, L., Moretta, A., Bottino, C., Norman, P. J., \& Falco, M. (2016). Hematopoietic stem cell transplantation: Improving alloreactive Bw4 donor selection by genotyping codon 86 of KIR3DL1/S1. European Journal of Immunology, 46(6), 1511-1517. https://doi.org/10.1002/ eji.201546236

Anderson, A., Raja, M., Vazquez, N., Morris, M., Komanduri, K., \& Camargo, J. (2020). Clincal "real-world" experience with Letermovir for prevention of cytomegalovirus infection in allogeneic hematopoietic cell transplant recipients. Clinical Transplantation, 34(7), e13866. https://doi.org/10.1111/ctr.13866

Artavanis-Tsakonas, K., Eleme, K., McQueen, K. L., Cheng, N. W., Parham, P., Davis, D. M., \& Riley, E. M. (2003). Activation of a subset of human NK cells upon contact with Plasmodium falciparum-infected erythrocytes. The Journal of Immunology, 171(10), 5396-5405. https://doi. org/10.4049/jimmunol.171.10.5396

Askar, M., Sayer, D., Wang, T., Haagenson, M., Spellman, S. R., Lee, S. J., Madbouly, A., Fleischhauer, K., Hsu, K. C., Verneris, M. R., Thomas, D., Zhang, A., Sobecks, R. M., Majhail, N. S., \& Center for International Blood and Marrow Transplant Research Immunology Working Committee (2019). Analysis of single nucleotide polymorphisms in the gamma block of the major histocompatibility complex in association with clinical outcomes of hematopoietic cell transplantation: A center for international blood and marrow transplant research study. Biology of Blood and Marrow Transplantation, 25(4), 664-672. https:// doi.org/10.1016/j.bbmt.2018.12.008

Askar, M., Sobecks, R., Wang, T., Haagenson, M., Majhail, N., Madbouly, A., Thomas, D., Zhang, A., Fleischhauer, K., Hsu, K., Verneris, M., Lee, S. J., Spellman, S. R., \& Fernández-Viña, M. (2017). MHC class I chainrelated gene A (MICA) donor-recipient mismatches and MICA-129 polymorphism in unrelated donor hematopoietic cell transplantations has no impact on outcomes in acute lymphoblastic leukemia, acute myeloid leukemia, or myelodysplastic syndrome: A center for international blood and marrow transplant research study. Biology of Blood and Marrow Transplantation, 23(3), 436-444. https://doi. org/10.1016/j.bbmt.2016.11.021

Atsuta, Y., Kato, S., Morishima, Y., Ohashi, K., Fukuda, T., Ozawa, Y., Eto, T., Iwato, K., Uchida, N., Ota, S., Onizuka, M., Ichinohe, T., Kanda, J., \& Kanda, Y. (2019). Comparison of HLA allele mismatch and antigen mismatch in unrelated bone marrow transplantation in patients with leukemia. Biology of Blood and Marrow Transplantation, 25(3), 436442. https://doi.org/10.1016/j.bbmt.2018.10.002

Aung, F. M., Lichtiger, B., Bassett, R., Liu, P., Alousi, A., Bashier, Q., Ciurea, S. O., de Lima, M. J., Hosing, C., Kebriaei, P., Nieto, Y., Oran, B., Parmar, S., Qazilbash, M., Shah, N., Khouri, I., Champlin, R. E., \& Popat, U. (2013). Incidence and natural history of pure red cell aplasia in major ABO-mismatched haematopoietic cell transplantation. British Journal of Haematology, 160(6), 798-805. https://doi.org/10.1111/bjh.12210

Ayuk, F., Bornhäuser, M., Stelljes, M., Zabelina, T., Wagner, E.-M., Schmid, C., Christopeit, M., Guellstorf, M., Kröger, N., \& Bethge, W. (2019). Predicted indirectly recognizable HLA epitopes (PIRCHE) are associated with poorer outcome after single mismatch unrelated donor stem cell transplantation: A study of the Cooperative Transplant Study Group (KTS) of the German Group for Bone Marrow and Stem Cell Transplantation (DAG-KBT). Transfusion Medicine and Hemotherapy, 46, 370-375. https://doi.org/10.1159/000502389

Ballen, K. (2017). Update on umbilical cord blood transplantation. F1000Research, 6, 1556. https://doi.org/10.12688/f1000resea rch.11952.1

Ballen, K. K., Gluckman, E., \& Broxmeyer, H. E. (2013). Umbilical cord blood transplantation: The first 25 years and beyond. Blood, 122(4), 491-498. https://doi.org/10.1182/blood-2013-02-453175

Ballen, K. K., Logan, B. R., Laughlin, M. J., He, W., Ambruso, D. R., Armitage, S. E., Beddard, R. L., Bhatla, D., Hwang, W. Y. K., Kiss, J. E., Koegler, G., Kurtzberg, J., Nagler, A., Oh, D., Petz, L. D., Price, T. H., Quinones, R. R., Ratanatharathorn, V., Rizzo, J. D., \& Eapen, M. (2015). Effect of Cord Blood Processing on Transplantation Outcomes after Single Myeloablative Umbilical Cord Blood Transplantation. Biology of Blood and Marrow Transplantation, 21(4), 688-695. https://doi. org/10.1016/j.bbmt.2014.12.017

Bao, X., Wang, M., Zhou, H., Zhang, H., Wu, X., Yuan, X., Li, Y., Wu, D., \& He, J. (2016). Donor killer immunoglobulin-like receptor profile Bx1 imparts a negative effect and centromeric B-specific gene motifs render a positive effect on standard-risk acute myeloid leukemia/myelodysplastic syndrome patient survival after unrelated donor hematopoietic stem cell transplantation. Biology of Blood and Marrow Transplantation, 22(2), 232-239. https://doi.org/10.1016/j. bbmt.2015.09.007

Bari, R., Rujkijyanont, P., Sullivan, E., Kang, G., Turner, V., Gan, K., \& Leung, W. (2013). Effect of donor KIR2DL1 allelic polymorphism on the outcome of pediatric allogeneic hematopoietic stem-cell transplantation. Journal of Clinical Oncology, 31(30), 3782-3790. https:// doi.org/10.1200/JCO.2012.47.4007

Barker, J. N., Kempenich, J., Kurtzberg, J., Brunstein, C. G., Delaney, C., Milano, F., Politikos, J., Shpall, E.J., Scaradavou, A., \& Dehn, J. (2019). CD34+ cell content of 126,341 cord blood units in the US inventory: Implications for transplantation and banking. Blood Advances, 3(8), 1267-1271. https://doi.org/10.1182/bloodadvances.2018029157

Barker, J. N., Kurtzberg, J., Ballen, K., Boo, M., Brunstein, C., Cutler, C., Horwitz, M., Milano, F., Olson, A., Spellman, S., Wagner, J. E., Delaney, C., \& Shpall, E. (2017). Optimal practices in unrelated donor cord blood transplantation for hematologic malignancies. Biology of Blood and Marrow Transplantation, 23(6), 882-896. https://doi. org/10.1016/j.bbmt.2017.03.006 
Barker, J. N., Scaradavou, A., \& Stevens, C. E. (2010). Combined effect of total nucleated cell dose and HLA match on transplantation outcome in 1061 cord blood recipients with hematologic malignancies. Blood, 115(9), 1843-1849. https://doi.org/10.1182/blood-2009-07-231068

Barker, J. N., Weisdorf, D. J., DeFor, T. E., Blazar, B. R., Miller, J. S., \& Wagner, J. E. (2003). Rapid and complete donor chimerism in adult recipients of unrelated donor umbilical cord blood transplantation after reduced-intensity conditioning. Blood, 102(5), 1915-1919. https://doi.org/10.1182/blood-2002-11-3337

Baxter-Lowe, L. A., Maiers, M., Spellman, S. R., Haagenson, M. D., Wang, T., Fernandez-Vina, M., Marsh, S. G. E., Horowitz, M., \& Hurley, C. K. (2009). HLA disparities illustrate challenges for ranking the impact of HLA mismatches on bone marrow transplant outcomes in the United States. Biology of Blood and Marrow Transplantation, 15(8), 971-981. https://doi.org/10.1016/j.bbmt.2009.04.015

Behrendt, C. E., Nakamura, R., Forman, S. J., \& Zaia, J. A. (2013). Donor killer immunoglobulin-like receptor genes and reactivation of cytomegalovirus after HLA-matched hematopoietic stem-cell transplantation: HLA-C allotype is an essential cofactor. Frontiers in Immunology, 4, 36. https://doi.org/10.3389/fimmu.2013.00036

Bettens, F., Brunet, L., \& Tiercy, J.-M. (2014). High-allelic variability in HLA-C mRNA expression: Association with HLA-extended haplotypes. Genes and Immunity, 15(3), 176-181. https://doi.org/10.1038/ gene. 2014

Bettens, F., Buhler, S., \& Tiercy, J.-M. (2016). Allorecognition of HLA-C mismatches by $\mathrm{CD}^{+} \mathrm{T}$ cells in hematopoietic stem cell transplantation is a complex interplay between mismatched peptide-binding region residues, HLA-C expression, and HLA-DPB1 disparities. Frontiers in Immunology, 7, 584. https://doi.org/10.3389/fimmu.2016.00584

Bochtler, W., Maiers, M., Bakker, J. N. A., Oudshoorn, M., Marsh, S. G. E., Baier, D., Hurley, C. K., \& Müller, C. R. (2011). World Marrow Donor Association framework for the implementation of HLA matching programs in hematopoietic stem cell donor registries and cord blood banks. Bone Marrow Transplantation, 46(3), 338-343. https://doi. org/10.1038/bmt.2010.132

Bolan, C. D., Leitman, S. F., Griffith, L. M., Wesley, R. A., Procter, J. L., Stroncek, D. F., Barrett, A. J., \& Childs, R. W. (2001). Delayed donor red cell chimerism and pure red cell aplasia following major $A B O-$ incompatible nonmyeloablative hematopoietic stem cell transplantation. Blood, 98(6), 1687-1694. https://doi.org/10.1182/blood. v98.6.1687

Booth, G. S., Gehrie, E. A., Bolan, C. D., \& Savani, B. N. (2013). Clinical guide to $A B O$-incompatible allogeneic stem cell transplantation. Biology of Blood and Marrow Transplantation, 19(8), 1152-1158. https://doi.org/10.1016/j.bbmt.2013.03.018

Boudreau, J. E., Giglio, F., Gooley, T. A., Stevenson, P. A., Le Luduec, J-B., Shaffer, B. C., Rajalingam, R., Hou, L., Hurley, C. K., Noreen, H., Reed, E. F., Yu, N., Vierra-Green, C., Haagenson, M., Malkki, M., Petersdorf, E. W., Spellman, S., \& Hsu, K. C. (2017). KIR3DL1/HLA-B Subtypes Govern Acute Myelogenous Leukemia Relapse After Hematopoietic Cell Transplantation. Journal of Clinical Oncology, 35(20), 2268-2278. https://doi.org/10.1200/jco.2016.70.7059

Brissot, E., Labopin, M., Stelljes, M., Ehninger, G., Schwerdtfeger, R., Finke, J., Kolb, H.-J., Ganser, A., Schäfer-Eckart, K., Zander, A. R., Bunjes, D., Mielke, S., Bethge, W. A., Milpied, N., Kalhs, P., Blau, I.-W., Kröger, N., Vitek, A., Gramatzki, M., \& Nagler, A. (2017). Comparison of matched sibling donors versus unrelated donors in allogeneic stem cell transplantation for primary refractory acute myeloid leukemia: A study on behalf of the Acute Leukemia Working Party of the EBMT. Journal of Hematology \& Oncology, 10(1), 130. https://doi. org/10.1186/s13045-017-0498-8

Brunstein, C. G., Gutman, J. A., Weisdorf, D. J., Woolfrey, A. E., DeFor, T. E., Gooley, T. A., Verneris, M. R., Appelbaum, F. R., Wagner, J. E., \& Delaney, C. (2010). Allogeneic hematopoietic cell transplantation for hematologic malignancy: Relative risks and benefits of double umbilical cord blood. Blood, 116(22), 4693-4699. https://doi. org/10.1182/blood-2010-05-285304

Brunstein, C. G., Noreen, H., DeFor, T. E., Maurer, D., Miller, J. S., \& Wagner, J. E. (2011). Anti-HLA antibodies in double umbilical cord blood transplantation. Biology of Blood and Marrow Transplantation, 17(11), 1704-1708. https://doi.org/10.1016/j.bbmt.2011.04.013

Brunstein, C. G., Petersdorf, E. W., DeFor, T. E., Noreen, H., Maurer, D., MacMillan, M. L., Ustun, C., Verneris, M. R., Miller, J. S., Blazar, B. R., McGlave, P. B., Weisdorf, D. J., \& Wagner, J. E. (2016). Impact of allele-level HLA mismatch on outcomes in recipients of double umbilical cord blood transplantation. Biology of Blood and Marrow Transplantation, 22(3), 487-492. https://doi.org/10.1016/j. bbmt.2015.09.025

Brunstein, C., Zhang, M.-J., Barker, J., St. Martin, A., Bashey, A., de Lima, M., Dehn, J., Hematti, P., Perales, M.-A., Rocha, V., Territo, M., Weisdorf, D., \& Eapen, M. (2017). The effect of inter-unit HLA matching in double umbilical cord blood transplantation for acute leukemia. Haematologica, 102(5), 941-947. https://doi.org/10.3324/ haematol.2016.158584

Büchler, T., Gallardo, D., Rodríguez-Luaces, M., Pujal, J. M., \& Grañena, A. (2002). Frequency of HLA-DPB1 disparities detected by referencestrand-mediated conformation analysis in HLA-A, -B, and -DRB1 matched siblings. Human Immunology, 63(2), 139-142. https://doi. org/10.1016/s0198-8859(01)00376-7

Burek Kamenaric, M., Stingl Jankovic, K., Grubic, Z., Serventi Seiwerth, R., Maskalan, M., Nemet, D., Mikulic, M., \& Zunec, R. (2017). The impact of KIR2DS4 gene on clinical outcome after hematopoietic stem cell transplantation. Human Immunology, 78(2), 95-102. https://doi. org/10.1016/j.humimm.2016.11.010

Burt, C., Parker, A., McQuaker, G., Copland, M., Brierley, C., Little, A.M., \& Clark, A. (2014). In a 12-allele analysis HLA-DPB1 matching is associated with improved OS in leukaemic and myelopdysplastic patients receiving myeloablative T-cell-depleted PBSCT from unrelated donors. Bone Marrow Transplantation, 49(5), 657-663. https:// doi.org/10.1038/bmt.2014.8

Carapito, R., Jung, N., Kwemou, M., Untrau, M., Michel, S., Pichot, A., Giacometti, G., Macquin, C., Ilias, W., Morlon, A., Kotova, I., Apostolova, P., Schmitt-Graeff, A., Cesbron, A., Gagne, K., Oudshoorn, M., van der Holt, B., Labalette, M., Spierings, E., \& Bahram, S. (2016). Matching for the nonconventional MHC-I MICA gene significantly reduces the incidence of acute and chronic GVHD. Blood, 128(15), 1979-1986. https://doi.org/10.1182/blood-2016-05-719070

Cardozo, D. M., Marangon, A. V., da Silva, R. F., Aranha, F. J. P., Visentainer, J. E. L., Bonon, S. H. A., Costa, S. C. B., Miranda, E. C. M., de Souza, C. A., \& Guimarães, F. (2016). Synergistic effect of KIR ligands missing and cytomegalovirus reactivation in improving outcomes of haematopoietic stem cell transplantation from HLA-matched sibling donor for treatment of myeloid malignancies. Human Immunology, 77(10), 861-868. https://doi.org/10.1016/j.humimm.2016.07.003

Castillo, N., Garcia-Cadenas, I., Barba, P., Martino, R., Azqueta, C., Ferrà, C., Canals, C., Sierra, J., Valcárcel, D., \& Querol, S. (2015). Post-thaw viable CD45+ cells and clonogenic efficiency are associated with better engraftment and outcomes after single cord blood transplantation in adult patients with malignant diseases. Biology of Blood and Marrow Transplantation, 21(12), 2167-2172. https://doi. org/10.1016/j.bbmt.2015.08.016

Chang, Y.-J., \& Huang, X.-J. (2014). Haploidentical SCT, the mechanisms underlying the crossing of HLA barriers. Bone Marrow Transplantation, 49(7), 873-879. https://doi.org/10.1038/bmt.2014.19

Chang, Y. J., Luznik, L., Ephraim, J., Fuchs, E. J., \& Huang, X. J. (2016). How do we choose the best donor for T-cell-replete, HLA-haploidentical transplantation? Journal of Hematology \& Oncology, 9, 35. https://doi. org/10.1186/s13045-016-0265-2

Ciurea, S. O., Al Malki, M. M., Kongtim, P., Fuchs, E. J., Luznik, L., Huang, X-J, Ciceri, F., Locatelli, F., Aversa, F., Castagna, Lu., Bacigalupo, A., 
Martelli, M., Blaise, D., Ben Soussan, P., Arnault, Y., Handgretinger, R., Roy, D-C., O'Donnell, P. V., Bashey, A., \& Nagler, A. (2020). The European Society for Blood and Marrow Transplantation (EBMT) consensus recommendations for donor selection in haploidentical hematopoietic cell transplantation. Bone Marrow Transplantation, 55(1), 12-24. https://doi.org/10.1038/s41409-019-0499-z

Ciurea, S. O., Cao, K., Fernandez-Vina, M., Kongtim, P., Malki, M. A., Fuchs, E., Luznik, L., Huang, X.-J., Ciceri, F., Locatelli, F., Aversa, F., Castagna, L., Bacigalupo, A., Martelli, M., Blaise, D., Handgretinger, R., Roy, D.-C., O'Donnell, P., Bashey, A., ... Nagler, A. (2018). The European Society for Blood and Marrow Transplantation (EBMT) consensus guidelines for the detection and treatment of donorspecific anti-HLA antibodies (DSA) in haploidentical hematopoietic cell transplantation. Bone Marrow Transplantation, 53, 521-534. https://doi.org/10.1038/s41409-017-0062-8

Clancy, J., Ritari, J., Lobier, M., Niittyvuopio, R., Salmenniemi, U., Putkonen, M., Itälä-Remes, M., Partanen, J., \& Koskela, S. (2019). Increased MHC matching by $\mathrm{C} 4$ gene compatibility in unrelated donor hematopoietic stem cell transplantation. Biology of Blood and Marrow Transplantation, 25, 891-898. https://doi.org/10.1016/j. bbmt.2018.12.759

Clausen, J., Kircher, B., Auberger, J., Schumacher, P., Ulmer, H., Hetzenauer, G., Wolf, D., Gastl, G., \& Nachbaur, D. (2010). The role of missing killer cell immunoglobulin-like receptor ligands in T cell replete peripheral blood stem cell transplantation from HLA-identical siblings. Biology of Blood and Marrow Transplantation, 16(2), 273-280. https://doi.org/10.1016/j.bbmt.2009.10.021

Clayberger, C., Lyu, S. C., De Kruyff, R., Parham, P., \& Krensky, A. M. (1994). Peptides corresponding to the CD8 and CD4 binding domains of HLA molecules block T lymphocyte immune responses in vitro. The Journal of Immunology, 153, 946-951.

Cook, M. A., Milligan, D. W., Fegan, C. D., Darbyshire, P. J., Mahendra, P., Craddock, C. F., Moss, P. A. H., \& Briggs, D. C. (2004). The impact of donor KIR and patient HLA-C genotypes on outcome following HLAidentical sibling hematopoietic stem cell transplantation for myeloid leukemia. Blood, 103(4), 1521-1526. https://doi.org/10.1182/blood $-2003-02-0438$

Cooley, S., Trachtenberg, E., Bergemann, T. L., Saeteurn, K., Klein, J., Le, C. T., Marsh, S. G. E., Guethlein, L. A., Parham, P., Miller, J. S., \& Weisdorf, D. J. (2009). Donors with group B KIR haplotypes improve replapse-free survival after unrelated hematopoietic cell transplantation for acute myelogenous leukemia. Blood, 113, 726-732. https:// doi.org/10.1182/blood-2008-07-171926

Cooley, S., Weisdorf, D. J., Guethlein, L. A., Klein, J. P., Wang, T., Le, C. T., Marsh, S. G. E., Geraghty, D., Spellman, S., Haagenson, M. D., Ladner, M., Trachtenberg, E., Parham, P., \& Miller, J. S. (2010). Donor selection for natural killer cell receptor genes leads to superior survival after unrelated transplantation for acute myelogenous leukemia. Blood, 116, 2411-2419. https://doi.org/10.1182/blood-2010-05-283051

Cooley, S., Weisdorf, D. J., Guethlein, L. A., Klein, J. P., Wang, T., Marsh, S. G. E., Spellman, S., Haagenson, M. D., Saeturn, K., Ladner, M., Trachtenberg, E., Parham, P., \& Miller, J. S. (2014). Donor killer cell Iglike receptor B haplotypes, recipient HLA-C1, and HLA-C mismatch enhance the clinical benefit of unrelated transplantation for acute myelogenous leukemia. Journal of Immunology, 192, 4592-4600. https://doi.org/10.4049/jimmunol.1302517

Craddock, C., \& Chakraverty, R. (2016). Stem cell transplantation. In A. V. Hoffbrand, D. R. Higgs, D. M. Keeling, \& A. B. Mehta (Eds), Postgraduate haematology (7th ed., pp. 651-675). Wiley Blackwell. https://doi.org/10.1002/9781118853771.ch35

Crivello, P., Zito, L., Sizzano, F., Zino, E., Maiers, M., Mulder, A., Toffalori, C., Naldini, L., Ciceri, F., Vago, L., \& Fleischhauer, K. (2015). The impact of amino acid variability on alloreactivity defines a functional distance predictive of permissive HLA-DPB1 mismatches in hematopoietic stem cell transplantation. Biology of Blood and
Marrow Transplantation, 21, 233-241. https://doi.org/10.1016/j. bbmt.2014.10.017

Crocchiolo, R., Ciceri, F., Fleischhauer, K., Oneto, R., Bruno, B., Pollichieni, S., Sacchi, N., Sormani, M. P., Fanin, R., Bandini, G., Bonifazi, F., Bosi, A., Rambaldi, A., Alessandrino, P. E., Falda, M., \& Bacigalupo, A. (2009). HLA matching affects clinical outcome of adult patients undergoing haematopoietic SCT from unrelated donors, a study from the Gruppo Italiano Trapianto di Midollo Osseo and Italian Bone Marrow Donor Registry. Bone Marrow Transplantation, 44, 571-577. https://doi.org/10.1038/bmt.2009.67

Cullen, M., Noble, J., Erlich, H., Thorpe, K., Beck, S., Klitz, W., Trowsdale, J., \& Carrington, M. (1997). Characterization of recombination in the HLA class II region. American Journal of Human Genetics, 60, 397-407.

Cunha, R., Loiseau, P., Ruggeri, A., Sanz, G., Michel, G., Paolalori, A., Socié, G., Arcese, W., Picardi, A., Dias de Heredia, C., Rio, B., Locatelli, F., O'Brien, T. A., Yakoub-Agha, I., Angel Diaz, M., Milpied, N., Bittencourt, H., Pedro Souza, M., Aljurf, M., ... Rocha, V. (2014). Impact of HLA mismatch direction on outcomes after umbilical cord blood transplantation for hematological malignant disorders, a retrospective Eurocord-EBMT analysis. Bone Marrow Transplantation, 49, 24-29. https://doi.org/10.1038/bmt.2013.120

Cutler, C. S., Lee, S. J., Greenberg, P., Deeg, H. J., Perez, W. S., Anasetti, C., Bolwell, B. J., Cairo, M. S., Gale, R. P., Klein, J. P., Lazarus, H. M., Liesveld, J. L., McCarthy, P. L., Milone, G. A., Rizzo, J. D., Schultz, K. R., Trigg, M. E., Keating, A., Weisdorf, D. J., . . ., Horowitz, M. M. (2004). A decision analysis of allogeneic bone marrow transplantation for the myelodysplastic syndromes, delayed transplantation for low-risk myelodyplasia is associated with improved outcome. Blood, 104, 579-585. https://doi.org/10.1182/blood-2004-01-0338

Dahi, P. B., Ponce, D. M., Devlin, S., Evans, K. L., Lubin, M., Gonzales, A. M., Byam, C., Sideroff, M., Wells, D., Giralt, S., Kernan, N. A., Scaradavou, A., \& Barker, J. N. (2014). Donor-recipient allele-level HLA matching of unrelated cord blood units reveals high degrees of mismatch and alters graft selection. Bone Marrow Transplantation, 49, 1184-1186. https://doi.org/10.1038/bmt.2014.135

de Latour, R. P., Brunstein, C. G., Porcher, R., Chevallier, P., Robin, M., Warlick, E., Xhaard, A., Ustun, C., Larghero, J., Dhedin, N., Mohty, M., Socié, G., \& Weisdorf, D. (2013). Similar overall survival using sibling, unrelated donor, and cord blood grafts after reduced-intensity conditioning for older patients with acute myelogenous leukemia. Biology of Blood and Marrow Transplantation, 19(9), 1355-1360. https://doi. org/10.1016/j.bbmt.2013.06.006

Dehn, J., Spellman, S., Hurley, C. K., Shaw, B. E., Barker, J. N., Burns, L. J., Confer, D. L., Eapen, M., Fernandez-Vina, M., Hartzman, R., Maiers, M., Marino, S. R., Mueller, C., Perales, M.-A., Rajalingam, R., \& Pidala, J. (2019). Selection of unrelated donors and cord blood units for hematopoietic cell transplantation: Guidelines from the NMDP/CIBMTR. Blood, 134(12), 924-934. https://doi.org/10.1182/ blood.2019001212

Delbos, F., Barhoumi, W., Cabanne, L., Beckerich, F., Robin, C., Redjoul, R., Astati, S., Toma, A., Pautas, C., Ansart-Pirenne, H., Cordonnier, C., Bierling, P., \& Maury, S. (2016). Donor immunization against human leukocyte class II antigens is a risk factor for graft-versus-host disease. Biology of Blood and Marrow Transplantation, 22(2), 292-299. https://doi.org/10.1016/j.bbmt.2015.09.027

Detrait, M., Morrisset, S., Chalandon, Y., Yakoub-Agha, I., Dufossé, F., Labalette, M., Top, I., Elsermans, V., Barraco, F., Quintela, A., Tedone, N., Michallet, M., Raus, N., Tiercy, J-M., \& Dubois, V. (2015). Suggestive evidence of a role of HLA-DRB4 mismatches in the outcome of allogeneic hematologic stem cell transplantation with HLA10/10-matched unrelated donors: A French-Swiss retrospective study. Bone Marrow Transplantation, 50(10), 1316-1320. https://doi. org/10.1038/bmt.2015.157

Ducreux, S., Dubois, V., Amokrane, K., Yakoub-Agha, I., Labalette, M., Michallet, M., Rubio, M.-T., Kennel, A., Forcade, E., Lafarge, X., 
Bulabois, C.-E., Masson, D., Daguindau, E., Devys, A., Moalic, V., Quelvennec, E., Boudifa, A., Picard, C., Van Endert, P., ... Peffault de Latour, R. (2018). HLA-DRB3/4/5 mismatches are associated with increased risk of acute GvHD in 10/10 matched unrelated donor hematopoietic cell transplantation. American Journal of Hematology, 93(8), 994-1001. https://doi.org/10.1002/ajh.25133

Eapen, M., Klein, J. P., Ruggeri, A., Spellman, S., Lee, S. J., Anasetti, C., Arcese, W., Barker, J. N., Baxter-Lowe, L. A., Brown, M., FernandezVina, M. A., Freeman, J., He, W., lori, A. P., Horowitz, M. M., Locatelli, F., Marino, S., Maiers, M., Michel, G., ... Rocha, V. (2014). Impact of allele-level HLA matching on outcomes after myeloablative single unit umbilical cord blood transplantation for hematologic malignancy. Blood, 123(1), 133-140. https://doi.org/10.1182/blood -2013-05-506253

Eapen, M., Wang, T., Veys, P. A., Boelens, J. J., St Martin, A., Spellman, S., Bonfim, C. S., Brady, C., Cant, A. J., Dalle, J.-H., Davies, S. M., Freeman, J., Hsu, K. C., Fleischhauer, K., Kenzey, C., Kurtzberg, J., Michel, G., Orchard, P. J., Paviglianiti, A., ... Ruggeri, A. (2017). Allele-level HLA matching for umbilical cord blood transplantation for non-malignant diseases in children: A retrospective analysis. Lancet Haematol, 4(7), e325-e333. https://doi.org/10.1016/S2352-3026(17)30104-7

El Helou, G., \& Razonable, R. R. (2019). Letermovir for the prevention of cytomegalovirus infection and disease in transplant recipients: An evidence-based review. Infection and Drug Resistance, 12, 1481-1491. https://doi.org/10.2147/IDR.S180908

El-Cheikh, J., Devillier, R., Crocchiolo, R., Fürst, S., Calmels, B., Faucher, C., Stoppa, A. M., Granata, A., Castagna, L., Ladaique, P., Lemarie, C., Bouabdallah, R., Zandotti, C., Merlin, M., Berger, P., Chabannon, C., \& Blaise, D. (2013). Impact of pretransplant donor and recipient cytomegalovirus serostatus on outcome for multiple myeloma patients undergoing reduced intensity conditioning allogeneic stem cell transplantation. Mediterranean Journal of Hematology and Infectious Diseases, 5(1), e2013026. https://doi.org/10.4084/MJHID.2013.026

Elmariah, H., Kasamon, Y. L., Zahurak, M., Macfarlane, K. W., Tucker, N., Rosner, G. L., Bolaños-Meade, J., Fuchs, E. J., Wagner-Johnston, N., Swinnen, L. J., Huff, C. A., Matsui, W. H., Gladstone, D. E., McCurdy, S. R., Borrello, I., Gocke, C. B., Shanbhag, S., Cooke, K. R., Ali, S. A., .. Ambinder, R. F. (2018). Haploidentical bone marrow transplantation with post-transplant cyclophosphamide using non-first-degree related donors. Biology of Blood and Marrow Transplantation, 24, 10991102. https://doi.org/10.1016/j.bbmt.2018.02.005

Emery, V., Zuckerman, M., Jackson, G., Aitken, C., Osman, H., Pagliuca, A., Potter, M., Peggs, K., \& Clark, A. (2013). Management of cytomegalovirus infection in haemopoietic stem cell transplantation. British Journal of Haematology, 162(1), 25-39. https://doi.org/10.1111/ bjh.12363

Faridi, R. M., Kemp, T. J., Dharmani-Khan, P., Lewis, V., Tripathi, G., Rajalingam, R., Daly, A., Berka, N., Storek, J., \& Masood Khan, F. (2016). Donor-recipient matching for KIR genotypes reduces chronic GVHD and missing inhibitory KIR ligands protect against relapse after myeloablative, HLA matched hematopoietic cell transplantation. PLoS One, 11(6), e0158242. https://doi.org/10.1371/journ al.pone. 0158242

Fernández-Viña,, M. A., Klein, J. P., Haagenson, M., Spellman, S. R., Anasetti, C., Noreen, H., de Baxter-Lowe, L. A., Cano, P., Flomenberg, N., Confer, D. L., Horowitz, M. M., Oudshoorn, M., Petersdorf, E. W., Setterholm, M., Champlin, R., Lee, S. J., \& de Lima, M. (2013). Multiple mismatches at the low expression HLA loci DP, DQ and DRB3/4/5 associate with adverse outcome in haematopoietic stem cell transplantation. Blood, 121(22), 4603-4610. https://doi.org/10.1182/ blood-2013-02-481945

Fernandez-Viña, M. A., Wang, T., Lee, S. J., Haagenson, M., Aljurf, M., Askar, M., Battiwalla, M., Baxter-Lowe, L.-A., Gajewski, J., Jakubowski, A. A., Marino, S., Oudshoorn, M., Marsh, S. G. E., Petersdorf, E. W., Schultz, K., Turner, E. V., Waller, E. K., Woolfrey, A., Umejiego, J., ..
Setterholm, M. (2014). Identification of a permissible HLA mismatch in hematopoietic stem cell transplantation. Blood, 123(8), 12701278. https://doi.org/10.1182/blood-2013-10-532671

Fleischhauer, K., Fernandez-Viña, M. A., Wang, T., Haagenson, M., Battiwalla, M., Baxter-Lowe, L. A., Ciceri, F., Dehn, J., Gajewski, J., Hale, G. A., Heemskerk, M. B. A., Marino, S. R., McCarthy, P. L., Miklos, D., Oudshoorn, M., Pollack, M. S., Reddy, V., Senitzer, D., Shaw, B. E., ... Spellman, S. R. (2014). Risk associations between HLA-DPB1 T-cell epitope matching and outcome of unrelated hematopoietic cell transplantation are independent of HLA-DPA1. Bone Marrow Transplantation, 49(9), 1176-1183. https://doi.org/10.1038/ bmt.2014.122

Fleischhauer, K., Shaw, B. E., Gooley, T., Malkki, M., Bardy, P., Bignon, J. D., Dubois, V., Horowitz, M. M., Madrigal, J. A., Morishima, Y., Oudshoorn, M., Ringden, O., Spellman, S., Velardi, A., Zino, E., Petersdorf, E. W., \& The International Histocompatibility Working Group in Hematopoietic Cell Transplantation (2012). Effect of T cell epitope matching at HLA-DPB1 in recipients of unrelated donor haematopoietic-cell transplantation, a retrospective study. The Lancet Oncology, 13(4), 366-374. https://doi.org/10.1016/S1470 -2045(12)70004-9

Flomenberg, N., Baxter-Lowe, L. A., Confer, D., Fernandez-Vina, M., Filipovich, A., Horowitz, M., Hurley, C., Kollman, C., Anasetti, C., Norren, H., Begovich, A., Hildebrand, W., Petersdorf, E., Schmeckpeper, B., Setterholm, M., Trachtenberg, E., Williams, T., Yunis, E., \& Weisdorf, D. (2004). Impact of HLA class I and class II high-resolution matching on outcomes of unrelated donor bone marrow transplantation, HLA-C mismatching is associated with a strong adverse effect on transplantation outcome. Blood, 104(7), 19231930. https://doi.org/10.1182/blood-2004-03-0803

Fuchs, E. J. (2012). Haploidentical transplantation for hematologic malignancies: Where do we stand? Hematology: American Society of Hematology Education Program, 2012(2012), 230-236. https://doi. org/10.1182/asheducation-2012.1.230

Fürst, D., Müller, C., Vucinic, V., Bunjes, D., Herr, W., Gramatzki, M., Schwerdtfeger, R., Arnold, R., Einsele, H., Wulf, G., Pfreundschuh, M., Glass, B., Schrezenmeier, H., Schwarz, K., \& Mytilineos, J. (2013). High resolution HLA-matching in hematopoietic stem cell transplantation, a retrospective collaborative analysis. Blood, 122(18), 32203229. https://doi.org/10.1182/blood-2013-02-482547

Geneugelijk, K., \& Spierings, E. (2017). Matching donor and recipient based on predicted indirectly recognizable human leucocyte antigen epitopes. International Journal of Immunogenetics, 45, 41-53. https:// doi.org/10.1111/iji.12359

Geneugelijk, K., Thus, K. A., van Deutekom, H. W. M., Calis, J. J. A., Borst, E., Keşmir, C., Oudshoorn, M., van der Holt, B., Meijer, E., Zeerleder, S., de Groot, M. R., von dem Borne, P. A., Schaap, N., Cornelissen, J., Kuball, J., \& Spierings, E. (2019). Exploratory study of predicted indirectly recognizable HLA epitopes in mismatched hematopoietic cell transplantations. Frontiers in Immunology, 10, 880. https://doi. org/10.3389/fimmu.2019.00880

Getz, J., Goldenstein, M., Bonfim, C., Funke, V. M., Colturato, V., Hamerschlak, N., Torres, M., Sayer, D., Boldt, A., Pasquini, R., \& Pereira, N. F. (2020). Investigation of MHC gamma block C4A and $\mathrm{C} 4 \mathrm{~B}$ polymorphisms in unrelated hematopoietic stem cell transplantation. Hematology, Transfusion and Cell Therapy, 42, 221-229. https:// doi.org/10.1016/j.htct.2019.06.004

González-Galarza, F. F., Takeshita, L. Y. C., Santos, E. J. M., Kempson, F., Maia, M. H. T., Silva, A. L. S., Silva, A. L. T., Ghattaoraya, G. S., Alfirevic, A., Jones, A. R., \& Middleton, D. (2015). Allele frequency net 2015 update: New features for HLA epitopes, KIR and disease and HLA adverse drug reaction associations. Nucleic Acid Research, 43, D784-D788. https://doi.org/10.1093/nar/gku1166

Gragert, L., Eapen, M., Williams, E., Freeman, J., Spellman, S., Baitty, R., Hartzman, R., Rizzo, J. D., Horowitz, M., Confer, D., \& Maiers, M. 
(2014). HLA match likelihoods for hematopoietic stem cell grafts in the US registry. New England Journal of Medicine, 371(4), 339-348. https://doi.org/10.1056/NEJMsa1311707

Gragert, L., Madbouly, A., Freeman, J., \& Maiers, M. (2013). Six-locus high resolution HLA haplotype frequencies derived from mixedresolution DNA typing for the entire US donor registry. Human Immunology, 74(10), 1313-1320. https://doi.org/10.1016/j. humimm.2013.06.025

Guerra, N., Tan, Y. X., Joncker, N. T., Choy, A., Gallardo, F., Xiong, N. A., Knoblaugh, S., Cado, D., Greenberg, N. R., \& Raulet, D. H. (2008). NKG2D-deficient mice are defective in tumor surveillance in models of spontaneous malignancy. Immunity, 28(4), 571-580. https://doi. org/10.1016/j.immuni.2008.02.016

Guinan, K. J., Cunningham, R. T., Meenagh, A., Gonzalez, A., Dring, M. M., McGuinness, B. W., Middleton, D., \& Gardiner, C. M. (2010). Signatures of natural selection and coevolution between killer cell immunoglobulin-like receptors (KIR) and HLA class I genes. Genes and Immunity, 11(6), 467-478. https://doi.org/10.1038/gene.2010.9

Gupta, R. K., Abdul-Jawad, S., McCoy, L. E., Mok, H. P., Peppa, D., Salgado, M., Martinez-Picado, J., Nijhuis, M., Wensing, A. M. J., Lee, H., Grant, P., Nastouli, E., Lambert, J., Pace, M., Salasc, F., Monit, Ch., Innes, A. J., Muir, L., Waters, L., ... Olavarria, Eduardo (2019). HIV-1 remission following CCR5 $\Delta 32 / \Delta 32$ haematopoietic stem-cell transplantation. Nature, 568(7751), 244-248. https://doi.org/10.1038/ s41586-019-1027-4

Gustafsson-Jernberg, A., Remberger, M., Ringdén, O., \& Winiarski, J. (2004). Risk factors in pediatric stem cell transplantation for leukemia. Pediatric Transplantation, 8(5), 464-474. https://doi. org/10.1111/j.1399-3046.2004.00175.x

Hansen, J. A. (2012). Related or unrelated donor. Blood, 119(10), 21832184. https://doi.org/10.1182/blood-2011-12-391318

Heatley, S. L., Mullighan, C. G., Doherty, K., Danner, S., O'Connor, G. M., Hahn, U., Szer, J., Schwarer, A., Bradstock, K., Sullivan, L. C., Brady, P. G., \& Brooks, A. G. (2018). Activating KIR haplotype influences clinical outcome following HLA-matched sibling hematopoietic stem cell transplantation. HLA, 92, 74-82. https://doi.org/10.1111/tan.13327

Heemskerk, M. B. A., van Walraven, S. M., Cornelissen, J. J., Barge, R. M. Y., Bredius, R. G. M., Egeler, R. M., Tj Lie, J. L. W., Révész, T., Sintnicolaas, K., Wulffraat, N. M., Donker, A. E., Hoogerbrugge, P. M., van Rood, J. J., Claas, F. H. J., \& Oudshoorn, M. (2005). How to improve the search for an unrelated haematopoietic stem cell donor. Faster is better than more. Bone Marrow Transplantation, 35(7), 645652. https://doi.org/10.1038/sj.bmt.1704865

Herr, W., Eichinger, Y., Beshay, J., Bloetz, A., Vatter, S., Mirbeth, C., Distler, E., Hartwig, U. F., \& Thomas, S. (2017). HLA-DPB1 mismatch alleles represent powerful lekemia rejection antigens in CD4 T-Cell immunotherapy after allogeneic stem-cell transplantation. Leukemia, 31(2), 434-445. https://doi.org/10.1038/leu.2016.210

Hiby, S. E., Ashrafian-Bonab, M., Farrell, L., Single, R. M., Balloux, F., Carrington, M., Moffett, A., \& Ebrahimi, Z. (2010). Distribution of killer cell immunoglobulin-like receptors (KIR) and their HLA-C ligands in two Iranian populations. Immunogenetics, 62(2), 65-73. https://doi.org/10.1007/s00251-009-0408-5

Hirv, K., Bloch, K., Fischer, M., Einsiedler, B., Schrezenmeier, H., \& Mytilineos, J. (2009). Prediction of duration and success rate of unrelated hematopoietic stem cell donor searches based on the patient's HLA-DRB1 allele and DRB1-DQB1 haplotype frequencies. Bone Marrow Transplantation, 44(7), 433-440. https://doi.org/10.1038/ bmt.2009.53

Hoff, G. A., Fischer, J. C., Hsu, K., Cooley, S., Miller, J. S., Wang, T., Haagenson, M., Spellman, S., Lee, S. J., Uhrberg, M., Venstrom, J. M., \& Verneris, M. R. (2017). Recipient HLA-C haplotypes and miRNA $148 \mathrm{a} / \mathrm{b}$ binding sites have no impact on allogeneic hematopoietic cell transplant outcomes. Biology of Blood and Marrow Transplantation, 23(1), 153-160. https://doi.org/10.1016/j.bbmt.2016.09.028
Holdsworth, R., Hurley, C. K., Marsh, S. G. E., Lau, M., Noreen, H. J., Kempenich, J. H., Setterholm, M., \& Maiers, M. (2009). The HLA dictionary 2008: A summary of HLA-A, -B, -C, -DRB1/3/4/5, -DQB1 alleles and their association with serologically defined HLA-A, -B, -C, -DR and -DQ antigens. Tissue Antigens, 73(2), 95-170. https://doi. org/10.1111/j.1399-0039.2008.01183.x

Hough, R., Danby, R., Russell, N., Marks, D., Veys, P., Shaw, B., Wynn, R., Vora, A., Mackinnon, S., Peggs, K. S., Crawley, C., Craddock, C., Pagliuca, A., Cook, G., Snowden, J. A., Clark, A., Marsh, J., Querol, S., Parkes, G., ... Rocha, V. (2016). Recommendations for a standard UK approach to incorporating umbilical cord blood into clinical transplantation practice: An update on cord blood unit selection, donor selection algorithms and conditioning protocols. British Journal of Haematology, 172(3), 360-370. https://doi.org/10.1111/bjh.13802

Hsu, K. C., Chida, S., Geraghty, D. E., \& Dupont, B. (2002). The killer cell immunoglobulin-like receptor (KIR) genomic region: Gene-order, haplotypes and allelic polymorphism. Immunological Reviews, 190, 40-52. https://doi.org/10.1034/j.1600-065x.2002.19004.x

Hurley, C. K., Woolfrey, A., Wang, T., Haagenson, M., Umejiego, J., Aljurf, M., Askar, M., Battiwalla, M., Dehn, J., Horan, J., Oudshoorn, M., Pidala, J., Saber, W., Turner, V., Lee, S. J., \& Spellman, S. R. (2013). The impact of HLA unidirectional mismatches on the outcome of myeloablative hematopoietic stem cell transplantation with unrelated donors. Blood, 121(23), 4800-4806. https://doi.org/10.1182/blood -2013-01-480343

Hurley, C. K., Kempenich, J., Wadsworth, K., Sauter, J., Hofmann, J. A., Schefzyk, D., Schmidt, A. H., Galarza, P., Cardozo, M. B. R., Dudkiewicz, M., Houdova, L., Jindra, P., Sorensen, B. S., Jagannathan, L., Mathur, A., Linjama, T., Torosian, T., Freudenberger, R., Manolis, A., \& Dehn, Jason (2020). Common, intermediate and well-documented HLA alleles in world populations: CIWD version 3.0.0. HLA, 95(6), 516-531. https://doi.org/10.1111/tan.13811

Hűtter, G., Nowak, D., Mossner, M., Ganepola, S., Műßig, A., Allers, K., ... Thiel, E. (2009). Long-term control of HIV by CCR5 Delta32/Delta32 stem-cell transplantation. New England Journal of Medicine, 360, 692698. https://doi.org/10.1056/NEJMoa0802905

Jaime-Pérez, J. C., Cancela-Murrieta, C. O., Salazar-Cavazos, L., AguilarCalderón, P. E., Salazar-Riojas, R., Méndez-Ramírez, N., CantúRodríguez, O. G., Gutiérrez-Aguirre, C. H., \& Gómez-Almaguer, D. (2020). Impact of HLA-DPB1 matching on clinical outcomes after haploidentical-related hematopoietic stem cell transplantation. Revista de Investigacion Clinica, 72(2), 69-79. https://doi. org/10.24875/RIC.19003215

Jiang, W., Johnson, C., Jayaraman, J., Simecek, N., Noble, J., Moffatt, M. F., Cookson, W. O., Trowsdale, J., \& Traherne, J. A. (2012). Copy number variation leads to considerable diversity for $B$ but not $A$ haplotypes of the human KIR genes encoding NK cell receptors. Genome Research, 22(10), 1845-1854. https://doi.org/10.1101/ gr.137976.112

Kanda, J., Atsuta, Y., Wake, A., Ichinohe, T., Takanashi, M., Morishima, Y., ... Kanda, Y. (2013). Impact of the direction of HLA mismatch on transplantation outcomes in single unrelated cord blood transplantation. Biology of Blood and Marrow Transplantation, 19(2), 247-254. https://doi.org/10.1016/j.bbmt.2012.09.017.f

Kanda, J., Saji, H., Fukuda, T., Kobayashi, T., Miyamura, K., Eto, T., Kurokawa, M., Kanamori, H., Mori, T., Hidaka, M., Iwato, K., Yoshida, T., Sakamaki, H., Tanaka, J., Kawa, K., Morishima, Y., Suzuki, R., Atsuta, Y., \& Kanda, Y. (2012). Related transplantation with HLA-1 Ag mismatch in the GVH direction and HLA-8/8 allele-matched unrelated transplantation, a nationwide retrospective study. Blood, 119(10), 2409-2416. https://doi.org/10.1182/blood-2011-08-372573

Klasberg, S., Lang, K., Günther, M., Schober, G., Massalski, C., Schmidt, A. H., Lange, V., \& Schöfl, G. (2019). Patterns of non-ARD variation in more than 300 full-length HLA-DPB1 alleles. Human Immunology, 80(1), 44-52. https://doi.org/10.1016/j.humimm.2018.05.006 
Kollman, C., Howe, C. W. S., Anasetti, C., Antin, J. H., Davies, S. M., Filipovich, A. H., Hegland, J., Kamani, N., Kernan, N. A., King, R., Ratanatharathorn, V., Weisdorf, D., \& Confer, D. L. (2001). Donor characteristics as risk factors in recipients after transplantation of bone marrow from unrelated donors, the effect of donor age. Blood, 98(7), 2043-2051. https://doi.org/10.1182/blood.v98.7.2043

Kollman, C., Maiers, M., Gragert, L., Muller, C., Setterholm, M., Oudshoorn, M., \& Hurley, C. K. (2007). Estimation of HLA-A, -B, -DRB1 haplotype frequencies using mixed resolution data from a national registry with selective retyping of volunteers. Human Immunology, 68(12), 950-958. https://doi.org/10.1016/j. humimm.2007.10.009

Kollman, C., Spellman, S. R., Zhang, M.-J., Hassebroek, A., Anasetti, C., Antin, J. H., Champlin, R. E., Confer, D. L., DiPersio, J. F., FernandezViña, M., Hartzman, R. J., Horowitz, M. M., Hurley, C. K., Karanes, C., Maiers, M., Mueller, C. R., Perales, M.-A., Setterholm, M., Woolfrey, A. E., ... Eapen, M. (2016). The effect of donor characteristics on survival after unrelated donor transplantation for hematologic malignancy. Blood, 127(2), 260-267. https://doi.org/10.1182/blood $-2015-08-663823$

Konuma, T., Kato, S., Oiwa-Monna, M., Tanoue, S., Ogawa, M., Isobe, M., Tojo, A., \& Takahashi, S. (2017). Cryopreserved CD34(+) cell dose, but not total nucleated cell dose, influences hematopoietic recovery and extensive chronic graft-versus-host disease after single-unit cord blood transplantation in adult patients. Biology of Blood and Marrow Transplantation, 23(7), 1142-1150. https://doi.org/10.1016/j. bbmt.2017.03.036

Laughlin, M. J., Barker, J., Bambach, B., Koc, O. N., Rizzieri, D. A., Wagner, J. E., Gerson, S. L., Lazarus, H. M., Cairo, M., Stevens, C. E., Rubinstein, P., \& Kurtzberg, J. (2001). Hematopoietic engraftment and survival in adult recipients of umbilical-cord blood from unrelated donors. New England Journal of Medicine, 344(24), 1815-1822. https://doi. org/10.1056/NEJM200106143442402

Lee, S. J., Klein, J., Haagenson, M., Baxter-Lowe, L. A., Confer, D. L., Eapen, M., Fernandez-Vina, M., Flomenberg, N., Horowitz, M., Hurley, C. K., Noreen, H., Oudshoorn, M., Petersdorf, E., Setterholm, M., Spellman, S., Weisdorf, D., Williams, T. M., \& Anasetti, C. (2007). High-resolution donor-recipient HLA matching contributes to the success of unrelated donor marrow transplantation. Blood, 110(13), 4576-4583. https://doi.org/10.1182/blood-2007-06-097386

Little, A.-M., Green, A., Harvey, J., Hemmatpour, S., Latham, K., Marsh, S. G. E., Poulton, K., \& Sage, D. (2016). BSHI guideline: HLA matching and donor selection for haematopoietic progenitor cell transplantation. International Journal of Immunogenetics, 43, 263-286. https:// doi.org/10.1111/iji.12282

Ljungman, P. (2014). The role of cytomegalovirus serostatus on outcome of hematopoietic stem cell transplantation. Current Opinion in Hematology, 21(6), 466-469. https://doi.org/10.1097/MOH.00000 00000000085

Ljungman, P., Brand, R., Hoek, J., de la Camara, R., Cordonnier, C., Einsele, H., Styczynski, J., Ward, K. N., \& Cesaro, S. (2014). Donor cytomegalovirus status influences the outcome of allogeneic stem cell transplant, a study by the European group for blood and marrow transplantation. Clinical Infectious Diseases, 59(4), 473-481. https:// doi.org/10.1093/cid/ciu364

Lown, R. N., Marsh, S. G. E., Switzer, G. E., Latham, K. A., Madrigal, J. A., \& Shaw, B. E. (2014). Ethnicity, length of time on the register and sex predict donor availability at the confirmatory typing stage. Bone Marrow Transplantation, 49, 525-531. https://doi.org/10.1038/bmt.2013.206

Mack, S. J., Cano, P., Hollenbach, J. A., He, J., Hurley, C. K., Middleton, D., Moraes, M. E., Pereira, S. E., Kempenich, J. H., Reed, E. F., Setterholm, M., Smith, A. G., Tilanus, M. G., Torres, M., Varney, M. D., Voorter, C. E. M., Fischer, G. F., Fleischhauer, K., Goodridge, D., \& FernandezVina, M. (2013). Common and well-documented HLA alleles: 2012 update to the CWD catalogue. Tissue Antigens, 81(4), 194-203. https://doi.org/10.1111/tan.12093

Maiers, M., Gragert, L., \& Klitz, W. (2007). High resolution HLA alleles and haplotypes in the United sates population. Human Immunology, 68(9), 779-788. https://doi.org/10.1016/j.humimm.2007.04.005

Mallhi, K. K., Smith, A. R., DeFor, T. E., Lund, T. C., Orchard, P. J., \& Miller, W. P. (2017). Allele-level HLA matching impacts key outcomes following umbilical cord blood transplantation for inherited metabolic disorders. Biology of Blood and Marrow Transplantation, 23(1), 119125. https://doi.org/10.1016/j.bbmt.2016.10.019

Mancusi, A., Ruggeri, L., Urbani, E., Pierini, A., Massei, M. S., Carotti, A., Terenzi, A., Falzetti, F., Tosti, A., Topini, F., Bozza, S., Romani, L., Tognellini, R., Stern, M., Aversa, F., Martelli, M. F., \& Velardi, A. (2015). Haploidentical hematopoietic transplantation from KIR ligand-mismatched donors with activating KIRs reduces nonrelapse mortality. Blood, 125(20), 3173-3182. https://doi.org/10.1182/ blood-2014-09-599993

Mariotti, J., Maura, F., Spina, F., Roncari, L., Dodero, A., Farina, L., Montefusco, V., Carniti, C., Sarina, B., Patriarca, F., Rambaldi, A., Onida, F., Olivieri, A., Zallio, F., \& Corradini, P. (2014). Impact of cytomegalovirus replication and cytomegalovirus serostatus on the outcome of patients with B cell lymphoma after allogeneic stem cell transplantation. Biology of Blood and Marrow Transplantation, 20(6), 885-890. https://doi.org/10.1016/j.bbmt.2014.02.015

Marsh, S. G. E., Albert, E.D., Bodmer, W. F., Bontrop, R. E., Dupont, B., Erlich, H. A., Fernández-Viña, M., Geraghty, D. E., Holdsworth, R., Hurley, C. K., Lau, M., Lee, K. W., Mach, B., Maiers, M., Mayr, W. R., Müller, C. R., Parham, P., Petersdorf, E. W., Sasazuki, T., ... Trowsdale, J. (2010). Nomenclature for factors of the HLA system, 2010. Tissue Antigens, 75(4), 291-455. https://doi.org/10.1111/j.1399-0039.2010.01466.x

Martin, P. J., Levine, D. M., Storer, B. E., Nelson, S. C., Dong, X., \& Hansen, J. A. (2020). Recipient and donor genetic variants associated with mortality after allogeneic hematopoietic cell transplantation. Blood Advances, 4(14), 3224-3233. https://doi.org/10.1182/bloodadvan ces. 2020001927

Martínez-Losada, C., Martín, C., Gonzalez, R., Manzanares, B., GarcíaTorres, E., \& Herrera, C. (2017). Patients lacking a KIR-ligand of HLA group C1 or C2 have a better outcome after umbilical cord blood transplantation. Frontiers in Immunology, 8, 810. https://doi. org/10.3389/fimmu.2017.00810

Maskalan, M., Grubic, Z., Serventi Seiwerth, R., Vrhovac, R., Mikulic, M., Burek Kamenaric, M., Stingl Jankovic, K., Durakovic, N., \& Zunec, R. (2020). The MHC gamma block matching: Impact on unrelated hematopoietic stem cell transplantation outcome. Human Immunology, 81, 12-17. https://doi.org/10.1016/j.humimm.2019.10.005

Mayor, N. P., Hayhurst, J. D., Turner, T. R., Szydlo, R. M., Shaw, B. E., Bultitude, W. P., Sayno, J.-R., Tavarozzi, F., Latham, K., Anthias, C., Robinson, J., Braund, H., Danby, R., Perry, J., Wilson, M. C., Bloor, A. J., McQuaker, I. G., MacKinnon, S., Marks, D. I., ... Marsh, S. G. E. (2019). Recipients receiving better HLA-matched hematopoietic cell transplantation grafts, uncovered by a novel HLA typing method, have superior survival: A retrospective study. Biology of Blood and Marrow Transplantation, 25(3), 443-450. https://doi.org/10.1016/j. bbmt.2018.12.768

Milano, F., Gooley, T., Wood, B., Woolfrey, A., Flowers, M. E., Doney, K., Witherspoon, R., Mielcarek, M., Deeg, J. H., Sorror, M., Dahlberg, A., Sandmaier, B. M., Salit, R., Petersdorf, E., Appelbaum, F. R., \& Delaney, C. (2016). Cord-Blood Transplantation in Patients with Minimal Residual Disease. New England Journal of Medicine, 375(10), 944-953. https://doi.org/10.1056/nejmoa1602074

Morin-Zorman, S., Loiseau, P., Taupin, J.-L., \& Caillat-Zucman, S. (2016). Donor-specific anti-HLA antibodies in allogeneic hematopoietic stem cell transplantation. Frontiers in Immunology, 7, 307. https://doi. org/10.3389/fimmu.2016.00307 
Morishima, S., Shiina, T., Suzuki, S., Ogawa, S., Sato-Otsubo, A., Kashiwase, K., Azuma, F., Yabe, T., Satake, M., Kato, S., Kodera, Y., Sasazuki, T., \& Morishima, Y. (2018). Evolutionary basis of HLADPB1 alleles affects acute GVHD in unrelated donor stem cell transplantation. Blood, 131(7), 808-817. https://doi.org/10.1182/blood -2017-08-801449

Morishima, Y., Sasazuki, T., Inoko, H., Juji, T., Akaza, T., Yamamoto, K., Ishikawa, Y., Kato, S., Sao, H., Sakamaki, H., Kawa, K., Hamajima, N., Asano, S., \& Kodera, Y. (2002). The clinical significance of human leukocyte antigen (HLA) allele compatibility in patients receiving a marrow transplant from serologically HLA-A, HLA-B, and HLA-DR matched unrelated donors. Blood, 99(11), 4200-4206. https://doi. org/10.1182/blood.v99.11.4200

Moyer, A. M., Hashmi, S. K., Kroning, C. M., Kremers, W. K., De Goey, S. R., Patnaik, M., Litzow, M., Gastineau, D. A., Hogan, W. J., Jacob, E. K., Kreuter, J. D., Wakefield, L. L., \& Gandhi, M. J. (2017). Clinical outcomes of HLA-DPB1 mismatches in 10/10 HLA-matched unrelated donor-recipient pairs undergoing allogeneic stem cell transplant. European Journal of Haematology, 99(3), 275-282. https://doi. org/10.1111/ejh.12916

Mrazek, F., Onderkova, J., Szotkowski, T., Königova, N., Ambruzova, Z., \& Raida, L. (2014). Somatic mutation in acute myelogenous leukemia cells imitate novel germline HLA-A allele, a case report. Tissue Antigens, 83(6), 414-417. https://doi.org/10.1111/tan.12362

National Institute for Health and Care Excellence (2019). Letermovir for preventing cytomegalovirus disease after a stem cell transplant. Technology appraisal guidance [TA591]. Retrieved from https://www. nice.org.uk/guidance/ta591/chapter/3-Committee-discussion

Neuchel, C., Fürst, D., Niederwieser, D., Bunjes, D., Tsamadou, C., Wulf, G., Pfreundschuh, M., Wagner, E., Stuhler, G., Einsele, H., Schrezenmeier, H., \& Mytilineos, J. (2017). Impact of donor activating KIR genes on HSCT outcome in C1-ligand negative myeloid disease patients transplanted with unrelated donors - A retrospective study. PLoS One, 12, e0169512. https://doi.org/10.1371/journ al.pone.0169512

Nunes, E., Heslop, H., Fernandez-Vina, M., Taves, C., Wagenknecht, D. R., Eisenbrey, A. B., Fischer, G., Poulton, K., Wacker, K., Hurley, C. K., Noreen, H., \& Sacchi, N. (2011). Definitions of histocompatibility typing terms. Human Immunology, 72(12), 1214-1216. https://doi. org/10.1016/j.humimm.2011.06.002 and Blood, 118, e180-e183. https://doi.org/10.1182/blood-2011-05-353490

Oevermann, L., Michaelis, S., Mezger, M., Lang, P., Toporski, J., Bertaina, A., Zecca, M., Moretta, L., Locatelli, F., \& Handgretinger, R. (2014). KIR B haplotype donors confer a reduced risk after haploidentical transplantation in children with ALL. Blood, 124(17), 2744-2747. https://doi.org/10.1182/blood-2014-03-565069

Oran, B., Cao, K., Saliba, R. M., Rezvani, K., de Lima, M., Ahmed, S., Hosing, C. M., Popat, U. R., Carmazzi, Y., Kebriaei, P., Nieto, Y., Rondon, G., Willis, D., Shah, N., Parmar, S., Olson, A., Moore, B., Marin, D., Mehta, R., ... Shpall, E. J. (2015). Better allele-level matching improves transplant related mortality after double cord blood transplantation. Haematologica, 100(10), 1361-1370. https://doi.org/10.3324/haema tol.2015.127787

Page, K. M., Zhang, L., Mendizabal, A., Wease, S., Carter, S., Gentry, T., Balber, A. E., \& Kurtzberg, J. (2011). Total colony-forming units are a strong, independent predictor of neutrophil and platelet engraftment after unrelated umbilical cord blood transplantation: A singlecenter analysis of 435 cord blood transplants. Biology of Blood and Marrow Transplantation, 17(9), 1362-1374. https://doi.org/10.1016/j. bbmt.2011.01.011

Panagouli, E., Dinou, A., Mallis, P., Michalopoulos, E., Papassavas, A., Spyropoulou-Vlachou, M., Meletis, J., Angelopoulou, M., Konstantopoulos, K., Vassilakopoulos, T., \& Stavropoulos-Giokas, C. (2018). Non-inherited maternal antigens identify acceptable HLA mismatches: A new policy for the Hellenic Cord Blood Bank.
Bioengineering, 5(4), 77. https://doi.org/10.3390/bioengineering5 040077

Passweg, J. R., Baldomero, H., Basak, G. W., Chabannon, C., Corbacioglu, S., Duarte, R., Kuball, J., Lankester, A., Montoto, S., de Latour, R. P., Snowden, J. A., Styczynski, J., Yakoub-Agha, I., Arat, M., Mohty, M., \& Kröger, N. (2019). The EBMT activity survey report 2017: A focus on allogeneic HCT for nonmalignant indications and on the use of nonHCT cell therapies. Bone Marrow Transplantation, 54(10), 1575-1585. https://doi.org/10.1038/s41409-019-0465-9

Passweg, J. R., Baldomero, H., Chabannon, C., Basak, G. W., Corbacioglu, S., Duarte, R., Dolstra, H., Lankester, A. C., Mohty, M., Montoto, S., de Latour, R. P., Snowden, J. A., Styczynski, J., Yakoub-Agha, I., \& Kröger, N. (2020). The EBMT activity survey on hematopoietic-cell transplantation and cellular therapy 2018. Bone Marrow Transplantation, 55(8), 1604-1613. https://doi.org/10.1038/s41409-020-0826-4

Passweg, J. R., Zhang, M-J., Rocha, V., Kan, F., Champlin, R. E., Isola, L. M., Gee, A. P., Gibson, J., Laughlin, M. J., Lazarus, H. M., Loren, A., Marks, D. I., Gratwohl, A., \& Eapen, M. (2011). Donor Characteristics Affecting Graft Failure, Graft-versus-Host Disease, and Survival after Unrelated Donor Transplantation with ReducedIntensity Conditioning for Hematologic Malignancies. Biology of Blood and Marrow Transplantation, 17(12), 1869-1873. https://doi. org/10.1016/j.bbmt.2011.07.008

Patel, S. S., Rybicki, L. A., Yurch, M., Thomas, D., Liu, H., Dean, R., Jagadeesh, D., Hill, B., Pohlman, B., Bolwell, B., Hanna, R., Hamilton, B. K., Kalaycio, M., Gerds, A. T., Cober, E., Mossad, S., Zhang, A., Majhail, N. S., Askar, M., \& Sobecks, R. (2020). Influence of major histocompatibility complex class I chain-related gene A polymorphisms on cytomegalovirus disease after allogeneic hematopoietic cell transplantation. Hematology/Oncology and Stem Cell Therapy, 13(1), 32-39. https://doi.org/10.1016/j.hemonc.2019.10.001

Petersdorf, E. W. (2017). Role of major histocompatibility complex variation in graft-versus-host disease after hematopoietic cell transplantation. F1000Research, 6, 617. https://doi.org/10.12688/f1000resea rch.10990.1

Petersdorf, E. W., Anasetti, C., Martin, P. J., Gooley, T., Radich, J., Malkki, M., Woolfrey, A., Smith, A., Mickelson, E., \& Hansen, J. A. (2004). Limits of HLA mismatching in unrelated hematopoietic cell transplantation. Blood, 104(9), 2976-2980. https://doi.org/10.1182/blood -2004-04-1674

Petersdorf, E. W., Carrington, M., O'hUigin, C., Bengtsson, M., De Santis, D., Dubois, V., Gooley, T., Horowitz, M., Hsu, K., Madrigal, J. A., Maiers, M. J., Malkki, M., McKallor, C., Morishima, Y., Oudshoorn, M., Spellman, S. R., Villard, J., Stevenson, P., Petersdorf, E. W., ... International Histocompatibility Working Group in Hematopoietic Cell Transplantation (2020). Role of HLA-B exon 1 in graft-versushost disease after unrelated haemopoietic cell transplantation: $A$ retrospective cohort study. Lancet Haematology, 7, e50-e60. https:// doi.org/10.1016/S2352-3026(19)30208-X

Petersdorf, E. W., Gooley, T. A., Malkki, M., Bacigalupo, A. P., Cesbron, A., Du Toit, E., Ehninger, G., Egeland, T., Fischer, G. F., Gervais, T., Haagenson, M. D., Horowitz, M. M., Hsu, K., Jindra, P., Madrigal, A., Oudshoorn, M., Ringdén, O., Schroeder, M. L., Spellman, S. R., ... Carrington, M. (2014). HLA-C expression levels define permissible mismatches in hematopoietic cell transplantation. Blood, 124(26), 3996-4003. https://doi.org/10.1182/blood-2014-09-599969

Petersdorf, E. W., Hansen, J. A., Martin, P. J., Woolfrey, A., Malkki, M., Gooley, T., Storer, B., Mickelson, E., Smith, A., \& Anasetti, C. (2001). Major-histocompatibility-complex class I alleles and antigens in hematopoietic-cell transplantation. New England Journal of Medicine, 345(25), 1794-1800. https://doi.org/10.1056/NEJMoa011826

Petersdorf, E. W., Malkki, M., Horowitz, M. M., Spellman, S. R., Haagenson, M. D., \& Wang, T. (2013). Mapping MHC haplotype effects in unrelated donor hematopoietic cell transplantation. Blood, 121(10), 18961905. https://doi.org/10.1182/blood-2012-11-465161 
Petersdorf, E. W., Malkki, M., O'hUigin, C., Carrington, M., Gooley, T., Haagenson, M. D., Horowitz, M. M., Spellman, S. R., Wang, T., \& Stevenson, P. (2015). High HLA-DP expression and graft-versus-host disease. New England Journal of Medicine, 373(7), 599-609. https:// doi.org/10.1056/NEJMoa1500140

Petersdorf, E. W., \& O'hUigin, C. (2019). The MHC in the era of nextgeneration sequencing: implications for bridging structure with function. Human Immunology, 80(1), 67-78. https://doi.org/10.1016/j. humimm.2018.10.002

Petersdorf, E. W., Stevenson, P., Malkki, M., Strong, R. K., Spellman, S. R., Haagenson, M. D., Horowitz, M. M., Gooley, T., \& Wang, T. (2018). Patient HLA germline variation and transplant survivorship. Journal of Clinical Oncology, 36(24), 2524-2531. https://doi.org/10.1200/ JCO.2017.77.6534

Pidala, J., Lee, S. J., Ahn, K. W., Spellman, S., Wang, H.-L., Aljurf, M., Askar, M., Dehn, J., Fernandez Viña, M., Gratwohl, A., Gupta, V., Hanna, R., Horowitz, M. M., Hurley, C. K., Inamoto, Y., Kassim, A. A., Nishihori, T., Mueller, C., Oudshoorn, M., ... Anasetti, C. (2014). Nonpermissive HLA-DPB1 mismatch increases mortality after myeloablative unrelated allogeneic hematopoietic cell transplantation. Blood, 124(16), 2596-2606. https://doi.org/10.1182/blood -2014-05-576041

Pidala, J., Wang, T., Haagenson, M., Spellman, S. R., Askar, M., Battiwalla, M., Baxter-Lowe, L. A., Bitan, M., Fernandez-Viña, M., Gandhi, M., Jakubowski, A. A., Maiers, M., Marino, S. R., Marsh, S. G. E., Oudshoorn, M., Palmer, J., Prasad, V. K., Reddy, V., Ringden, O., ... Anasetti, C. (2013). Amino acid substitution at peptide-binding pockets of HLA class I molecules increases risk of severe acute GVHD and mortality. Blood, 122(22), 3651-3658. https://doi.org/10.1182/ blood-2013-05-501510

Politikos, I., Davis, E., Nhaissi, M., Wagner, J. E., Brunstein, C. G., Cohen, S., Shpall, E. J., Milano, F., Scaradavou, A., \& Barker, J. N. (2020). Guidelines for cord blood unit selection. Biology of Blood and Marrow Transplantation, 26, 2190-2196. https://doi.org/10.1016/j. bbmt.2020.07.030

Pond, G. R., Lipton, J. H., \& Messner, H. A. (2006). Long-term survival after blood and marrow transplantation: Comparison with an ageand gender-matched normative population. Biology of Blood and Marrow Transplantation, 12(4), 422-429. https://doi.org/10.1016/j. bbmt.2005.11.518

Powley, L., Brown, C., Melis, A., Li, Y., Parkes, G., \& Navarrete, C. V. (2016). Consideration of noninherited maternal Ags as permissible HLA mismatches in cord blood donor selection. Bone Marrow Transplantation, 51(5), 675-679. https://doi.org/10.1038/bmt.2015.344

Purtill, D., Smith, K., Devlin, S., Meagher, R., Tonon, J., Lubin, M., Ponce, D. M., Giralt, S., Kernan, N. A., Scaradavou, A., Stevens, C. E., \& Barker, J. N. (2014). Dominant unit CD34+ cell dose predicts engraftment after double-unit cord blood transplantation and is influenced by bank practice. Blood, 124(19), 2905-2912. https://doi.org/10.1182/ blood-2014-03-566216

Querol, S., Gomez, S. G., Pagliuca, A., Torrabadella, M., \& Madrigal, J. A. (2010). Quality rather than quantity: The cord blood bank dilemma. Bone Marrow Transplantation, 45(6), 970-978. https://doi. org/10.1038/bmt.2010.7

Querol, S., \& Rocha, V. (2019). Procurement and management of cord blood. In E. Carreras, C. Dufour, M. Mohty, \& N. Kröger (Eds.), The EBMT handbook: Hematopoietic stem cell transplantation and cellular therapies (7th ed., chapter 18, pp. 131-136).Springer Open.

Rashidi, A., Hamadani, M., Zhang, M.-J., Wang, H.-L., Abdel-Azim, H., Aljurf, M., Assal, A., Bajel, A., Bashey, A., Battiwalla, M., Beitinjaneh, A. M., Bejanyan, N., Bhatt, V. R., Bolaños-Meade, J., Byrne, M., Cahn, J.-Y., Cairo, M., Ciurea, S., Copelan, E., ... Saber, W. (2019). Outcomes of haploidentical vs matched sibling transplantation for acute myeloid leukemia in first complete remission. Blood Advances, 3(12), 1826-1836. https://doi.org/10.1182/bloodadvances. 2019000050
Reisner, Y., Hagin, D., \& Martelli, M. F. (2011). Haploidentical hematopoietic transplantation: Current status and future perspectives. Blood, 118(23), 6006-6017. https://doi.org/10.1182/blood -2011-07-338822

Robin, M., Porcher, R., Adès, L., Boissel, N., Raffoux, E., Xhaard, A., Larghero, J., Gardin, C., Himberlin, C., Delmer, A., Fenaux, P., Dombret, H., Socié, G., \& Peffault de Latour, R. (2013). Matched unrelated or matched sibling donors result in comparable outcomes after non-myeloablative HSCT in patients with AML or MDS. Bone Marrow Transplantation, 48(10), 1296-1301. https://doi. org/10.1038/bmt.2013.50

Robinson, J., Halliwell, J. A., Hayhurst, J. D., Flicek, P., Parham, P., \& Marsh, S. G. E. (2015). The IPD and IMGT/HLA database: Allele variant databases. Nucleic Acids Research, 43, D423-431. https://doi. org/10.1093/nar/gku1161

Rocha, V., Cornish, J., Sievers, E. L., Filipovich, A., Locatelli, F., Peters, C., Remberger, M., Michel, G., Arcese, W., Dallorso, S., Tiedemann, K., Busca, A., Chan, K-W., Kato, S., Ortega, J., Vowels, M., Zander, A., Souillet, G., Oakill, A., \& Gluckman, E. (2001). Comparison of outcomes of unrelated bone marrow and umbilical cord blood transplants in children with acute leukemia. Blood, 97(10), 2962-2971. https://doi.org/10.1182/blood.v97.10.2962

Rocha, V. R., Giannotti, F., Ruggeri, A., Chevallier, P., Blaise, D., Ceballos, P., Michallet, M., Deconinck, E., Cornelissen, J., de la Tour, R. P., Petersen, E., Karakasis, D., Volt, F., Paviglianiti, A., \& Gluckman, E. (2015). Selecting double cord blood units for adults with hematological malignancies: Impact of ABO, HLA and cell dose on outcomes after double cord blood transplants a CBC-Cellular Therapy \& Immunobiology Working Party, EBMT and Eurocord Study, [abstract]. Blood, 126(23), Abstract 3214.

Rocha, V., Spellman, S., Zhang, M.-J., Ruggeri, A., Purtill, D., Brady, C., Baxter-Lowe, L. A., Baudoux, E., Bergamaschi, P., Chow, R., Freed, B., Koegler, G., Kurtzberg, J., Larghero, J., Lecchi, L., Nagler, A., Navarrette, C., Prasad, V., Pouthier, F., ... Eurocord-European Blood and Marrow Transplant Group and the Center for International Blood and Marrow Transplant Research (2012). Effect of HLA-matching recipients to donor non-inherited maternal antigens on outcomes after mismatched umbilical cord blood transplantation for hematologic malignancy. Biology of Blood and Marrow Transplantation, 18(12), 1890-1896. https://doi.org/10.1016/j.bbmt.2012.07.010

Rocha, V., Wagner, J. E., Sobocinski, K. A., Klein, J. P., Zhang, M.-J., Horowitz, M. M., \& Gluckman, E. (2000). Graft-versus-host disease in children who have received a cord-blood or bone marrow transplant from an HLA-identical sibling. New England Journal of Medicine, 342(25), 18461854. https://doi.org/10.1056/NEJM200006223422501

Roe, D., Vierra-Green, C., Pyo, C.-W., Eng, K., Hall, R., Kuang, R., Spellman, S., Ranade, S., Geraghty, D. E., \& Maiers, M. (2017). Revealing complete complex KIR haplotypes phased by long-read sequencing technology. Genes and Immunity, 18(3), 127-134. https:// doi.org/10.1038/gene.2017.10

Roelen, D., de Vaal, Y., Vierra-Green, C., Waldvogel, S., Spellman, S., Claas, F., \& Oudshoorn, M. (2018). HLA mismatches that are identical for the antigen recognition domain are less immunogenic. Bone Marrow Transplantation, 53(6), 729-740. https://doi.org/10.1038/ s41409-018-0108-6

Ruggeri, L., Capanni, M., Casucci, M., Volpi, I., Tosti, A., Perruccio, K., Urbani, E., Negrin, R. S., Martelli, M. F., \& Velardi, A. (1999). Role of natural killer cell alloreactivity in HLA-mismatched hematopoietic stem cell transplantation. Blood, 94(1), 333-339. https://doi. org/10.1182/blood.V94.1.333.413a31_333_339

Ruggeri, L., Capanni, M., Urbani, E., Perruccio, K., Shlomchik, W. D., Tosti, A., Posati, S., Rogaia, D., Frassoni, F., Aversa, F., Martelli, M. F., \& Velardi, A. (2002). Effectiveness of donor natural killer cell alloreactivity in mismatched hematopoietic transplants. Science, 295(5562), 2097-2100. https://doi.org/10.1126/science.1068440 
Ruggeri, L., Mancusi, A., Urbani, E., \& Velardi, A. (2016). Identifying NK alloreactive donors for haploidentical hematopoietic stem cell transplantation. Methods in Molecular Biology, 1393, 141-145. https://doi. org/10.1007/978-1-4939-3338-9_14

Rutten, C. E., van Luxemburg-Heijs, S. A. P., Griffioen, M., Marijt, E. W. A., Jedema, I., Heemskerk, M. H. M., Posthuma, E. F. M., Willemze, R., \& Falkenburg, J. H. F. (2008). HLA-DP as specific targetfor cellular immunotherapy in HLA class II-expressing B-cell leukemia. Leukemia, 22(7), 1387-1394. https://doi.org/10.1038/leu.2008.90

Rutten, C. E., van Luxemburg-Heijs, S. A. P., Halkes, C. J. M., van Bergen, C. A. M., Marijt, E. W. A., Oudshoorn, M., Griffioen, M., \& Falkenburg, J. H. F. (2013). Patient HLA-DP-specific CD4+ T cells from HLA-DPB1-mismatched donor lymphocyte infusion can induce graft-versus-leukemia reactivity in the presence or absence of graftversus-host disease. Biology of Blood and Marrow Transplantation, 19(1), 40-48. https://doi.org/10.1016/j.bbmt.2012.07.020

Sacchi, N., Sormani, M. P., Marcon, J., Lamparelli, T., Fanin, R., Garbarino, L., Miotti, V., Bandini, G., Bosi, A., Ciceri, F., Bacigalupo, A., Fleischhauer, K., \& Gruppo Italiano Trapianto di Midollo Osseo, Cellule Staminale Ematopoietiche (CSE) e Terapia Cellulare, and the Italian Bone Marrow Donor Registry (2009). Nonpermissive HLA-DPB1 disparity is a significant independent risk factor for mortality after unrelated hematopoietic stem cell transplantation. Blood, 114(7), 1437-1444. https://doi.org/10.1182/blood-2009-01-200378

Sahin, U., Dalva, K., Gungor, F., Ustun, C., \& Beksac, M. (2018). Donorrecipient killer immunoglobulin like receptor (KIR) genotype matching has a protective effect on chronic graft versus host disease and relapse incidence following HLA-identical sibling hematopoietic stem cell transplantation. Annals of Hematology, 97, 1027-1039. https://doi.org/10.1007/s00277-018-3274-0

Sanchez-Mazas, A., Nunes, J. M., Middleton, D., Sauter, J., Buhler, S., McCabe, A., Hofmann, J., Baier, D. M., Schmidt, A. H., Nicoloso, G., Andreani, M., Grubic, Z., Tiercy, J.-M., \& Fleischhauer, K. (2017). Common and welldocumented HLA alleles over all of Europe and within European subregions: A catalogue from the European Federation for Immunogenetics. HLA, 89, 104-113. https://doi.org/10.1111/tan.12956

Sanz, J., Montesinos, P., Saavedra, S., Lorenzo, I., Senent, L., Planelles, D., Larrea, L., Martín, G., Palau, J., Jarque, I., Martínez, J., de la Rubia, J., Moscardó, F., Martinez, D., Gómez, I., López, M., Sanz, M. A., Sanz, G. F. (2010). Single-Unit Umbilical Cord Blood Transplantation from Unrelated Donors in Adult Patients with Chronic Myelogenous Leukemia. Biology of Blood and Marrow Transplantation, 16, (11), 1589-1595. https://doi.org/10.1016/j.bbmt.2010.05.014

Scaradavou, A., Brunstein, C. G., Eapen, M., Le-Rademacher, J., Barker, J. N., Chao, N., Cutler, C., Delaney, C., Kan, F., Isola, L., Karanes, C., Laughlin, M. J., Wagner, J. E., \& Shpall, E. J. (2013). Double unit grafts successfully extend the application of umbilical cord blood transplantation in adults with acute leukemia. Blood, 121, 752-758. https://doi.org/10.1182/blood-2012-08-449108

Scaradavou, A., Smith, K. M., Hawke, R., Schaible, A., Abboud, M., Kernan, N. A., Young, J. W., \& Barker, J. N. (2010). Cord blood units with low CD34+ cell viability have a low probability of engraftment after double unit transplantation. Biology of Blood and Marrow Transplantation, 16, 500-508. https://doi.org/10.1016/j.bbmt.2009.11.013

Schmidt, A. H., Solloch, U. V., Baier, D., Yazici, B., Özcan, M., Stahr, A., Schumacher, S., Ehninger, G., \& Rutt, C. (2009). Criteria for initiation and evaluation of minority donor programs and application to the example of donors of Turkish descent in Germany. Bone Marrow Transplantation, 44, 405-412. https://doi.org/10.1038/bmt.2009.55

, Socié, G., Schwerdtfeger, R., Kröger, N., Ganser, A., Niederwieser, D., Polge, E., Blau, I. W., Mohty, M. (2013). CMV serostatus still has an important prognostic impact in de novo acute leukemia patients after allogeneic stem cell transplantation: a report from the Acute Leukemia Working Party of EBMT. Blood, 122, (19), 3359-3364. https://doi.org/10.1182/blood-2013-05-499830
Schöne, B., Bergmann, S., Lang, K., Wagner, I., Schmidt, A. H., Petersdorf, E. W., \& Lange, V. (2018). Predicting an HLA-DPB1 expression marker based on standard DPB1 genotyping: Linkage analysis of over 32,000 samples. Human Immunology, 79(1), 20-27. https://doi. org/10.1016/j.humimm.2017.11.001

Sharma, P., Purev, E., Haverkos, B., Pollyea, D. A., Cherry, E., Kamdar, M., Mark, T., Forsberg, P., Sherbenou, D., Hammes, A., Rabinovitch, R., Smith, C. A., \& Gutman, J. A. (2020). Adult cord blood transplant results in comparable overall survival and improved GRFS vs matched related transplant. Blood Advances, 4, 2227-2235. https:// doi.org/10.1182/bloodadvances.2020001554

Shaw, B. E., Gooley, T. A., Malkki, M., Madrigal, J. A., Begovich, A. B., Horowitz, M. M., Gratwohl, A., Ringdén, O., Marsh, S. G. E., \& Petersdorf, E. W. (2007). The importance of HLA-DPB1 in unrelated donor haematopoietic stem cell transplantation. Blood, 110, 45604566. https://doi.org/10.1182/blood-2007-06-095265

Shaw, B. E., Logan, B. R., Spellman, S. R., Marsh, S. G. E., Robinson, J., Pidala, J., Hurley, C., Barker, J., Maiers, M., Dehn, J., Wang, H., Haagenson, M., Porter, D., Petersdorf, E. W., Woolfrey, A., Horowitz, M. M., Verneris, M., Hsu, K. C., Fleischhauer, K., \& Lee, S. J. (2018). Development of an unrelated donor selection score predictive of survival after HCT: Donor age matters most. Biology of Blood and Marrow Transplantation, 24, 1049-1056. https://doi.org/10.1016/j. bbmt.2018.02.006

Shaw, B. E., Mayor, N. P., Richard, S., Bultitude, W. P., Keiren, K., Julia, P., Marie, W., Clark, A., Mackinnon, S., Marks, D. I., Pagliuca, A., Potter, M., Russell, N., Thomson, K., Madrigal, J. A., \& Marsh, S. G. E. (2014). Patient/donor CMV matching is a critical determinant of survival in unrelated donor haematopoietic stem cell transplantation, [abstract]. Blood, 124(21), Abstract 1207. https://doi.org/10.1182/ blood.V124.21.1207.1207

Shaw, B. E., Mayor, N. P., Russell, N. H., Apperley, J. F., Clark, R. E., Cornish, J., Darbyshire, P., Ethell, M. E., Goldman, J. M., Little, A-M., Mackinnon, S., Marks, D. I., Pagliuca, A., Thomson, K., Marsh, S. G. E., Madrigal, J. A. (2010). Diverging effects of HLA-DPB1 matching status on outcome following unrelated donor transplantation depending on disease stage and the degree of matching for other HLA alleles. Leukemia, 24(1), 58-65. https://doi.org/10.1038/leu.2009.239

Shaw, B. E., Mayor, N. P., Szydlo, R. M., Bultitude, W. P., Anthias, C., Kirkland, K., Perry, J., Clark, A., Mackinnon, S., Marks, D. I., Pagliuca, A., Potter, M. N., Russell, N. H., Thomson, K., Madrigal, J. A., \& Marsh, S. G. E. (2017). Recipient/donor HLA and CMV matching in recipients of T-cell-depleted unrelated donor haematopoietic cell transplants. Bone Marrow Transplantation, 52, 717-725. https://doi.org/10.1038/ bmt.2016.352

Shaw, B. E., Robinson, J., Fleischhauer, K., Madrigal, J. A., \& Marsh, S. G. E. (2013). Translating the HLA-DPB1 T-cell epitope-matching algorithm into clinical practice. Bone Marrow Transplantation, 48, 15101512. https://doi.org/10.1038/bmt.2013.91

Shimoni, A., Vago, L., Bernardi, M., Yerushalemi, R., Peccatori, J., Greco, R., Shem-Tov, N., Russo, A. L., Danylesko, D., Apel, A., Bonini, C., Stanghellini, M. T. L., Nagler, A., \& Ciceri, F. (2017). Missing HLA C group 1 ligand in patients with AML and MDS is associated with reduced risk of relapse and better survival after allogeneic stem cell transplantation with fludarabine and treosulfan reduced toxicity conditioning. American Journal of Hematology, 92, 1011-1019. https:// doi.org/10.1002/ajh.24827

Shouval, R., Fein, J. A., Labopin, M., Kröger, N., Duarte, R. F., Bader, P., chabannon, C., Kuball, J., Basak, G. W., Dufour, C., Galimard, J-E., Polge, E., Lankester, A., Montoto, S., Snowden, J. A., Styczynski, J., Yakoub-Agha, I., Mohty, M., \& Nagler, A. (2019). Outcomes of allogeneic haematopoietic stem cell transplantation from HLA-matched and alternative donors: A European Society for Blood and Marrow Transplantation registry retrospective analysis. Lancet Haematology, 6, 573-584. https://doi.org/10.1016/S2352-3026(19)30158-9 
Sobecks, R. M., Askar, M., Thomas, D., Rybicki, L., Kalaycio, M., Dean, R., Avery, R., Mossad, S., Copelan, E., \& Bolwell, B. J. (2011). Cytomegalovirus reactivation after matched sibling donor reducedintensity conditioning allogeneic hematopoietic stem cell transplant correlates with donor killer immunoglobulin-like receptor genotype. Experimental and Clinical Transplantation, 9(1), 7-13.

Sobecks, R. M., Wang, T., Askar, M., Gallagher, M. M., Haagenson, M., Spellman, S., Fernandez-Vina, M., Malmberg, K-J., Müller, C., Battiwalla, M., Gajewski, J., Verneris, M.I R., Ringdén, O., Marino, S., Davies, S., Dehn, J., Bornhäuser, M., Inamoto, Y., Woolfrey, A., \& Hsu, K. (2015). Impact of KIR and HLA Genotypes on Outcomes after Reduced-Intensity Conditioning Hematopoietic Cell Transplantation. Biology of Blood and Marrow Transplantation, 21(9), 1589-1596. https://doi.org/10.1016/j.bbmt.2015.05.002

Solberg, O. D., Mack, S. J., Lancaster, A. K., Single, R. M., Tsai, Y., SanchezMazas, A., \& Thomson, G. (2008). Balancing selection and heterogeneity across the classical human leukocyte antigen loci: A meta analytic review of 497 population studies. Human Immunology, 69(7), 443-464. https://doi.org/10.1016/j.humimm.2008.05.001

Steinle, A., Li, P., Morris, D. L., Groh, V., Lanier, L. L., Strong, R. K., \& Spies, T. (2001). Interactions of human NKG2D with its ligands MICA, MICB, and homologs of the mouse RAE-1 protein family. Immunogenetics, 53(4), 279-287. https://doi.org/10.1007/s002510100325

Stern, M., Ruggeri, L., Mancusi, A., Bernardo, M. E., de Angelis, C., Bucher, C., Locatelli, F., Aversa, F., \& Velardi, A. (2008). Survival after T cell-depleted haploidentical stem cell transplantation is improved using the mother as donor. Blood, 112, 2990-2995. https://doi. org/10.1182/blood-2008-01-135285

Stevanovic, S., van Bergen, C. A. M., van Luxembourg-Heijs, S. A. P., van der Zouwen, B., Jordanova, E. S., Kruisselbrink, A. B., ... Falkenburg, J. H. F. (2013). HLA-class II upregulation during viral infection leads to HLA-DP-directed graft-versus-host disease after CD4+ donor lymphocyte infusion. Blood, 122, 1963-1973. https://doi.org/10.1182/ blood-2012-12-470872

Stevens, C. E., Carrier, C., Carpenter, C., Sung, D., \& Scaradavou, A. (2011). HLA mismatch direction in cord blood transplantation, impact on outcome and implications for cord blood unit selection. Blood, 118, 3969-3978. https://doi.org/10.1182/blood-2010-11-317271

Taniguchi, K., Yoshihara, S., Maruya, E., Ikegame, K., Kaida, K., Hayashi, K., Kato, R., Inoue, T., Fujioka, T., Tamaki, H., Okada, M., Onuma, T., Fujii, N., Kusunoki, Y., Soma, T., Saji, H., \& Ogawa, H. (2012). Donorderived HLA antibody production in patients undergoing SCT from HLA antibody-positive donors. Bone Marrow Transplantation, 47, 1338. https://doi.org/10.1038/bmt.2012.28

Tie, R., Zhang, T., Yang, B. O., Fu, H., Han, B., Yu, J., Tan, Y., \& Huang, H. E. (2017). Clinical implications of HLA locus mismatching in unrelated donor hematopoietic cell transplantation: A meta-analysis. Oncotarget, 8(16), 27645-27660. https://doi.org/10.18632/oncot arget.15291

Tiercy, J. M. (2016). How to select the best available related or unrelated donor of hematopoietic stem cells? Haematologica, 101, 680-687. https://doi.org/10.3324/haematol.2015.141119

Tiercy, J.-M., Bujan-Lose, M., Chapuis, B., Gratwohl, A., Gmür, J., Seger, R., Kern, M., Morell, A., \& Roosnek, E. (2000). Bone marrow transplantation with unrelated donors, what is the probability of identifying an HLA-A/B/Cw/DRB1/B3/B5/DQB1 - Matched donor? Bone Marrow Transplantation, 26, 437-441. https://doi.org/10.1038/ sj.bmt.1702529

Tiercy, J.-M., Nicoloso, G., Passweg, J., Schanz, U., Seger, R., Chalandon, Y., Heim, D., Güngör, T., Schneider, P., Schwabe, R., \& Gratwohl, A. (2007). The probability of identifying a 10/10 HLA allele-matched unrelated donor is highly predictable. Bone Marrow Transplantation, 40, 515-522. https://doi.org/10.1038/sj.bmt.1705787

Tozatto-Maio, K., Giannotti, F., Labopin, M., Ruggeri, A., Volt, F., Paviglianiti, A., Kenzey, C., Hayashi, H., Cornelissen, J., Michallet, M.,
Karakasis, D., Deconinck, E., Rohrlich, P.-S., de la Tour, R. P., Blaise, D., Petersen, E., D'Aveni, M., Sengeloev, H., Lamy, T., ... Rocha, V. (2018). Cord blood unit dominance analysis and effect of the winning unit on outcomes after double-unit umbilical cord blood transplantation in adults with acute leukemia: A retrospective study on behalf of Eurocord, the Cord Blood Committee of Cellular Therapy, Immunobiology Working Party, and the Acute Leukemia Working Party of the European Group for Blood and Marrow Transplantation. Biology of Blood and Marrow Transplantation, 24(8), 1657-1663. https://doi.org/10.1016/j.bbmt.2018.02.014

Uhrberg, M., Valiante, N. M., Shum, B. P., Shilling, H. G., LienertWeidenbach, K., Corliss, B., Tyan, D., Lanier, L. L., \& Parham, P. (1997). Human diversity in killer cell inhibitory receptor genes. Immunity, 7, 753-763. https://doi.org/10.1016/s1074-7613(00)80394-5

Ustun, C., Giannotti, F., Zhang, M.-J., Wang, H.-L., Brunstein, C., Labopin, M., Rocha, V., de Lima, M., Baron, F., Sandmaier, B. M., Eapen, M., Gluckman, E., Nagler, A., Weisdorf, D. J., \& Ruggeri, A. (2017). Outcomes of UCB transplantation are comparable in FLT3+ AML: Results of CIBMTR, EUROCORD and EBMT collaborative analysis. Leukemia, 31, 1408-1414. https://doi.org/10.1038/leu.2017.42

Valcárcel, D., Sierra, J., Wang, T., Kan, F., Gupta, V., Hale, G. A., Marks, D. I., McCarthy, P. L., Oudshoorn, M., Petersdorf, E. W., Ringdén, O., Setterholm, M., Spellman, S. R., Waller, E. K., Gajewski, J. L., Marino, S. R., Senitzer, D., \& Lee, S. J. (2011). One-antigen mismatched related versus HLA-matched unrelated donor hematopoietic stem cell transplantation in adults with acute leukemia: Center for International Blood and Marrow Transplant Research results in the era of molecular HLA typing. Biology of Blood and Marrow Transplantation, 17(5), 640-648. https://doi.org/10.1016/j.bbmt.2010.07.022

van Balen, P., van Luxemburg-Hejis, S. A. P., van de Meent, M., van Bergen, C. A. M., Halkes, C. J. M., Jedema, I., \& Falkenburg, J. H. F. (2017). Mismatched HLA-DRB3 can induce a potent immune response after HLA 10/10 matched stem cell transplantation. Transplantation, 101(12), 2850-2854. https://doi.org/10.1097/TP.0000000000 001713

Van der Zanden, H. G. M., Van Rood, J. J., Oudshoorn, M., Bakker, J. N. A., Melis, A., Brand, A., Scaradavou, A., \& Rubinstein, P. (2014). Noninherited maternal antigens identify acceptable HLA mismatches: Benefit to patients and cost-effectiveness for cord blood banks. Biology of Blood and Marrow Transplantation, 20(11), 17911795. https://doi.org/10.1016/j.bbmt.2014.07.011

van Rood, J. J., Scaradavou, A., \& Stevens, C. E. (2012). Indirect evidence that maternal microchimerism in cord blood mediates a graft-versusleukaemia effect in cord blood transplantation. Proceedings of the National Academy of Sciences of the United States of America, 109(7), 2509-2514. https://doi.org/10.1073/pnas.1119541109

van Rood, J. J., Stevens, C. E., Smits, J., Carrier, C., Carpenter, C., \& Scaradavou, A. (2009). Reexposure of cord blood to noninherited maternal HLA antigens improves transplant outcome in hematological malignancies. Proceedings of the National Academy of Sciences of the United States of America, 106(47), 19952-19957. https://doi. org/10.1073/pnas.0910310106

Venstrom, J.M., Pittari, G., Gooley, T. A., Chewning, J. H., Spellman, S., Haagenson, M., Gallagher, M. M., Malkki, M., Petersdorf, E., Dupont, B., \& Hsu, K. C. (2012). HLA-C-Dependent Prevention of Leukemia Relapse by Donor ActivatingKIR2DS1. New England Journal of Medicine, 367(9), 805-816. https://doi.org/10.1056/nejmoa1200503

Vierra-Green, C., Roe, D., Hou, L., Hurley, C. K., Rajalingam, R., Reed, E., Lebedeva, T., Yu, N., Stewart, M., Noreen, H., Hollenbach, J. A., Guethlein, L. A., Wang, T., Spellman, S., \& Maiers, M. (2012). Allelelevel haplotype frequencies and pairwise linkage disequilibrium for 14 KIR loci in 506 European-American individuals. PLoS One, 7(11), e47491. https://doi.org/10.1371/journal.pone.0047491

Wang, Y. U., Chang, Y.-J., Xu, L.-P., Liu, K.-Y., Liu, D.-H., Zhang, X.-H., Chen, H., Han, W., Chen, Y.-H., Wang, F.-R., Wang, J.-Z., Chen, Y., 
Yan, C.-H., Huo, M.-R., Li, D., \& Huang, X.-J. (2014). Who is the best donor for a related HLA haplotype-mismatched transplant? Blood, 124(6), 843-850. https://doi.org/10.1182/blood-2014-03-563130

Watz, E., Remberger, M., Ringden, O., Lundahl, J., Ljungman, P., Mattsson, J., Wikman, A., \& Uhlin, M. (2014). Analysis of donor and recipient $A B O$ incompatibility and antibody-associated complications after allogeneic stem cell transplantation with reduced-intensity conditioning. Biology of Blood and Marrow Transplantation, 20(2), 264-271. https://doi.org/10.1016/j.bbmt.2013.11.011

Weisdorf, D. (2008). Should all unrelated donors for transplantation be matched? Best Practice \& Research Clinical Haematology, 21(1), 79-83. https://doi.org/10.1016/j.beha.2007.11.011

Weisdorf, D., Cooley, S., Wang, T., Trachtenberg, E., Haagenson, M. D., Vierra-Green, C., Spellman, S., Spahn, A., Vogel, J., Kobusingye, H., Fehninger, T., Woolfrey, A., Devine, S., Ross, M., Waller, E. K., Sobecks, R., Parham, P., Guethlein, L. A., Marsh, S. G. E., \& Miller, J. (2019). KIR donor selection: Feasibility in identifying better donors. Biology of Blood and Marrow Transplantation, 25(1), e28-e32. https:// doi.org/10.1016/j.bbmt.2018.08.022

Weisdorf, D., Eapen, M., Ruggeri, A., Zhang, M.-J., Zhong, X., Brunstein, C., Ustun, C., Rocha, V., \& Gluckman, E. (2014). Alternative donor transplantation for older patients with acute myeloid leukemia in first complete remission: A Center for International Blood and Marrow Transplant Research-Eurocord analysis. Biology of Blood and Marrow Transplantation, 20(6), 816-822. https://doi.org/10.1016/j. bbmt.2014.02.020

Woolfrey, A., Klein, J. P., Haagenson, M., Spellman, S., Petersdorf, E., Oudshoorn, M., Gajewski, J., Hale, G. A., Horan, J., Battiwalla, M., Marino, S. R., Setterholm, M., Ringden, O., Hurley, C., Flomenberg, N., Anasetti, C., Fernandez-Vina, M., \& Lee, S. J. (2011). HLA-C antigen mismatch is associated with worse outcome in unrelated donor peripheral blood stem cell transplantation. Biology of Blood and Marrow Transplantation, 17(6), 885-892. https://doi.org/10.1016/j. bbmt.2010.09.012

Woolfrey, A., Wang, T., Lee, S. J., Haagenson, M. D., Chen, G. E., Fleischhauer, K., Horan, J., Hsu, K., Verneris, M., Spellman, S. R., \& Fernandez-Vina, M. (2019). Donor-specific anti-HLA antibodies in unrelated hematopoietic cell transplantation for non-malignant disorders. Bone Marrow Transplantation, 54(3), 494-496. https://doi. org/10.1038/s41409-018-0334-y

Wu, G. Q., Zhao, Y. M., Lai, X. Y., Luo, Y., Tan, Y. M., Shi, J. M., Li, L., Zheng, W. Y., Zhang, J., Hu, X. R., Jin, A. Y., He, J. S., Xie, W. Z., Ye, X. J., Cai, Z., Lin, M. F., \& Huang, H. (2010). The beneficial impact of missing KIR ligands and absence of donor KIR2DS3 gene on outcome following unrelated hematopoietic SCT for myeloid leukemia in the Chinese population. Bone Marrow Transplantation, 45(10), 1514-1521. https:// doi.org/10.1038/bmt.2010.3
Wulf, G., Glass, B., Pfreundschuh, M., Einsele, H., Arnold, R., Stuhler, G. Schaefer-Eckart, K., Freitag, S., Casper, J., Kaufmann, M., Wattad, M., Hertenstein, B., Klein, S., . . ., Mytilineos, Joannis (2016). Matching for the MICA-129 polymorphism is beneficial in unrelated hematopoietic stem cell transplantation. Blood, 128(26), 3169-3176. https:// doi.org/10.1182/blood-2016-05-716357

Yabe, T., Azuma, F., Kashiwase, K., Matsumoto, K., Orihara, T., Yabe, H., Kato, S., Kato, K., Kai, S., Mori, T., Morishima, S., Satake, M., Takanashi, M., Nakajima, K., \& Morishima, Y. (2018). HLA-DPB1 mismatch induces a graft-versus-leukemia effect without severe acute GVHD after single-unit umbilical cord blood transplantation. Leukemia, 32(1), 168-175. https://doi.org/10.1038/leu.2017.202

Yuji, K., Ohno, N., Kawamata, T., Jo, N., Yokoyama, K., Uchimaru, K., Tojo, A., \& Takahashi, S. (2014). Impact of sex incompatibility on the outcome of single-unit cord blood transplantation for adult patients with hematological malignancies. Bone Marrow Transplantation, 49(5), 634-639. https://doi.org/10.1038/bmt.2014.10

Zhao, X. Y., Huang, X. J., Liu, K. Y., Xu, L. P., \& Liu, D. H. (2007). Prognosis after unmanipulated HLA-haploidentical blood and marrow transplantation is correlated to the numbers of KIR ligands in recipients. European Journal of Haematology, 78(4), 338-346. https://doi. org/10.1111/j.1600-0609.2007.00822.x

Zhao, X.-Y., Yu, X.-X., Xu, Z.-L., Cao, X.-H., Huo, M.-R., Zhao, X.-S., Chang, Y.-J., Wang, Y. U., Zhang, X.-H., Xu, L.-P., Liu, K.-Y., \& Huang, X.-J. (2019). Donor and host coexpressing KIR ligands promote NK education after allogeneic hematopoietic stem cell transplantation. Blood Advances, 3, 4312-4325. https://doi.org/10.1182/bloodadvan ces. 2019000242

Zino, E., Frumento, G., Marktel, S., Sormani, M. P., Ficara, F., Terlizzi, S. D., Parodi, A. M., Sergeant, R., Martinetti, M., Bontadini, A., Bonifazi, F., Lisini, D., Mazzi, B., Rossini, S., Servida, P., Ciceri, F., Bonini, C., Lanino, G., Bandini, G., \& Fleischhauer, K. (2004). A T-cell epitope encoded by a subset of HLA-DPB1 alleles determines nonpermissive mismatches for hematologic stem cell transplantation. Blood, 103, 1417-1424. https://doi.org/10.1182/blood-2003-04-1279

How to cite this article: Little A-M, Akbarzad-Yousefi A, Anand $A$, et al. BSHI guideline: HLA matching and donor selection for haematopoietic progenitor cell transplantation. Int J Immunogenet. 2021;48:75-109. https://doi.org/10.1111/ iji.12527 